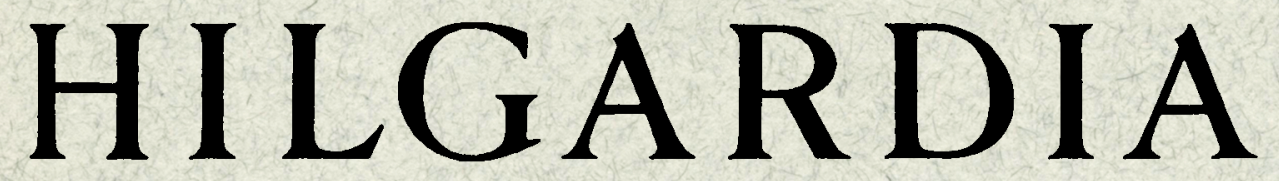

A Journal of Agricultural Science Published by the California Agricultural Experiment Station

\title{
AGING OF WINES AND OTHER SPIRITOUS PRODUCTS, ACCELERATION BY PHYSICAL TREATMENTS
}

\author{
V. L. SINGLETON
}

UNIVERSITY OF CALIFORNIA • BERKELEY, CALIFORNIA 
The quality of wines and other spiritous products is strongly influenced by the nature and the length of the aging treatment to which the product is subjected. The traditional methods of aging wines and related products are costly and slow. Their effects are imperfectly understood with the result that they are unpredictable, poorly controlled, and wasteful.

Nearly every conceivable physical treatment has been tested as a means of improving the quality of spiritous products by accelerating or simulating aging. The results of these tests are often individually unconvincing or apparently conflicting, involving as they do many problems of engineering, chemistry, and quality evaluation.

The extensive and scattered bibliography on this subject has been collected, summarized, and evaluated in the light of recent developments. This publication aims at informing on the one hand, chemists and food scientists regarding the state of the art and future possibilities of accelerated wine and spiritous beverage aging; and, on the other hand, persons in the industry regarding the scientific understanding of the effects produced by various physical treatments intended to accelerate aging. It is hoped that both basic scientific and commercial research will be stimulated and to that end several suggestions are made upon lines of attack that appear promising for further study. 


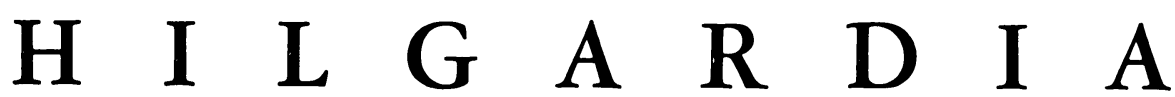

A Journal of Agricultural Science Published by

the California Agricultural Experiment Station

VOL. 32

MAY, 1962

No. 7

\section{AGING OF WINES AND OTHER SPIRITOUS PRODUCTS, ACCELERATION BY PHYSICAL TREATMENTS}

\section{L. SINGLETON ${ }^{2}$}

\section{FOREWORD}

WITH THE increasing interest of the general public in wine appreciation and quality, coupled with the need for cost reduction through modern technology, California wine makers have become increasingly interested in accelerated aging treatments.

The purpose of this publication is to provide a comprehensive and critical summary of the reported physical methods of accelerated aging. The literature upon this subject is extensive and unusually widely scattered-by language, type of product, date of publication, and type of publication (trade journal, applied scientific journal, basic scientific journal, etc.). As a result, many of the papers are not readily available in any one library. Although the emphasis is upon wines, the reactions should be similar and much important information is available on other products; therefore references not bearing directly on wines are included as they appear necessary for as complete an understanding as possible.

It was difficult to draw the line with regard to articles of a trade-journal nature. To make the bibliography as complete as possible, the tendency has been to include such material. In such cases greater emphasis has probably been placed upon articles published in English since these were more readily available and more pertinent to the situation in California and the United States of America.

Many citations have been obtained through Chemical Abstracts, and the abbreviations of publication names and reference designation will, in so far as possible, reflect the practices of that publication. Other important sources of citations have been the bibliographies of cited articles and reviews, and the abstract sections of Chemisches Z entralblatt, Industries alimentaires et agricoles, Bulletin de l'Office International de la vigne et du vin, Zeitschrift für Lebensmittel-Untersuchung und-Forschung, and others. The original articles have been studied in most cases. Those which it was impossible

\footnotetext{
${ }^{1}$ Received for publication October 9, 1961.

${ }^{2}$ Lecturer in Enology and Assistant Enologist in the Experiment Station, Department of Viticulture and Enology, Davis.
} 
to obtain have been evaluated by cross comparison of as many reviews or abstracts as possible.

This publication aims at informing, on the one hand, chemists and food scientists regarding the state of the art and future possibilities of accelerated wine and spiritous beverage aging; and, on the other hand, winery personnel regarding the scientific understanding of the effects produced by various physical treatments intended to accelerate aging. Many of the older reports are re-evaluated in the light of more recent developments. Since improvement in a wine is difficult to agree upon, particularly when different national, dietary, climatic, etc. factors are involved, emphasis is placed upon the more definite experimental results such as compositional changes.

\section{INTRODUCTION}

The slow, uncontrolled, and imperfectly understood traditional methods of aging of spiritous products are expensive and wasteful. The large inventory of product and storage facilities with the attendant immobilization of capital and tax liability result in raising the cost of the product considerably to provide a reasonable return on the investment. These costs increase continually with longer aging. Traditional methods do not give uniform, predictable improvement in each lot and the long storage increases the unavoidable or accidental loss and damage hazard. Consumers are not always informed enough or individual lots may not be improved enough to justify increased selling prices to cover the increased cost. As a result there continues to be strong pressure to avoid the traditional methods of aging either by modifying the product so that less aging is needed or by accelerating the aging process.

For one reason or another interest in accelerated aging of wine and spirits has been very sporadic. For example, the immediate post-repeal era in the United States saw an intense interest in quick-aging methods. Almost every conceivable treatment was hastily tried in an effort to market products in short order with reasonable quality. As inventories were built up, producers returned to traditional methods and the majority of the proposed methods of quick-aging had a very short life. In fact, many treatments never achieved commercial application and were not tested by what today would be considered adequate methods. The situation at other times and in other countries has been similar-an intense interest, diligent study for a short period, acclaim and strong partisanship for various procedures, followed by silence, and return essentially to the status quo.

It is believed that a less frantic and more sustained study of accelerated aging should bear more permanent fruit and that the improved techniques of product treatment and evaluation available today promise more clear-cut and permanently useful results. This opinion is apparently shared as evidenced by the renewed scientific interest in the problem not only in the United States, but also in the U.S.S.R., France, Germany, Spain, Italy, and other winegrowing countries. So many man-years having been already expended, it seems imperative to evaluate and summarize these efforts as prelude to further experimentation.

The estimation of the effects produced and the value of a given quick-aging 
treatment is a knotty problem and may be the stumbling block that has prevented more general adoption of previously proposed procedures. Certainly there is no unanimity of opinion as to the optimum degree of aging for any product. At the outset it should be recognized that just as the label "imported" will be preferred by a certain class of consumer regardless of the merits of the product, so will products "aged by ancient, traditional methods" have appeal and probably maintain a place in commerce. "Aging" is not an entity or single reaction; neither is a single product produced by a single method expected to be the utlimate, desired by all consumers above all other similar products. The approach taken here, then, will be to estimate the effect of specific types of physical treatment on the quality and chemistry of the treated product based upon the available data and in relation to the effects generally considered desirable in traditional aging without insisting that the traditionally aged product be exactly simulated. Wines and other products of this class are expected by the consumer to have differences, at least within certain limits, depending upon the particular producer, etc. A flavor change in a product such as, for instance, grape juice is likely to be interpreted as an "off" flavor and discriminated against. In wine and related products, however, the consumer expects flavor change as a result of processing and aging. It would appear that, with proper merchandizing, a flavor that is unusual with respect to any existing product yet not objectionable might be saleable as a new product. With this in mind, the eventual commercial application of procedures first considered as accelerated aging treatments appears even more promising.

Another point worth mentioning by way of introduction is that, considering the risk and expense involved, it is not surprising that only the premium lots of wine were habitually saved for extended traditional treatment. Conversely, at least within small commercial organizations, a premium lot of wine may not have been risked in testing any experimental quick-aging process. The quick-aging treatment was expected to up-grade standard or even slightly defective products and yet was often compared, consciously or unconsciously, with the traditionally aged premium products. It is believed that expecting too much of quick aging, together with ill-defined goals and prejudice against innovation, may have prevented adoption of useful treatments. With dispassionate reassessment, the scientific basis and potential value of the myriad suggested treatments should become clearer. To limit this report to manageable size, consideration has been restricted to physical treatments. This classification has been necessarily arbitrary. For example, distillation and adsorption are physical in nature, but the results are achieved by chemical fractionation so they are not discussed here.

\section{TRADITIONAL AGING TREATMENTS}

Before accelerated aging can be considered, it is necessary to consider the traditional methods and their objectives. It is intended to make the voluminous literature upon the chemistry and technology of traditional aging the subject of another report, so only the briefest outline will be considered here. General references on the subject include those by Amerine (1938, 1950), 
Sichel (1946), Carles and Lamazou-Betbeder (1959), Ribéreau-Gayon (194849), Bedoukian (1952), Strausz (1947a, b), Joslyn and Amerine (1941a, $b$ ), Jacobs (1951), and the standard technical reference books for particular products.

Our use of the terms maturing and aging of alcoholic solutions is intended to relate to those changes perceived by the senses as color, flavor, or odor changes in freshly finished or semi-finished products as a result of time or additional treatment. Under our broad definition any quality change and the underlying compositional changes are considered a part of aging if they occurred or were produced after the product had been fermented, distilled, or blended to its typical alcohol content or if they accomplish the same ends as such changes. Some writers have applied "maturing" to aging in wood and "aging" to bottle aging of wines. This distinction does not seem useful and will not be used here. Maturing does, however, imply changes in the earlier and overall still desirable stages, whereas aging is still going on in products that are deteriorating with time. Particularly in older reports, the processes of natural or assisted clarification and loss of yeastiness of freshly fermented products are considered a part of aging. Clarity and yeast removal are readily achieved today in very young products without resort to treatments that are considered part of aging, and terming such treatments "aging" should be avoided. Such treatments do, however, change composition and quality and thus do relate to aging.

Although the details vary greatly with the specific wine type, the producer, and the different geographical areas, wines traditionally have been aged for a period of several months to a few years in relatively small wooden containers, usually made of some species of oak. When the wine is judged "ripe" to bottle, the final processing and bottling is done. The bottle, stoppered with natural cork, is then stored by the producer or other members of the distribution chain and perhaps by the consumer for various lengths of time ranging up to many years. Except for frequent filling up of the wooden container to prevent the harmful effects of the air space produced by evaporation, the maintenance of appropriate-usually relatively cool-temperatures, and occasional transfer to other containers for various reasons, there is little direct participation in this traditional process of wine aging by the wine maker. Time is expected to produce the desired effect and the control of the process involves primarily the decision to terminate each stage based upon frequent sensory evaluation, traditionally depending upon the sole judgment of the master cellarman. This description is over-simplified, and in modern wineries many modifications and more elaborate controls and evaluations are used. There seems to be a feeling, however, justified or not, even among scientifically trained wine producers that these newer treatments may be indispensable for other reasons, but from the single viewpoint of the most desirable aging either contribute little or represent compromises.

The chemical reactions that occur during the wine aging process include limited oxidation, esterification, ester interchange, polymerization and precipitation, hydrolysis, etc. Compounds that participate directly or indirectly in color or flavor are contributed from the wooden container, probably from the cork, and possibly from the glass bottle. In some wines special processes 
contribute to the modification of color and flavor. Aging of bottle-fermented sparkling wine on the yeast sediment is accompanied by yeast autolysis and flavor change. The various wines called sherry include types whose flavor depends upon a secondary aerobic yeast fermentation during aging as well as Madeira-like wines baked to produce special flavors. The degree of oxidation which produces a desirable sherry would "spoil" a wine intended for market in many other categories ; this fact re-emphasizes that the desirability of a reaction or its extent cannot be considered entirely separately from the specific product.

Among alcoholic products other than wine, perfumes and flavor tinctures are usually blended and then subjected to a period of "marrying." This requires a few weeks or months of storage of the alcoholic solution, usually in impervious containers, to allow interaction of the odorous constituents and precipitation of substances which are not soluble in the mixture. As a result, the product usually acquires a fuller aroma and is also stabilized as to odor quality and clarity before leaving the producer's hands or being bottled. Beer may be aged for short periods, in some cases some contact with wood shavings is included, but in the United States little true aging is involved, and once the beer has deposited or been relieved of yeasts and haze-forming substances it is considered marketable. Whiskey and brandy, on the other hand, are largely dependent upon the changes produced during aging. Their identity and quality depend heavily upon colored and flavored substances extracted from the wooden barrel, although oxidation and chemical interaction with the constituents of the distillate being aged also appear to be involved.

The effects of aging from a sensory point of view are also several. The amount of brown color (or yellow, amber, gold, etc.) ordinarily increases. In red-colored wines, the red decreases, the net effect being change from a frank red or purplish red to a tawny, brown or orange-hued red. The flavor should improve from three directions-harsh or too strong flavors appear less strongly, extra flavors are added, and flavors change by interaction. As a result, the flavor becomes more mellow, more complex, "rounder," fuller, and more interesting. The "hot," alcoholic, raw taste of distillates and fortified wines is lost or masked. The hard, astringent, tannic taste of young red wines is mellowed. Flavorsome amounts of wood flavor may contribute favorably to several kinds of beverages. Bottle bouquet is an extra, desirable odor and flavor in most table wines and some fortified wines. The known odorous and tasteable compounds in several fruits, wines, and other fermented beverages are numerous. Many of these compounds are quite reactive. As an illustration related to aging, imagine a solution containing appreciable amounts of four primary alcohols. If portions of each of these were oxidized to aldehydes and some of each of the aldehydes further oxidized to carboxylic acids, the remaining alcohols could each esterify with each acid and the mixture would contain 28 compounds as compared to the original four. If the possibilities of mixed acetals are considered, the number is multiplied even more. Similar multiplications of flavorsome compounds undoubtedly contribute to the improved fullness and complexity produced during marrying and aging of spiritous products. 
Just as it is difficult to define the point in time that aging of a product starts, it is also difficult to define the traditional practices even for a single type of product. There are no inviolate operations in modern commercial practices and what is "traditional" at one moment is greatly or slightly modified the next. Although such treatments are not directly accelerated aging, the net result is the same if the requirement for aging can be lowered or eliminated. Some of the most successful yet least heralded treatments for shortening aging time lie in this area. Since the composition of the young wine governs its need for and reaction to the various changes introduced during aging, any processing change with effect upon wine composition will probably also affect the aging of the wine produced. It is not within the scope of this report to detail all such interrelationships and one or two examples will serve to illustrate the importance of such manipulation. It goes without saying, of course, that sound initial products are assumed-aging, accelerated or not, should not be used to cover up defects resulting from poor wine-making practices.

One of the common defects of young dry red table wines one expects to rectify by aging is the extreme astringency and roughness resulting from a high tannin content. The tannin is extracted from the seeds, skins, and stems during the early stages of the fermentation, but once the wine has been separated from the particulate matter no further extraction can occur. If the wine is separated from the skins, etc., earlier, the tannin content and the resultant aging requirement are reduced. Since color extraction from the skins parallels tannin extraction (Ough and Amerine, 1961), color may be too low if early pressing is carried to extreme. It is true, however, that the trend has been to earlier pressing of red wine fermentations. Specific data upon current commercial practices are difficult to obtain, but Amerine and Cruess in 1960 state that for red table wines the wine is drawn off after about three to four days and rarely more than five in California. Amerine and Joslyn in 1951 stated that four to six days in contact with the skins was desirable in California for red table wines and might be as long as 15 days depending upon the degree of astringency and color desired. The diversion of some red grapes to the making of pink rather than red wine is part of this trend. Rosé wines generally require much less aging than is traditional for red wines. The same trend-reduction of time on the skins and aging requirement-has been noted in other viticultural areas. For example, Reuss (1961) has noted a decrease in the age at which Bordeaux and Burgundy wines are retailed in England owing at least in part to changes in vinification practices. Although wines produced by decreased contact with the skins may not have as high potential quality as those with longer contact, they do appear to realize their potential sooner.

Another example of the effect of a change in production procedures upon aging lies in the use of more nearly pure ethanol for fortifying dessert wines or for beverage spirits. The "hotness" of freshly distilled spirits has been attributed to some ingredient among the more volatile constituents or "heads." Less volatile constituents including the fusel oil or higher alcohol fraction also affect the flavor. The distillate with the most congeneric substances may eventually yield the most interesting and highest quality prod- 
uct, but more time is ordinarily required for the hot or heavy flavors to be lost or adequately modified by the reactions of aging. Conversely then, the use of as pure ethanol as permitted by practical or legal considerations should shorten the aging requirement. Arroyo (1940) reports the reduction of aging of rum from four years to six to nine months by controlling the nature of the distillate. Again the ultimate quality may be somewhat less, but acceptable quality is achieved sooner. With the shift away from pot stills and the improvement of continuous stills with efficient fractionating columns, the spirits for use in blending and in making dessert wines have been more and more nearly pure ethanol. The resultant products can lack much of the raw, fiery taste which required either long aging or customer fortitude in years past. Legal restrictions, in the United States at least, limit the extent to which this idea can be pursued in production of straight beverage brandy or whiskey. However, the use for blending of neutral spirits aged for a short time in previously used barrels, the market growth of blends, and approaching the legal limit of proof of distillation as closely as possible appear to be widespread and growing. The result is non-offensive products requiring less expensive aging than has been traditional.

In both of the examples given, the product required less aging than before because of a decrease in some constituents. As already implied, the quality score of such products would be expected to be satisfactory, but not as high as well aged, premium "old-fashioned" products, at least if scored by connoisseurs of the traditional product. Whether or not the general public really favors the decreased flavor level and increased mildness (or insipidness) which seem to be the commercial vogue in many mass produced products is subject to debate. Even if so, however, the manipulations of product preparation which may delete objectionable features or enhance some desirable ones such as fruitiness will not completely obviate the need for aging of spiritous products since there are desirable qualities added during aging. These qualities are recognized and prized by a portion of the consuming public. If they can be introduced into the products reliably and inexpensively it is reasonable to suppose the products would have increased appeal to additional portions of the public.

\section{ACCELERATED AGING BY PHYSICAL TREATMENTS}

It is proposed to discuss the methods of physical treatment which relate to attempts to accelerate aging of spiritous products under several subheads. In most cases the critical review of the data available from previous studies specifically upon accelerated aging will be supplemented with a discussion of the physical and chemical effects to be expected from the treatment. Previous general publications on accelerated aging include those by Malvezin (1903), Pozzi-Escot (1905), Snell (1934), Joslyn (1934), Brown (1937), Jacobs (1947a), Deibner (1957a), Singleton (1959), and others which will be mentioned later in connection with specific treatments.

\section{Agitation}

Mechanical Treatments. In common with several other "quick aging" ideas there has been a great deal of occultism associated with the effect of various 
forms of agitation on wines and spirits. The pleasant legend of the miller who, noting that he lacked aged wine for his daughter's wedding feast, attached small casks to the arms of his windmill and was able to serve well aged wine to his guests two days later has been quoted by Malvezin (1903). Malvezin immediately points out that this treatment is more likely to lead to casse formation-oxidation and turbid wine. He also quotes an 1844 article by J. Fauré to the effect that agitation of a bottle of wine followed by repose hastened the deposit of sediment and improved the wine. In the modern situation, clarity is achieved preferably by stabilization before bottling and hastening deposit formation in bottles probably would not apply. Of course, much agitation of a bottled wine which contains a deposit would not ordinarily be desirable because the sediment probably would be dispersed in the wine and decantation of clear wine would be impossible at least for the time being. Malvezin believed that the effects noted were due to hastened oxidation rather than the movement as such and stated that if the wine was sealed in the presence of carbon dioxide rather than air the improvement by bottle agitation described by Fauré did not occur.

The agitation produced by shipment (often a round-trip) on ocean-going ships has often been claimed to improve wines. As recently as 1959 considerable publicity was given to the return of a cask of wine which had sojourned some time on a ship. The tasting of this wine by several reputed experts in a garden-party atmosphere led to several favorable opinions upon the effect of the "treatment." There may be some historical justification for the belief held by some that baking of wine under oxidative conditions to produce baked sherry or Madeira-type wines was copied from the effect of transportation of wines in the hot holds of slow ships. One report (Malvezin, 1903) describes the shipment of French dry red wines, vintage 1848 bottled in 1851, on a year-long voyage to Calcutta. When compared with bottles of the same wines retained in the cellar, the shipped wines had more orange color, less softness and fruitiness, much more developed bouquet, and in short appeared much older than the samples not shipped. Pasteur (1873) concluded that the effect of an ocean trip to warmer climates was the result of high temperature and aeration perhaps encouraged by the alternate positive and negative pressure effects within the container (especially wood) and not agitation itself. He notes that wines so treated often take on a cooked or burnt taste suggesting the important effect of temperature. This flavor change was prevented if the wine was hermetically sealed and was less in bottles than in casks.

The location of storage cellars near heavy traffic and other vibrationproducing conditions has been considered as an aging treatment. Malvezin (1903) described storage cellars built under railway arches in London in which wine became perfectly clear more readily than in other cellars. This effect appears to involve primarily clarification rather than aging and is likened to the effects of hand turning in encouraging sedimentation of yeasts from bottle-fermented sparkling wines. Treatment with sound will be discussed in another section but at low intensity is just another vibration. More has been claimed for rocking or violent agitation than for tremulous agitation (Jacobs, 1947). Among the early French patents reviewed by Malvezin (1903) were those by Timby (1892), Cousseilhat (1867), and by an organi- 
zation with a most intriguing name, the "Mechanical Spirit Maturing Syndicate Ltd." (1890). Cousseilhat aged alcoholic liquors by agitation in a barrel with rotatable wooden paddles much like a butter churn. Timby used a small circular railroad with vertical waves in the rails and pulled the casks around on little cars which resulted in changing "the molecular state" and aging wines and spirits. The Syndicate's machine was supposed to age brandy and other liquors by agitation and dispersion in air in a closed container, but the drawing shown by Malvezin seems mechanically inoperable.

Perhaps frightened away by such antics as just described, in more recent times workers have evidenced relatively little interest in agitation or other purely mechanical treatments. As a part of other treatments they are more common. In France, continuous stirring at $35^{\circ} \mathrm{C}$ to accelerate oxidation, uptake of tannin (from wood), and esterification may be used with distilled spirits (Bonis and Moroy, 1948). Drew (1935) has patented an aging container for spirits which, by wooden baffles, resists motion of the contents, although his primary purpose was to increase the wood surface available for extraction. The improvement of flavor of spirits by treating in a vibrating ball mill or similar device containing ceramic balls vibrating $0.5 \mathrm{~mm}$ at 100 cycles/sec has been claimed (Kiesskalt, 1951). Pressure with agitation and then vacuum treatment without appreciable evaporation of alcohol have been recommended by Wilkin (1952) for the improvement of distilled spirits such as gin and whiskey. The primary effect claimed is the removal of relatively volatile constituents. A British patent (Farbenindustrie, 1925) covers a process involving use of rapidly moving beaters, pressure, and perhaps heat or cold to mature alcoholic beverages such as sherry and port, and perfumes. Kawasaki (1954) ages cider or beer by injecting $\mathrm{CO}_{2}$ under pressure and agitating. Takahashi (1907) suggests quick-aging of sake by rotating the container at high speed for more than 20 days. Kraft (1950) claims production of a superior whiskey distillate by mixing with air under pressure and explosive release of the pressure.

These reports are not very satisfying and one is tempted to write off agitation except as a way of speeding some other effect such as evaporation, aeration, etc. One further thought, which has not been mentioned by previous authors in this connection suggests itself. Ruggli (1912) in his classic work on high dilution reactions has shown that if two functional groups capable of reacting with each other occur on the ends of a relatively long molecule one can get good yields of the cyclic product if there are few reactive molecules present at any given moment, but gets instead the alternative polymeric product if the concentration is increased. Similar effects may occur in wines. It is the usual experience that rapid aeration does not give the same aging effect that slow diffusion of oxygen through wood does. It is also known that gradients may exist in static containers and portions of the liquid may be relatively concentrated or dilute with respect to some constituents or reactants. These facts suggest that fewer side-reaction products may be formed if the mixture receives sufficient agitation to ensure that concentration gradients do not exist. For example, if one oxidizable substrate is considerably more reactive than others, under conditions of agitation in the presence of air it should be consumed before others are attacked. Without agitation it might be 
locally depleted at the top of the cask and other compounds could be attacked in that layer. The result would be that the ultimate products produced with agitation and without agitation would not have aged in the same way (which would be better is unknown, of course). As has been emphasized before, a change involving only a relatively small number of molecules of an odorous compound need be made to change the flavor. For these reasons it is believed that agitation may be found to be an important factor to be controlled in achieving maximum rate of aging reaction in large containers without overthrowing the desired flavor.

Sonic and Ultrasonic Treatment. The vibration produced by sound waves has been claimed to have favorable effects in wine aging. Although the idea of improving fine wines by subjecting them to violin concerts is romantically attractive, it has never been seriously advocated and might be more appropriately applied to mellowing the consumers than the wine. The claimed effects of audible sound on wine have been attributed to the agitation produced (Malvezin, 1903). Ultra sound (that above about 20,000 cycles/sec) has been reported to have special properties with respect to beverage treatment. Let us first outline what can be expected to occur under sonic and ultrasonic treatment and then detail the reports of applications to spiritous products.

Sonic treatment sufficient to produce physical and chemical changes in liquids requires considerable intensity or power. This does not necessarily mean high frequency. This point is often confused, probably because only at high frequency is high power attainable economically (Henry, 1954). A sound wave whether in, or higher than, the audible range consists of regularly alternating higher followed by rarified pressure pulses accompanied by an alternating, orderly, forward and recovery movement of the molecules. Some of the sonic energy is absorbed and appears as disordered molecular motion or heat. The relative movement of different molecular species and particles within a liquid under the influence of a sound wave would differ somewhat depending upon their size (inertia), their tendency to absorb sound, and other factors such as sound reflection in the container used. Agitation and mixing would result.

Another effect of sonic vibration which can operate at relatively low frequency and power is the agglomeration or dispersion of particles. Whether a particle is dispersed into smaller particles or combines with other particles to form a larger unit depends upon its own nature (size, the strength of the forces of coherence, etc.) and the sound used (frequency, intensity). As a rule, the larger the particle the lower the optimum frequency for agglomeration (Weissler, 1953). Were it not for the effects of cavitation, the use of sonic treatment of beverages would seem to be of rather feeble interest and certainly less elaborate methods can be used to stir, heat, or clarify wines. Treatment of liquids with intense sound can, however, produce more profound effects, practically all of which appear to be the result of cavitation.

Cavitation is the phenomenon which results when the rarified pressure stage of a sound pulse is low enough to produce a bubble-like fracture, or void, within the liquid. This void collapses as the following high pressure phase of the sound pulse arrives. The violent hammering produced may be likened to 
that produced when steam is vented into cold water. The momentary pressure and temperature produced by the rushing together of the essentially incompressible liquid as a cavity collapses are very high-of the order of millions of atmospheres and at least $10,000^{\circ} \mathrm{C}$ are predicted by calculation of the forces involved (Richardson, 1957). Cavitation is also related to sonoluminescence, a faint light believed to arise from electrical discharge across the cavitation bubble. These virtually unique conditions of pressure, temperature, etc. not surprisingly produce interesting chemical effects. Although the mechanisms are debated (Del Duca, et al., 1958), there is evidence for chemical bond fracture resulting in reactive ions and free radicles.

Weissler (1953) has studied and reviewed the chemical effects of ultrasound (see also Richardson, 1957). Intensity of the order of $0.03 \mathrm{watt} / \mathrm{cm}^{2}$ or higher is required to produce cavitation (and hence most chemical effects) in ordinary distilled water. The frequency has as a rule little or no direct effect upon cavitation rate. As the intensity (above the threshold) increases cavitation generally increases linearly to some optimum and then decreases, although not all reactions show the expected decrease (Lindstrom, 1955). The decrease is believed the result of absorbing or damping out of further energy by the intense bubble production or by decreased cavitation as a result of degassing. The optimum intensity for $\mathrm{H}_{2} \mathrm{O}_{2}$ production in water was 0.1 $\mathrm{w}$ per $\mathrm{g}$ of solution in one series of experiments. As the volume of the liquid in the treatment chamber was increased the optimum intensity increased. Cavitation is difficult or impossible to produce with present equipment in completely degassed water. Cavitation bubble initiation and the subsequent violent collapse seem to require or at least are much more easily produced when gas is dissolved or very finely dispersed in the liquid. The nature of the gas has a great effect upon the reaction produced. When oxygen is dissolved in water the major chemical effect of cavitation is hydrogen peroxide production. If air is used nitrous and nitric acid are produced in addition. Pressure has a profound effect as might be expected ; low pressure inhibits (degassing) as does high (bubble suppression). The optimum for maximum cavitation appears to be about $1,000-1,500 \mathrm{~mm} \mathrm{Hg}$. As long as all reactants are present in excess, ultrasonically produced reactions ordinarily proceed linearly with time after the first few minutes. Temperature, in the $20-50^{\circ} \mathrm{C}$ range, apparently does not have a great effect upon reactions depending upon ultrasonic energy. The rate often decreases as the temperature increases. In addition to the production of $\mathrm{H}_{2} \mathrm{O}_{2}$ in water solution, many other chemical effects of ultrasonic cavitation have been observed. Most of these reactions are oxidative in character, but at least one case of a reduction has been reported (Richardson, 1957). Oxidative rancidity of unsaturated fats may be hastened. Polymerization or depolymerization reactions may be produced (equilibrium molecular weight appears to be of the order of 25,000). Halogen or sulfur may be liberated from organic molecules (Srivastava, 1958). Alcohol and acetone inhibited this action and such relatively volatile compounds apparently suppress cavitation or its effects. Aromatic rings can be completely disrupted, acetylene being one of the products (Zechmeister and Magoon, 1957) and nuclear hydroxylation of the ring may be produced (Parke and Taylor, 1956). 
The effect of ultrasound upon the rate of reactions that will proceed without ultrasound is variable. In some cases the reaction or the attainment of equilibrium is speeded up-at least partly by increasing the frequency of contact or diffusion of the reacting molecules. In other cases the reaction may be stopped or inhibited-particularly if $\mathrm{H}_{2} \mathrm{O}_{2}$ is detrimental or if complex molecules are disrupted. Ultrasonic treatment of a reaction catalysed by insoluble mineral catalysts speeded the reaction, presumably by comminution of the catalyst particles (Nikolaev and Askadskii, 1958). The rate of hydrolysis of ethyl acetate and other esters was usually considerably increased by ultrasonic treatment (Thompson, et al., 1953; Miyagawa, 1949). Ultrasonic treatment of aqueous ethanol solutions gave little oxidation unless the ethanol content was below 45 per cent, but at low alcohol content aldehyde, free acid, and ester increased with time of treatment (Taki and Kunitomi, 1951). Lapinskaya and Khenokh (1953) report that $3 \mathrm{hr}$ treatment with 30,000 cycle/sec sound of $0.02 M$ ethanol solution produced $7.98 \mathrm{mg}$ of aldehyde/100 ml. Glycine, lactose, or glucose inhibited the oxidation. Loiseleur (1954) groups the chemical effects of ultrasound with other oxygen activating or "peroxidizing" agents, namely X-ray and ultraviolet irradiation, and notes that ultrasound is the least efficient of the three in a model dye-producing reaction. The rate of ultrasonically produced chemical reactions is usually rather low; $4 \mathrm{mg} / \mathrm{l} / \mathrm{hr}$ at 16 watts $/ \mathrm{cm}^{2}$ has been suggested as typical (Richardson, 1957).

Although these and other reports cover a great amount of phenomenological data on relatively simple solutions, the overall picture of the chemical effects of ultrasound is still incompletely understood. Certainly in a complex solution such as wine it is not possible to satisfactorily predict the nature and the extent of the reactions ultrasound will produce.

Another feature of ultrasonic treatment is the difficulty of quantitatively reproducing a given reaction. What have been called topographic effects by Zechmeister and Magoon (1957) account for much of this difficulty. The shape, wall thickness, precise orientation with respect to the generator, capacity, etc. of the treatment chamber affect the sound pattern and intensity. These geometrical factors interact with the wave length of the sound to give standing waves, etc. As a result it is difficult to reproduce results of other investigators even if considerable detail of their experiments is reported (which is often not the case).

Several applications of ultrasound to fermentation and spiritous beverage production have been covered in general reviews of Chambers (1938), Bergmann (1954), Mattiat (1954), Ots (1954), and Renaud (1960). Fermentation, particularly by poorly nourished yeasts, may be increased by ultrasound presumably by increasing the diffusion of nutrients to and products from the cell or by disrupting polymeric nutrients to make them more readily assimulated (Egger, 1955). Ultrasound can disrupt and kill microorganisms, but sterilization by this means has not proven practical (Proctor and Goldblith, 1951). The use of ultrasound to improve extraction of hops has enabled considerable reduction in the quantity of hops required in beer manufacture. The resultant beer is said to be improved and the process has been investigated and applied on a commercial scale (Speight, 1958 ; Salač, 1955 ; Ultra- 
Technik, 1957; Purtschert and Caratsch, 1955; Schild and Weyh, 1960). Experiments on clarification of wine with ultrasound have been mentioned (Anon., 1956).

Use of ultrasonic treatment as a rapid-aging procedure was actually one of the first nonmilitary applications of ultrasound investigated. Such use has been mentioned in several summaries of quick-aging applications (Burmeister, 1952; Miyagawa, 1949; Bláha, 1955; Perin, 1952) as well as in the general reviews previously mentioned. Processes for sonic or ultrasonic treatment to accelerate aging reactions in raw fermented or distilled alcoholic beverages have been patented. Bachman and Wilkins (1937) emphasized acceleration of normal aging reactions such as esterification, wood extraction, tannin hydrolysis, and aldehyde oxidation by 2 megacycle/sec ultrasonic irradiation of distillate in casks or in the presence of wood. Several hours treatment in the presence of oak chips is said to produce taste and bouquet equivalent to one year or more in traditional barrel aging. Chambers and Smith $(1937,1940)$ also obtained patents on sonic and ultrasonic treatment by equipment suitable to be used in wooden barrels. The application was considered to be beneficial for whiskies, brandies, rums, liqueurs, and to some extent for wines, cider, champagne, beer, and ale. Details of the equipment are given, but in neither case were actual experiments reported with chemical or sensory analysis. Somewhat similar processes making use of ultrasound have been patented in Germany (Atlas-Werke, 1952), France (Bugard, 1948), Switzerland (Eisenegger, 1951, 1954) and Russia (Protopopov, 1938). Bergmann (1954) in his rather exhaustive summary mentions work by Kilp (1951) who had no success in treating various corn distillates except for a fore-run distillate which after $10 \mathrm{~min}$ of ultrasound definitely improved to become similar to a middle-run sample.

Treatment of spirits, wines and perfumes with ultrasound has also been reported in German journals unavailable to the author (Specht, 1950c, $d$; Curtze and Burmeister, 1950; Koch, 1950, 1951; Schmidt, 1951; Conrad, 1950). However, other reports by most of these investigators were available. Specht $(1950 a)$ reported the treatment of various distilled spirits in 100 to $1,000 \mathrm{l}$ portions with a 1 megacycle/sec generator producing 300 watts of sound energy. Periods of a few minutes raised the ester content to about 120 per cent of the original value with a wine distillate. Aldehyde decreased and no great or consistent change in total acids or $\mathrm{pH}$ was found. As a rule a degradation of fusel oil was noted and a trace of methanol was apparently removed or destroyed in "K spirit." The increased ester was partly lost in six months storage, but did not sink below the value reached in the same period by untreated spirit. In a more detailed report apparently on an extension of the same research, but covering many more kinds of alcoholic beverage the results appear less favorable (Specht, 1950b). He reports increase in quality of flavor has been obtained with several distilled products (wine, gin, rum), but notes that the conditions of treatment are important, either too long or too short treatment may cause damage, and there seems to be considerable lot to lot variation.

Bláha (1955) reports that ultrasonics appear to offer the best results among 
physical treatments for rapid aging of wine and Janicki et al. reached the same conclusion with rye whiskey in a comparison with ultraviolet light and distillation with a catalyst. Lichev (1956) found brandy was improved and the improvement coincided with increased aldehyde content. The treatment was with $950 \mathrm{kc} / \mathrm{sec}$ at $20-2^{\circ} \mathrm{C}$ with a $100 \mathrm{w}$ generator. The improved character was retained through subsequent storage in oak barrels and bottles. A process patented in Germany (Siemens-Schuckertwerke, 1952) utilizes ultrasound to accentuate the effect of ozone in aging of wines and spirits.

Aging of wines by treatment with ultrasound has been reported by Rakcsányi and Peszeszér (1958). Some minutes of treating five lots of wine with 1,600 and $4,800 \mathrm{kc} / \mathrm{sec}$ sound waves under cavitating conditions were followed by chemical analyses of the wines. Part of the sound energy was "stored" in the wine and by flavor judgment and chemical analysis it was concluded that two effects were produced-an immediate shift toward chemical equilibrium and faster subsequent aging as compared to the untreated wine. The analyses as percentage of the control samples averaged for the five lots for the 1,600 and $4,800 \mathrm{kc} / \mathrm{sec}$ treatment respectively were: total acid 157, 188; total ester 109, 195; acetaldehyde 120, 152; and fusel oil 91, 88. Maňková (1957) mentioned using ultrasound in the production of sherrytype wines from hybrids of New World grapes.

Koch and Bretthauer (1950-51) studied the effect of ultrasound administered by several methods to various spirits-gooseberry, currant, and cherry dessert wines, vermouth, a liqueur, a Müller-Thurgau dry white table wine, and 96 per cent distilled spirit. A comparative tasting was made about 1-7 months after treatment. They report grape wines to be unfavorably influenced in all their tests-aroma was lost and the flavor became somewhat oxidized or less lively. The fruit dessert wines were usually improved, becoming less alcoholic, more harmonious, and with more rancio or dessert wine taste. The vermouth (apparently a finished young wine, i.e. no herbs present as such) had less strong, bitter herb taste and became more like a dessert wine after treatment. Under their conditions the equipment generated 3.5 $\mathrm{w} / \mathrm{sq} \mathrm{cm}$ and produced the equivalent of 164 cubic mm of active $0_{2}$ (calculated to standard temperature and pressure) in $30 \mathrm{~min}$ in a $350 \mathrm{ml}$ water sample or 18 cubic $\mathrm{mm} / 350 \mathrm{cc}$ in water flowing at $10 \mathrm{~min} / \mathrm{l}$-approximately the conditions used on the wine samples. Analytical data selected from their report are shown in table 1 .

A report by Hennig (1951) describes experiments with dry table wines. White wines were not improved and, in fact, hardly changed. Analyses remained the same with both white and red wine. A mousey taste was made more apparent in red wine. Sulfur dioxide remained unchanged in the treated wine and this suggests that air was carefully excluded.

In summary, it appears from the data outlined that one may expect oxidative effects from the resultant $\mathrm{H}_{2} \mathrm{O}_{2}$ and probably molecular fragmentation and recombination of the reactive fragments produced, if wines or spiritous products are treated with ultrasound under cavitating conditions in the presence of some dissolved oxygen. Ultrasound may or may not hasten the attainment of an equilibrium or increase the rate of a pre-existing reaction. Thus, one could hardly expect to achieve the identical effect of long, tra- 
ditional aging merely by ultrasonic treatment. The comments of Ots (1954) in this regard are particularly succinct. To the extent that more rapid extraction of wood and oxidative changes are desirable in a given product, these two types of sonically accelerated "aging" would appear to be interesting. It is unlikely that delicately flavored wines (dry white table wines, for example) will survive or benefit from sonic treatment. More robust products may be improved and will withstand more intense treatment. There is no evidence for specific "ultrasonic" flavor production although with intense treatment Koch and Bretthauer (1950-1) noted a burnt taste and Surkov

TABLE 1

EFFECTS OF ULTRASONIC TREATMENT ON SPIRIT COMPOSITION

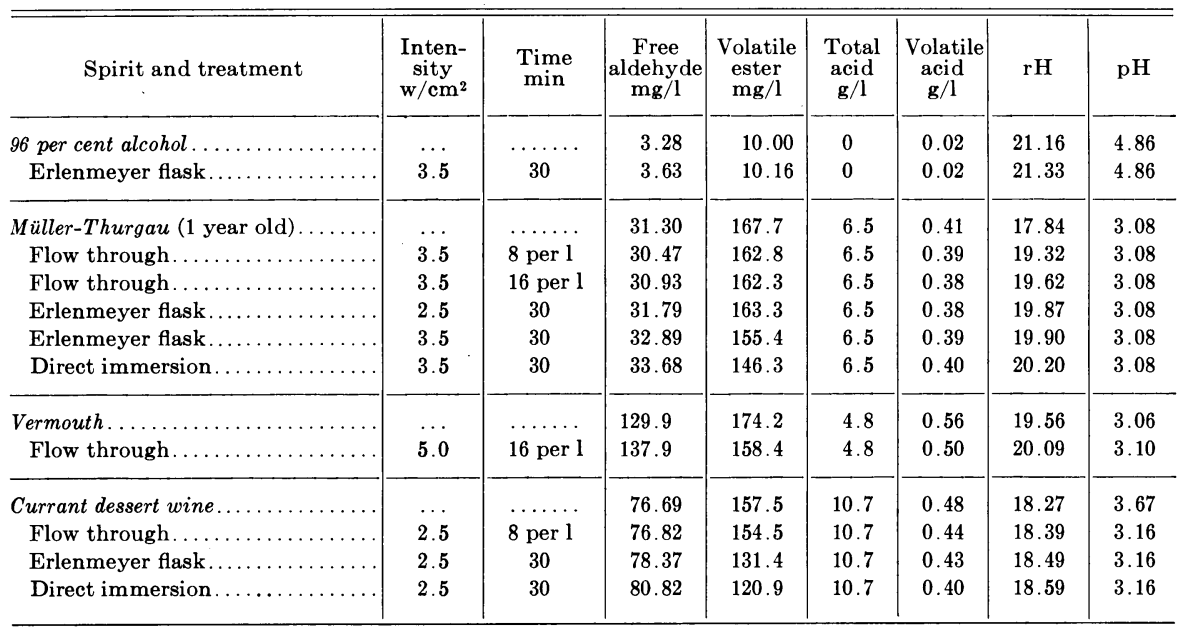

et al. (1960) mention a scorched flavor produced in milk. The slowness of reaction rates produced by ultrasound might prove to be an advantage in aging applications because a major problem in accelerated aging is overtreatment and for flavor changes a relatively small number of molecules need be changed. Further investigation of ultrasound seems warranted as a controlled method of introducing small amount of $\mathrm{H}_{2} \mathrm{O}_{2}$, as a means of increasing the rate of extraction of wood components (and perhaps herbs in vermouth production), and perhaps (for example, under the influence of dissolved gases other than air) production of other reactions related to accelerated aging of wines and other spiritous products.

\section{Temperature Control}

The microclimate desirable in a good aging cellar for wines has been studied by Wegner (1955) and reviewed by Saller (1955). For red table wines $12-14^{\circ} \mathrm{C}\left(54-66^{\circ} \mathrm{F}\right)$ and for white table wines $7-11^{\circ} \mathrm{C} .\left(45-52^{\circ} \mathrm{F}\right)$ are suggested with annual variation not to exceed $3-5^{\circ} \mathrm{C}, 92-95$ per cent relative humidity, and adequate air circulation. Amerine and Cruess (1960) recommend $52-60^{\circ} \mathrm{F}$ for table wines and $70^{\circ} \mathrm{F}$ for dessert wines. Escritt (1960) 
suggests $54^{\circ} \mathrm{F}$ as the best temperature for a mixed cellar. There is general agreement today on the desirability of a minimal variation in cellar temperature and that which occurs should be slow and infrequent. That cooler temperatures are more desirable for aging the lighter and less alcoholic wines, warmer for the robust table wines, and warmer still for the fortified wines is also generally agreed.

The same trend is noted with other beverages. Beer storage is quite cool, about $32^{\circ} \mathrm{F}$ (Sieben and Elliott, 1959). Distilled beverage storage is variable by product and area-ventilated sheet metal warehouses exposed to the weather are often used for bourbon whiskey, masonry buildings heated in winter for rye whiskey, and insulated buildings kept from overheating in summer for California brandy (Herstein and Jacobs, 1948; Crampton and Tolman, 1908). The trend appears to be toward more complete control of temperature, humidity, and air circulation to minimize evaporative losses. The temperature used is usually rather warm compared to that for other products. Brown (1937) reports $70-80^{\circ} \mathrm{F}$ as most favorable for California brandy.

As can readily be appreciated the time-temperature conditions for aging reactions in spiritous products are quite unusual compared to conditions used with food processing or chemical reactions where time is money if reactions are slow. Since the aging reaction rate must be related to temperature, it is not surprising that the possibilities of improving or controlling aging by temperature manipulation were among the earliest accelerated aging treatments to be explored. For our purposes the use of any temperature outside the "normal" conditions just outlined is to be considered an effort to control or accelerate aging and therefore of interest.

Heating is the most obvious means of accelerating chemical reactions and has been investigated again and again both alone and as part of other treatments for accelerating the aging process. The temperature coefficients of most chemical reactions lie between 1.5 and 3 (i.e. the rate is increased 1.5 to 3 fold for a $10^{\circ} \mathrm{C}$ temperature rise near room temperature). In many cases the Arrhenius equation is applicable to systems involving several reactions even when they are not individually known (Steiger, 1958). It would seem on this basis that one would need only to hold other conditions constant and raise the temperature from $10^{\circ}$ to $60^{\circ} \mathrm{C}$ to shorten an aging requirement from four years to six weeks, assuming an overall temperature coefficient of 2 . It has not proved this simple, however. For one thing, aging involves several reactions and the effect of increased temperature over such a wide range could hardly be expected to be the same for all of them. The temperature coefficients of the desired reactions may differ and other reactions which may be negligible under traditional aging storage temperatures may become important at elevated temperatures.

At the risk of considerable oversimplification let us review briefly the reasons behind these effects. As we apply heat to a solution and increase its temperature we are increasing the speed of the molecules present in the solution. This increase in kinetic energy increases the frequency of collisions and the colliding molecules give or receive energy to each other depending upon their speed, collision rectors, mass, etc. As a result, more molecules 
acquire sufficient energy to be "activated" and able to enter into a given chemical reaction than would be the case at lower temperatures. A reaction may be thermodynamically possible, but it will not occur at a useful rate until sufficient numbers of the molecules capable of reacting can acquire the necessary activation energy. Charcoal combines with the oxygen of the air and the heat evolved maintains the reaction once the charcoal is ignited, but as many backyard chefs will testify, it requires considerable activation energy to initiate the reaction. If the activation energy for a given possible reaction is low, then some of the reactive molecules can readily become activated and the reaction should proceed at a measurable rate at low temperatures. The larger the activation energy of a reaction, the higher the temperature, in general, at which the reaction rate becomes appreciable (Glasstone, 1946). Conversely, of course, as temperature is lowered the reactions should cease being observable in order of highest activation energy first. If a series of reactions are arranged in order of increasing activation energy, it will be found that their temperature coefficients increase in the same order.

Since traditional temperatures for aging spiritous products have been relatively low-for the most part below room temperature, it appears that the activation energy of the desired reactions is low. One would expect, then, not only to bring in appreciable rates of other reactions of higher activation energy as the temperature was raised, but also that further temperature increase would increase the rate of these higher activation energy reactions more rapidly than it increases the rate of the desired low activation energy reactions. This undoubtedly helps explain why, if one attempts to accelerate aging by heating, the flavor of the product is often altered compared to the traditionally aged product.

Heat treatments of wines to alter their quality and serve as quick aging treatments, as broadly defined here, fall primarily into two classes: those which drastically change the flavor of the wine and result in new types of wine, and those which simulate aging but leave the product still recognizable. In the first case the product is more the result of the process than any nuances of raw material, as the ham may be more the child of the smokehouse than the pig. In the second class, however, the process must be delicately engineered to improve without spoiling the elegance of the starting material-perhaps as cooking a prime beef steak-medium well done, please.

Many wines, if stored too long or in too frequent or intense contact with air, become brown and take on special flavors. This condition is referred to as maderization (or becoming Madeira-like) for white wines and has been called rancio for red wines. Since the precise flavor connotation of the latter term is not clear to the author and the ultimate result is very similar whether red or white wine was the starting material, maderization is considered here as the result of extensive oxidative changes in both red or white wine.

Whether or not such products originally resulted from making a virtue of a necessity or a frequent calamity is beside the point. The fact is that today there are a series of wines of this type which are widely appreciated and are produced in considerable volume such as Madeira, Marsala, American baked sherry, tawny port and others. These wines or parts of them are now usually cooked, baked or otherwise processed at relatively high temperatures 
and often for a considerable time. However, as has already been said, the primary reaction is oxidation and detailed discussion does not belong under the heading of physical treatments. It is tempting to digress long enough to point out that the usual modern process for baked sherry is in reality a quick-aging procedure in itself. It is the fate of an accelerated processing technique to be considered as such for only a short time. If it works it soon becomes the "traditional" process and research then starts to replace it with a further accelerated, better controlled, or otherwise improved process. The Tressler (1939b) process and the changes during baked sherry production may be referred to by the reader for comparison with the more strictly physical processes we will discuss (Heitz et al., 1951; Guymon, 1955; Mattick and Robinson, 1960).

It was well known by 1900 (Malvezin, 1903) that heating of wines in the presence of oxygen or air produced "cooked" flavors and the condition we would describe as maderization. He reported, however, little or no change in the flavor of wines heated in the absence of air. This distinction was apparently made clear from studies of pasteurization which Pasteur (1873) developed not for milk, but for wine. The improvement of wines by heating was a much more ancient practice, however. Some attention was paid to the type of container and mode of heating, but from the descriptions one suspects that maderization was the result. Curtel (1903) describes various practices of Greek and Roman times. The practice came into vogue, apparently about 120 B.C., of storing wine in amphorae or other ceramic forerunners of bottles. These were sometimes placed in the sun to heat. Another type called apothecae were covered with gum inside and out and the wine sealed in with plaster. They were usually hung in the kitchen or bath since these were heated. In fact they were often hung in the chimney or in the smoke of the heating fire. For processing large numbers of these vessels heated chambers, fumaria, were used. The Romans understood that the heat was the agent not the smoke and were aware that aging was produced as well as preservation. A pre-Christian era quick-aging procedure! The placing of containers of wine, whether bottles and carboys or casks, in the sun for aging is probably largely a matter of benefiting from heat although light may be a factor. Part of the effect of a sea voyage to tropical countries and return no doubt was produced by heat in the hold.

There have been relatively few studies of heating in the complete absence of or in controlled, limited amounts of air as aging treatments. Recently, however, there has been a reawakening to the fact that one reason that quick aging by heating has generally resulted in overtreatment probably lies in the excessive oxidation produced when free contact with air was allowed. This was first recognized in connection with pasteurization. Pasteurization, although a life-saver for many commercial operators troubled with various microorganisms contaminating their wines, fell into disrepute for fine wines not requiring disinfection. Two important reasons for this were failure to exclude oxygen efficiently enough and localized or general overheating of the product being processed (Miroir, 1931). It is now more generally appreciated that the temperatures used should not be excessive, the processing time must be carefully controlled, and the degree of oxidation must be sharply 
limited. Under these conditions it is possible to pasteurize wines with little or no quality damage. Improved quality has been reported. Valvassori (1957) treated vermouth at $85^{\circ} \mathrm{C}$ for $3 \mathrm{~min}, 100^{\circ} \mathrm{C}$ for $1 \mathrm{~min}, 105^{\circ} \mathrm{C}$ for $20 \mathrm{sec}$, and $105^{\circ} \mathrm{C}$ for 40 sec. Organic nitrogen dropped from $170-210 \mathrm{mg} / \mathrm{l}$ to $110-200$ $\mathrm{mg} / \mathrm{l}$, volatile esters calculated as ethyl acetate increased from $246-264 \mathrm{mg} / \mathrm{l}$ to $282-300 \mathrm{mg} / \mathrm{l}$, and oxidase activity decreased or disappeared. Organoleptic properties were improved and faster aging achieved. Little or no effect on $\mathrm{SO}_{2}$, total acids, $\mathrm{pH}$, or oxidation-reduction potential was produced. Ordinarily wines decrease in oxidation-reduction potential as the dissolved oxygen present is consumed provided further contact with air is prevented. Lipis (1957) reports that sweet wines heated to $65^{\circ} \mathrm{C}$ with exclusion of air for periods of 4 to 10 hrs dropped in potential as much as would ordinarily have required a year in enameled cisterns. Heating of cider away from air lowers the oxidation-reduction potential and the lowered potential correlates with desirable flavor (Creff, 1957). Deibner (1956) did not, however, find an entirely consistent relationship between flavor quality, oxidation-reduction potential, and heat treatment of fortified sweet wines. Deibner and Benard $(1956 a, b)$ extensively reviewed the effects of heat on wines and reported some of their own experiments. They found that heating wines in bottles (swept with $\mathrm{CO}_{2}$ to exclude air) at $40-45^{\circ} \mathrm{C}$ improved them, but the optimum time and effect was variable by type and lot of wine. Particularly some white sweet fortified wines were resistant to the treatment. Pretesting would appear to be necessary to avoid overtreatment, but ten to fifteen days at $40-45^{\circ} \mathrm{C}$ in the absence of air contact was usually beneficial to sensory quality. The improvement was not clearly relatable to aldehyde content (which changed little), acetal content (which was not detected), oxidation-reduction potential (which usually decreased, but not uniformly or to any certain value), or other usual analytical determination.

In general, fortified sweet wines appear to benefit from heating, particularly from severe treatment, more than do low alcohol, low extract wines. This has been noted by several authors from Malvezin (1903) to the present date. Kuttelvašer (1955) reviewed the treatment of wine with heat and noted especially that warming dessert wines for a short time at $65-70^{\circ} \mathrm{C}$ improved the flavor. Gerasimov $(1955,1958)$ has summarized work on the improvement of wines with heat in a diagram which is reproduced in figure 1 . Note the low-heat conditions recommended for table wines compared to the extensive heating with air for maderized wines and free of air for wines of the port type. The application of these regimes in Russia is described with some details of the layout and operation of a commercial scale processing plant utilizing a sequence of connected tanks in which it is possible to cold-stabilize wines and heat them with or without addition of oxygen (Gerasimov, 1958). The different treatment temperature-time conditions are not entirely equivalent and Gerasimov notes that generally better quality results if the lower temperature, longer time treatment is chosen over the faster, higher temperature treatment.

Gerasimov and Politova-Sovzenko (1950) note that heating of fortified wines without oxygen develops the dessert wine flavor (as opposed to maderization) and limited access of oxygen may be used beneficially with 
heat for port. A good port resulted from heating in $0.75 \mathrm{l}$ bottles with limited oxygen $\left(13 \mathrm{mg} 0_{2} / \mathrm{l}\right)$ under the following regimes: $40^{\circ} \mathrm{C}-25$ days, $45^{\circ} \mathrm{C}-$ 20 days, $50^{\circ} \mathrm{C}-15$ days, and $60^{\circ} \mathrm{C}-10$ days. The best quality, however, resulted from heating without oxygen. Good results were obtained with treatment for three to five days at $70^{\circ} \mathrm{C}$ followed by ten to twelve days at 40 $45^{\circ} \mathrm{C}$. They found that wines already maderized lost the maderized taste and became like old ports if heated 15 days in the absence of oxygen at $65-70^{\circ} \mathrm{C}$. Politova-Sovzenko (1954) reports analytical data in table 2 on samples of a port-type, low sugar (3.1 per cent) wine heated at $60^{\circ} \mathrm{C}$ for 60 days.

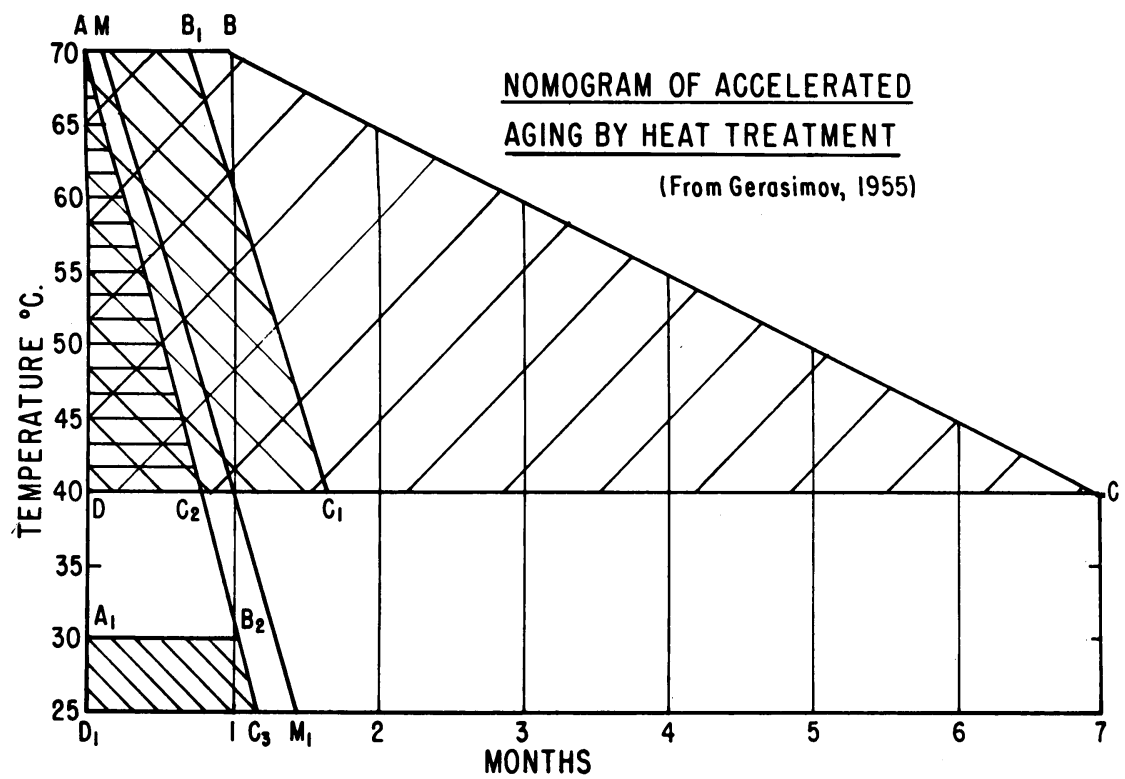

Fig. 1. Heat treatment for wines: Programs recommended for table wines lie in the area $\mathrm{A}_{1} \mathrm{~B}_{2} \mathrm{C}_{3} \mathrm{D}_{1}$; port treatment with air $\mathrm{AC}_{2} \mathrm{D}$ and without air $\mathrm{AB}_{1} \mathrm{C}_{1} \mathrm{D}$; maderization (with air) begins at $\mathrm{MM}_{1}$ and is considered complete at $\mathrm{BC}$.

Kazumov et al. (1956) heated light (table) and heavy (fortified?) white wines at $60^{\circ} \mathrm{C}$ for $35-40$ days. Maderization was the objective and the tannins and coloring substances were found to play an important role in the reaction to the treatment. A caramel note was found in the wines with sugar. Nanitashvili (1957) reported rather detailed analyses of a Kakhetinic wine with $6.2 \mathrm{mg} 0_{2} / 1$ subjected to heating for up to three days at $65^{\circ} \mathrm{C}$, six days at $45^{\circ} \mathrm{C}$, and fifteen days at $30^{\circ} \mathrm{C}$. This wine was most improved by 1.5 days at $65^{\circ} \mathrm{C}$, according to taste-score, and required less heating than did maderization of European-type wines. Kakhetinic wines are quite different from any produced in California. Both white and red wines of this type are left in contact with the grape skins for about six months (Beridze, 1956).

Timova (1959) compared several treatments on Bulgarian wines from several grape varieties. The wines from different grapes reacted differently, but the best general treatment among several examined was low-temperature 
treatment near the freezing point for seven days, then $55^{\circ} \mathrm{C}$ for $30 \mathrm{~min}$. This is very similar to the Monti (1914) process which will be discussed further under refrigeration. The Monti process, Malvezin's (1903) "Pasteuroxyfrigorie" process, and others like them include a cold step with some access to oxygen then a pasteurization step ; the idea being to achieve stable clarity (tartrate, protein, microorganisms, etc.) as well as some acceleration of oxidative aging reactions. Heating experiments of this type were reported by Lipis et al. (1959). They pasteurized fortified wines at $65-68^{\circ} \mathrm{C}$ and stabilized in the cold to remove microorganisms, tartrates, proteins, and some tannins. Acetals and aldehydes increased and a high oxidation-reduction potential pertained owing to the contact with air (about $3 \mathrm{mg} / \mathrm{l}$ ). Storage

TABLE 2

EFFECTS OF HEATING ON A PORT-TYPE, LOW-SUGAR WINE

(Heated at $60^{\circ} \mathrm{C}$ for 60 days)

\begin{tabular}{|c|c|c|c|c|}
\hline & Control & $\begin{array}{c}\text { Heated } \\
\text { without } \mathrm{O}_{2}\end{array}$ & $\begin{array}{l}\text { Heated with } \\
12 \mathrm{mgO}_{2} / 1\end{array}$ & $\begin{array}{l}\text { Heated with } \\
300 \mathrm{mgO}_{2} / \mathrm{l}\end{array}$ \\
\hline Alcohol (per cent) ........ & 18.8 & 18.7 & 18.5 & 18.4 \\
\hline Aldehyde $\mathrm{mg} / \mathrm{l} \ldots \ldots \ldots \ldots \ldots \ldots \ldots$ & 37.8 & 28.2 & 40.0 & 120.0 \\
\hline Acetal $\mathrm{mg} / \mathrm{l} \ldots \ldots \ldots \ldots \ldots \ldots \ldots \ldots \ldots \ldots \ldots$ & 21.2 & 28.9 & 29.0 & 41.2 \\
\hline Neutral esters $\mathrm{mg} / \mathrm{l} \ldots \ldots \ldots \ldots \ldots \ldots$ & 404.8 & 598.4 & 686.4 & 756.0 \\
\hline Volatile acid $\mathrm{mg} / 1 \ldots \ldots \ldots \ldots$ & 900.0 & 810.0 & 810.0 & 870.0 \\
\hline Tannin plus pigment $\mathrm{mg} / \mathrm{l} \ldots \ldots \ldots \ldots$ & 790.0 & 800.0 & 450.0 & 260.0 \\
\hline Total nitrogen $\mathrm{mg} / \mathrm{l} \ldots \ldots \ldots \ldots \ldots \ldots$ & 172.0 & 164.0 & 162.0 & 151.0 \\
\hline \multicolumn{5}{|l|}{ Oxidation-reduction potential } \\
\hline Before heating MV ......... & 355 & 355 & 372 & 377 \\
\hline After heating MV $\ldots \ldots \ldots \ldots \ldots \ldots$ & $\ldots$ & 296 & 270 & 272 \\
\hline
\end{tabular}

for two to nine months at $25^{\circ} \mathrm{C}$ with air excluded by an atmosphere of $\mathrm{CO}_{2}$ gave good improvement of quality and in their opinion better than more drastic heat treatment.

Berti (1936) described rapid aging of dessert wines in California. $\mathrm{He}$ states that the hot, alcoholic taste of fortified wines can be decreased by heating. Heating treatments suggested (for clarification and pasteurization as well as aging effect) were either $130-160^{\circ} \mathrm{F}$ for a few minutes or 100 $130^{\circ} \mathrm{F}$ for from a few days to several weeks (the longer time for maderized products especially).

In a report upon flor sherry, Ter-Karapetyan and Ogandzhanyan (1953) note that wine produced with submerged, aldehyde-producing cultures is improved and acquires a sherry-like taste if heated at $45^{\circ} \mathrm{C}$ for about two weeks in the absence of air. This is attributed to conversion of acetaldehyde to acetals.

The production of tawny ports often involves heat treatments, but as a rule oxidation is also involved and this might be better discussed under oxidation. Muraki and coworkers $(1957,1960 a, b)$ studied the process. They report that baking at $40^{\circ} \mathrm{C}$ gives a better product than $60^{\circ} \mathrm{C}$. Treatment at $60^{\circ} \mathrm{C}$ for 60 days gave a good aged-flavored product with Muscat Bailey $A$ and Adirondac varieties. Added acetaldehyde was not converted to acetal by the heating and addition of $20 \mathrm{ppm}$ of $\mathrm{Cu}^{++}, \mathrm{Fe}^{++}$, or $\mathrm{Mn}^{++}$and 12 per cent 
sucrose before heating were stated to be helpful, causing the formation of a good intense flavor. Heating of mixtures of fruit juice and alcohol gave a good wine with grapes, but not with apple or orange juices.

Treatment of sweet table wines has been the subject of very few reports. Joslyn (1936), and Brown and Henriques (1935) describe the production of Sauternes-type wines by adding 3-4 per cent sugar (via juice concentrate) to a good dry white table wine, raising the $\mathrm{SO}_{2}$ level to $300 \mathrm{ppm}$ and baking in oak barrels. Joselyn says $60^{\circ} \mathrm{C}$ for several months, Brown $120-130^{\circ} \mathrm{F}$ for one week. This practice is not now followed for the wines called California sauterne.

Ough et al. (1960) report tests on dry white wines in which storage temperatures of $32^{\circ}, 53^{\circ}, 70^{\circ}$, and $120^{\circ} \mathrm{F}$ were compared for periods of one, nine, and twenty-two months. In general, the results showed the best quality at the lowest storage temperature and the shortest time. Unguryan and Lipis (1957) treated both red and white table wines with controlled oxygen contact and heat. Prolonged heating at $40-68^{\circ} \mathrm{C}$ with restricted access of air was required to produce good quality white wines. Red wines took up oxygen more rapidly than white wines and could be processed under air without affecting their quality if the tannin content exceeded $2 \mathrm{~g} / \mathrm{l}$. Results of Maverhoff (1949) reportedly show that several days at $30-40^{\circ} \mathrm{C}$ age white table wines equivalent to several years, but the details of the experiments are not available to the author.

In a series of tests of several quick-aging methods Joslyn (1935) heated dry red, white, and California tokay wines in bottles with various headspaces at $120^{\circ} \mathrm{F}$ for two, seven, and fourteen days. Samples heated without air were practically unchanged. In the presence of 0.1 per cent oak chips the heated wines were improved by two days heating, 10 per cent headspace, with exception of the tokay which became too oxidized. Tressler's process (1939a) of oxidation and heating is used to remove the characteristic socalled foxy taste from non-vinifera grapes. If the processing is stopped short of maderization it enables production of wine types resembling traditional European-type wines from these grapes.

Treatments involving heating of sparkling wines and the base wine for their preparation have been the subject of some study. Kielhöfer (1956) patented a procedure in which the champagne is produced by the bulk process, bottled, and the bottled wine heated under counterpressure in pressure vessels at $35-45^{\circ} \mathrm{C}$ for eight to fourteen days. A fine aged character is claimed and the cork is set to the mushroom shape at the same time. Rudopulo and Agapov (1957) studied the heating and cooling of champagne stock and champagne with and without oxygen. Sylvaner wine plus yeast autolysate, Riesling wine, and finished champagne were treated at $40^{\circ} \mathrm{C}$ for $48 \mathrm{hrs}$ and at $70^{\circ} \mathrm{C}$ for $15 \mathrm{hrs}$ with 0,1 , and $3 \mathrm{ml}$ of $0_{2} / \mathrm{l}$. Cold stabilization at $-4.5^{\circ} \mathrm{C}$ for five days was tested before and after most treatments. The best flavor rating was given to the wine treated without oxygen at $40^{\circ} \mathrm{C}$ for 48 hrs and then $-4.5^{\circ} \mathrm{C}$ for five days. All the usual analytical values for wine were determined and the amino acids were studied by paper chromatography. With the exception of $\mathrm{pH}$ which remained nearly the same, all analytical values decreased during heating with oxygen at $70^{\circ} \mathrm{C}$ for $15 \mathrm{hrs}$ in all three 
wines compared to their own controls (but the wines differed considerably before and after heating). Changes in analyses were generally very small during heating at $40^{\circ} \mathrm{C}$ for $48 \mathrm{hrs}$ except that the champagne and Sylvaner plus autolysate contained more different free amino acids after heating and the total quantity of free amino acids appeared to be greater. Protein nitrogen decreased as did total nitrogen in all cases shown. It is concluded that heating in the presence of oxygen is undesirable for champagne stock or champagne from both color and flavor viewpoints, but without oxygen present, warming to promote protein breakdown and improve champagne appears desirable. Sarishvili and Pazyrev (1959) agree that oxygen is harmful and use a preliminary fermentation to consume the oxygen, heat treatment at $36^{\circ}-40^{\circ} \mathrm{C}$ for $48 \mathrm{hrs}$, cooling to $16^{\circ}-18^{\circ} \mathrm{C}$, recharging with fresh yeast plus sugar solution, and completion of the champagnization fermentation. This appears to be an improvement upon the continuous process described by Brusilovskii $(1959 a, b)$ who mentioned use of $40-50^{\circ}$ for $24 \mathrm{hrs}$. The process also accomplishes liberation of amino acids by lysis of the cells of the first small yeast inoculum used to consume the oxygen. This promotes the following fermentation and may contribute to the flavor improvement.

The rapid aging of distilled spirits via heating appears to be less complex than with wines. The aging of distilled spirits like whiskey, brandy, and rum requires the presence of wood and is indeed at least as much a function of the wood extractives as the distillate. Therefore heat treatment of such products has largely taken the form of heating the barrel and its contents or alternatively heating the spirit in contact with chips, shavings, staves, etc. of wood. Since during normal spirit-aging the ullage is not made up and oxidative conditions prevail (relatively free air contact), no effort is made to exclude air in rapid aging of spirits, in fact the contrary is usual. Of course, evaporative losses must be controlled especially if heating is to be used. Carrell (1936) patented an apparatus which connected a series of charred barrels individually to small heat exchangers warmed with oil piped from a boiler controlled so that the temperature never exceeded $150^{\circ} \mathrm{F}$. Copper tubing connected both ends of the barrel with the heat exchanger so that the heating produced a slow mixing and flow through the tube and each barrel formed a closed system so that the fire hazard was reduced. The temperature of $120^{\circ} \mathrm{F}$ was stated to be preferred, but no data on the times or effect of processing were reported. New barrels were used each time and the catalytic and adsorptive properties of the internal charcoal was considered as the primary factor.

Plume (1937) patented a similar idea but the heating coil and a stirrer were inserted into the barrels via the bung and modification of the barrel itself was not required. An expansion chamber for fumes and fluid volume increase was provided. Temperatures of $145^{\circ}-155^{\circ} \mathrm{F}$ were preferred and the liquor may be "purified in a few days to the same extent as has heretofore been possible by storage over several years." A thermostated electric heater and stirrer was patented by Naylor (1929). Brown (1937) referred to the use of such in-barrel heating methods ("goose-necking") at about $155^{\circ} \mathrm{F}$ for beverage brandy and noted that esters are destroyed, aldehyde increased, and extraction from the barrel increased to an undesirable extent. He there- 
fore preferred that heat treatment be limited to maintaining the brandy barrel storage warehouse at $70^{\circ}-80^{\circ} \mathrm{F}$ and $40-50$ per cent relative humidity for best results. A process patented by Reiman (1938) involves heating distillates in metal or glass-lined tanks for several hours near their boiling point in the presence of powdered wood char previously leached with boiling alcohol. The distillate may be colored and flavored before this step by means of toasted or partially charred white oak chips or afterward by storage in charred barrels for a period of weeks. The hot char is claimed to accelerate esterification and air may be passed through to also accelerate oxidation. Forer (1933) has patented an apparatus for aging liquors by heating and aeration.

Quick-aging of whiskey by heat treatment in barrels increased the color, solids, and acids more rapidly than normally occurs (Valaer and Frazier, 1936). Dekov and Tsakov (1957) report results of storage of 4 liters of cognac distillate in 5 liter oak barrels for 15 days at $39^{\circ}-75^{\circ} \mathrm{C}$. The sensory properties were greatly improved and the product appeared aged. The analytical values averaged for duplicate tests for the control and the heated samples were respectively: extract $0,31 \mathrm{~g} / \mathrm{l}$; alcohol $69.0,73.2$ per cent; aldehydes $40.2,117.7 \mathrm{mg} / \mathrm{l}$; esters $750,928 \mathrm{mg} / \mathrm{l}$; acids $14.2,204 \mathrm{mg} / \mathrm{l}$; fusel oil 1762, $3292 \mathrm{mg} / \mathrm{l}$, and methanol 178, $59 \mathrm{mg} / \mathrm{l}$. If the barrels were stored in 70 per cent relative humidity the increase in ethanol and fusel oils was much less.

Lichev et al. (1958) studied treatment of cognac spirit at $45-50^{\circ} \mathrm{C}$ and relative humidity 70-5 per cent for periods up to 30 days. Old kegs, new kegs, and glass containers with and without added sawdust were used. Heat accelerated extraction from the wood and favored aroma production. Taste was altered to a lesser degree. The use of an old, previously used, keg gave a more harmonious product. Heating gave increased titrable acidity, aldehydes, acetals, tannin, and furfural. Other experiments by Lichev (1958, 1959 ) upon plum brandy showed that heating of the casks themselves to $140^{\circ} \mathrm{C}$ for $50 \mathrm{hrs}$ resulted in increased adehydic components, especially furfural, in the brandy stored in them.

Heat may also be applied as part of the processing of spiritous products with several objectives in mind other than aging. The changes produced may alter the product's quality in a manner contributing to aging even though that was not part of the original objective. Some such applications of heat directly and indirectly affecting aging are reviewed by Koch (1955, 1956), Pozzi-Escot (1905), Reynet (1960), Scazzola (1959), and in general works such as Amerine and Cruess (1960).

Several of these indirect effects have been mentioned already in passing, but a few words of explanation may be in order. Pasteurization of wines, for example, is primarily intended to produce biological stability by killing the microorganisms in the wine (or beer). Ordinarily the time and temperature are controlled and air is excluded so as to minimize effects upon the flavor of the product. This effort is not always successful and positive or negative flavor changes may be produced. To the extent that possibly desirable further activity of microorganisms or enzymes is prevented by pasteurization it affects further aging. Direct effects occur also. For example, 
Jenard (1960) noted that pasteurization of beer increased the ester content in relation to the higher alcohol content.

Urion (1957) noted that storage of beer at slightly warmer than usual (but still cool) temperatures hastens the loss of the immature unpleasant taste of freshly racked beer, but this probably relates primarily to completion of fermentation and yeast precipitation. It is well recognized that warm storage may favor the development of malo-lactic fermentations in wine (Röttgen, 1926). The use of heat to stop fermentation thus retaining sugar (Kusida and Maruyama, 1960b) or to suppress originally present organisms and enable fermentation by pure yeast inocula (Rosentiehl, 1908) has been reported. Arroyo (1939) has reported that pasteurization $\left(80^{\circ} \mathrm{C} / 10 \mathrm{~min}\right)$ of cane juice controlled microbiological off-flavor development and resulted in a better quality rum that aged faster than that from natural cane juice or from molasses. Van Haarlem et al. considered the varietal differences in relation to sherry baking important enough to include such tests in a grape breeding program (1956).

Heating of musts produces compositional changes in the wine which affect the quality. Kushida (1960) reported production of red wine of a new type from Koshu grapes by heating the must to $80^{\circ} \mathrm{C}$ for $40 \mathrm{~min}$ and then fermenting it. Cooking the must at $150^{\circ} \mathrm{C}$ for $40 \mathrm{~min}$ resulted in a wine too bitter and spoiled for usual purposes. Musts heated to $40^{\circ}-50^{\circ} \mathrm{C}$ for $1 \mathrm{hr}$ produced wines judged superior to those heated to $60^{\circ}-70^{\circ} \mathrm{C}$. (Kushida and Maruyama, 1960a). Amerine and Ough (1957) found that heating Cabernet Sauvignon musts to $71^{\circ} \mathrm{C}$ before fermenting at $21^{\circ} \mathrm{C}$ increased tannin and color extraction but decreased the quality rating of the wine. Fermentation of red wines at $21^{\circ}$ and $27^{\circ} \mathrm{C}$ gave higher tannin, higher color, and higher quality score than fermentation at $12^{\circ}$ and $16^{\circ} \mathrm{C}$. Dubaquié (1929) recommended heating a portion of the must at about $40^{\circ}-50^{\circ} \mathrm{C}$ for several hours, pressing, and adding the fluid to the remainder of the lot after the tumultuous fermentation is over. The wine was said to be more mellow and the flavor changed in a manner such as would result from aging. Berg and Marsh (1956) treated red grape musts with heat to release the pigment. The quality of the wines fermented on the heated skins was definitely inferior although the red color was increased. Similar results have been reported by Nedelchev (1959). Nikandrova (1957) has also shown that agitation and heating at $60^{\circ} \mathrm{C}$ greatly increased the extraction rate of anthocyanins and tannins from the particulate matter into the fluid of red grape must. The anthocyanins became maximal after $6 \mathrm{hrs}$, but the tannin continued to increase throughout the treatments used. Konlecher and Haushofer (1958) also studied warm fermentation of red wine. Dascalov (1957) studied various methods of color extraction including heating of the skins separately then recombining with the grape juice before fermenting. This gave better flavor than heating the whole crushed grapes. Aso et al. (1956) reported that Concord grape juice lost as much as 10 per cent of its color when heated to $75^{\circ} \mathrm{C}$ for $30 \mathrm{~min}$ and the shade was shifted from purple toward yellow. Similar effects occurred in storage and, of course, resemble color changes during aging of red wines.

Heating of spiritous products, wine in particular, often produces hazes and precipitates. These substances rendered insoluble by heat may be removed 
by filtration and the product thus clarified is ordinarily stable to further precipitation of the same type. Proteins are the most important group of such heat precipitable compounds in wine. Schaffer and Philippe showed as early as 1912 that pasteurization greatly reduced the content of nitrogenous compounds precipitable by alcohol from grape juice. More recent studies by Koch and his coworkers have added to the knowledge of the subject, particularly with regard to white table wines. Heating of wine 2 min at $75^{\circ} \mathrm{C}$ is sufficient to produce stability to further such precipitation (Koch, 1957). The resultant precipitate contains the same amino acids as natural precipitates and is composed largely of protein with some pectic and mineral material (Koch and Geiss, 1955; Koch and Bretthauer, 1957a, b). Analytical evidence for the effects of heat on protein removal, color change, etc. can be found in many of the references already mentioned, see for example Unguryan and Lipis (1957).

Heating, then, directly or indirectly affects the quality and composition of wine and other spirits and may simulate or affect normal aging. More specific compositional changes have been reported. Hydroxymethylfurfural is produced by dehydration of hexoses, especially fructose, during heating of acid solutions such as wines; furfural may be similarly produced from pentose sugars. Furfural derivatives have been found in wines that have been pasteurized, baked, made from concentrated must, or otherwise heated (Amerine, 1948; Prostoserdov and Taranova, 1949; Cresa, 1960; Mehlitz and Drews, 1959 ; Espinosa, 1959 ; and Querberitz, 1961). In fact, the qualitative identification of hydroxymethylfurfural in wines has been suggested as a means of detecting heating of the wine at some stage of production. Although the direct importance of furfural derivatives to the flavor and quality of wines and spirits is not clear, they are not flavorless compounds. The browning of black tea during fermentation and drying has been attributed to furfural-tannin reactions (Bokuchava and Skobeleva, 1957). Similar components occur in wine and certainly browning does result from heat treatments of wines (Berg, 1953a).

Bokuchava et al. (1958) have shown that heating of tea extracts intraconverts catechins without appreciable effect upon the total tannin content. They quote similar work with grape tannins by Nutsubidze. Bitterness was decreased by the heat treatment and a pleasant tart flavor developed in tea. Smirnova and Babkina (1960) have reported a decrease of tannin oxidizable by permanganate and a decrease in both phloroglucinol and pyrogallol types in treated wines, but since both low temperature stabilization and pasteurization were used the specific effect of heat is obscured. Berg (1953a, $b$ ), in his investigations of the absorption spectra of white wines in relation to browning, found that heating increased the absorption in the 240-297 $\mathrm{m} \mu$ region. Heat has variable effects on the anthocyanins of fruits, but the majority (including those from currants) seem to have heat instability (Lamort, 1958).

Miscellaneous heat treatments for spiritous product aging not previously mentioned include treatments reported by Muraki et al. (1960c) on sake, brandy, and plum wine mixtures. The sake was altered to a new type of rice wine, the brandy was not appreciably changed, and the plum products were 
rated as good. Vianna (1913) patented a process for aging wines and spirits by agitating them in closed vessels for some months at $110^{\circ} \mathrm{F}$. Jean and Lizée (1935) patented a procedure and appartus in both England and France used to age alcoholic beverages by heating them to $57^{\circ}-109^{\circ} \mathrm{C}$ in a closed system. Potable spirits were heated as a part of the treatments of Wilken (1952) and Farbenindustrie (1925). Treating of perfumes and flavorings with heat has seldom been reported (Chatelanat, 1948; Farbenindustrie, 1925) and is evidently both unnecessary and apt to be harmful (Strausz, $1947 a, b)$. Heat is used to produce special ingredients for such mixtures (and for addition to wines and spirits) such as caramel, pyrolysis mixtures (Guenther, 1957), and wood char (Merritt and White, 1943), but to go into these subjects would take us too far afield.

The future of heat treatment seems secure as we have every reason to expect that temperature manipulation of one form or another will be required in any system of rapid aging and quality improvement for any of the products we are considering. More information is needed before the specific optimal regimes can be considered known, but it is clear that different products will require different heating programs. Probably some adjustment lot to lot of the same product will be needed. More information upon the activation energies of the individual reactions is needed. Arrhenius plots of the temperature-rate relationships of specific aging processes (maderization for example) in specific types of products should be possible. Recognition and better understanding of the competitive effect on quality of some effects of higher temperature versus others is needed.

Refrigeration has long been known to affect wine. Winter temperatures in many European wine producing areas may be sufficiently low to freeze wine or rather some of the water from wine. Remarks upon the phenomenon and the resultant concentration of the wine were made in the writings of Pliny and Horace. Early experimentalists who interested themselves in the effects of cold on wine include Van Helmont, Stalh, Parmentier, Pasteur, and Raoult. This is another intriguing example of the breadth of interest of the scientific pioneers on the one hand and, on the other, the central role in early science played by wine and its problems.

The first definitive experiments upon the effect of winter or artificially produced low temperature on wine were those of de Vergnette-Lamotte (1868) who studied both the concentration and clarification effects. Although the details of the process are much better understood and the equipment is much improved today, the effects of strong cooling upon wine were well covered in several of the older reports and surprisingly little other than amplification has been added in all the subsequent summaries.

The effects of refrigeration made use of in processing alcoholic products are several. Precipitation of excess tartrates from supersaturated young wines to a degree ensuring no further precipitation under conditions of commerce can be hastened by several days at a temperature near the freezing point of the wine followed by cold filtration. Similar "chill proofing" may be used to remove inorganic, pigment, protein, and other turbidities from beer, wine, and from aged distilled spirits diluted for bottling. Retention of fruit aromas and highly volatile constituents may be much better at lower temperatures. 
The composition of fermented products can be changed and in many cases the quality improved by conducting the fermentation at controlled low temperatures. Secondary fermentation, microbiological spoilage, and enzyme action can be prevented or minimized by refrigeration. Ice can be removed from dilute alcoholic products or materials to be fermented by fractional freezing and the residual solution thus concentrated. All of these treatments have been used in commercial practice (Saller, 1955; Marsh and Guymon, 1959 ; Joslyn and Marsh, 1935).

Although all these treatments relate at least indirectly to the product's aging, refrigeration can affect aging directly or substitute in part for traditional aging. For example, the less soluble or partly oxidized and polymerized polyphenolic compounds precipitate from wine during aging. Refrigeration has been used to speed up this process, especially in dry red table wines, and the wines not only appear to the taste and to the eye more similar to aged products for having lost some color and some astringency, but the formation of precipitates and coatings during bottle storage is probably lessened. The color change may not simulate aging, however, Mestre Artigas (1942) notes that the red color is apt to be more lively and a premature old look is avoided.

The nature of the precipitate produced by chilling wine is apparently variable. Some authors report that in their experiments it was nearly all potassium bitartrate, calcium tartrate, ferric phosphate, and such salts with only a small amount of tannin, protein, and pigments entrained (Joslyn and Marsh, 1935; Flanzy, et al., 1953). In other cases appreciable amounts of tannins, pigments, pectins, or proteins were found in the precipitate (Jaulmes and Hamelle, 1954; Okolelov and Kotlyarenko, 1951). Rentschler and Schaeppi (1957) report experiments with a red Veltliner wine which was rich in tannin and color but low in tartrates. The precipitate from cold treatment $\left(-4^{\circ}\right.$ to $-8^{\circ} \mathrm{C}$, eight days) contained about 8 per cent protein, at least 24 per cent tannin, considerable coloring matter, but only a trace of tartrates. Part of this apparent disagreement depends upon the nature of the wine and part upon the degree of cold treatment (Joslyn, 1935), but the effect of a given treatment upon the color and tannin content of a given wine cannot yet be predicted without experimentation. It appears that cold treatment cannot be depended upon to prevent turbidity resulting from proteinaceous precipitates (Koch and Geiss, 1954).

Le Corvaisier (1959) noted that the permanent precipitate of aged beer resembles that induced by oxidation and is not the same composition as that formed by chilling. Waldschmidt-Leitz and Kloos (1959) found leucoanthocyanins, carbohydrates, and peptides in the chill precipitate and analysed them in detail.

Oxygen and other gases are more soluble in wine and similar solutions at cool than at warm temperatures. This, then, is the second important way that refrigeration can accelerate reactions related to aging. Cooling and handling of cold wine in the presence of air has been noted by many authors to cause loss of a little of the grape aroma and to produce flavors similar to heating. The flavor has been described as burnt (Gerasimov and PolitovaSovzenko, 1946), cooked grape (de Vergnette-Lamotte, 1868), dried-prune- 
like (Malvezin, 1903), and maderized or rancio (Astruc, 1910). Malvezin (1903) notes that such flavor changes are not without merit. Other workers report flavor improvement without oxidized or cooked flavor-“riper, rounder, smoother, aged"-upon refrigeration of wines (Mayer-Oberplan, 1953; Okolelov and Kotlyarenko, 1951; Deleuze, 1931; Anquez, 1950). The workers' opinions depend upon the wine used, the treatment, and their concept of desirable change, but oxidation or the lack of it is certainly involved. The oxidation-reduction potential shifts showing oxidation (Saller, 1955) and sulfur dioxide is oxidized to sulfate (Jaulmes and Hamelle, 1954) in refrigerated wines exposed to the air. If the wine is prevented from contacting the oxygen of the air, the cooked-oxidized tastes do not develop (Malvezin, 1903). Of course, the desirability and degree of oxidation desirable is very variable. Desert wines and vermouth are particularly susceptible to improvement by refrigeration (presumably in the presence of air) (Mayer-Oberplan, 1953). Especially "green" young wines or those rich in oxidizable substances may withstand and benefit from more oxidation coupled with refrigeration than other wines (Astruc, 1910; Carles, 1913).

On the other hand, maderization (oxidized, browned, Madeira or bakedsherry-like changes of white wine) was prevented by cold stabilization and pasteurization in experiments by Malvezin (1909).

Oxidation by air will have to be discussed elsewhere, but aging is not only oxidation. Several authors suggest that esterification and other aging changes which would be presumably inhibited by cold temperatures may account for the observed fact that although the product may be improved by refrigeration-oxidation treatment it usually isn't as high quality as may be possible by slower "natural" aging (Jaulmes and Hamelle, 1954; Astruc, 1910; Saller, 1955). They also caution against expecting improvement sufficient to pay for the treatment, if one starts with a seriously defective wine. In fact, if concentration by freezing is involved, defects are likely to be concentrated too (Flanzy et al., 1953; Malvezin, 1903).

On the other hand, because of the risk of damage or ultimately lower quality most authors suggest limiting of quick aging by refrigeration with air contact to standard wines and not including costly premium wines (Saller, 1955 ; Jaulmes and Hamelle, 1954).

Another way refrigeration is related to quick aging is the prevention or limiting of other effects by cold temperatures. If a heat treatment, chemical reaction, or microbiological effect being used in an accelerated aging program has proceeded far enough, a simple way to stop or control it may be refrigeration. Rentschler (1956) and others have mentioned the prevention of the malolactic fermention by refrigeration.

Reviews and worthwhile references not cited previously that relate to our interests and action of refrigeration on spiritous products include those by Gay (1954), Hege (1954), Slave (1960), and Querberitz (1951, 1953).

Discussions and reference to pilot or commercial application of refrigeration to rapid aging include several patents. Monti has patented wine clarification and quick aging processes in several countries $(1905,1906,1914)$. He reports that wine dissolves $17 \mathrm{cc}$ of air $/ 1$ at $20^{\circ} \mathrm{C}, 25 \mathrm{cc} / 1$ at $0^{\circ} \mathrm{C}$, and $40 \mathrm{cc} / \mathrm{l}$ at $-10^{\circ} \mathrm{C}$. Aging of spirits already containing oak extract is claimed. 
The process consists of cooling the solution to be treated to the lowest temperature possible without freezing, saturation of it with air with or without excess pressure, cool storage with air addition repeated until clarity is obtained, and warming to $25^{\circ}$ to $35^{\circ} \mathrm{C}$ until the excess dissolved air has escaped or been consumed. The cycle is repeated until no further tartrates separate and the product has attained the desired apparent age. Wine and brandy, it is claimed, can at the age of six months taste as if it were six years old. A final cooling and filtration without air is always used to remove the final oxidized precipitate. The process is claimed to be especially good for sherry, Madeira, Malaga, Marsala, and other fortified white wines. For red table wines, the air used is diluted with 1 to 3 volumes of inert gas such as $\mathrm{CO}_{2}$. The experimental application of this process was reported by Joslyn (1935) who refrigerated to $0^{\circ} \mathrm{C}$, saturated with oxygen, and pasteurized $10 \mathrm{~min}$ at $140^{\circ} \mathrm{F}$. Red wines were reported to be improved by 3 cycles and overoxidized by 4 ; white wines were improved by 1 or 2 but overoxidized by 3 cycles. It was felt that the process was less desirable than the use of aeration and oak chips.

Other practical experiments along the same line were mentioned by Mestre Artigas (1942) who notes that Zaporta in Spain and Roos in France produced rapid aging of Rioja wines and reduced the aging of dessert wines from eighteen months to three, respectively. La Grassa $(1926,1927)$ studied the effect of refrigeration on stabilization and aging of Marsala wine. His process was modeled on that of Monti $(1905,1906,1914)$ and he reports satisfactory results for four vintages. He notes that air contact is required for the treatment to be effective and that prevention of clarity problems resulting from further oxidation must be considered. Astruc (1910) notes satisfactory applications of cold-oxidation in commercial practice, the details of which were trade secrets. Another patent is that by Chatelanat (1948) who aged liquors, perfumes, and similar spiritous solutions by alternating heat and cold. Negui et al. (1934), patented a refrigeration-oxidation aging process for wine. Ravinetti (1955) has a similar stabilization process and apparatus in which the wine can be also carbonated. Castaing (1951) includes cooling with a process also involving electrolysis and infrared treatment. Other processes including cooling as part of the treatment, notably Malvezin's (1903) "Pasteuroxyfrigorie" process, will be discussed elsewhere.

The future of refrigeration in wine and spirit aging would appear to lie in further tests and improvements with regard to those features already known: controlling oxygen solubility in wine, stopping or controlling reactions by lowered temperature, and partial removal of some constituents by cold precipitation. A further extension which does not appear to have been investigated suggests itself. Rapid oxidation has been probably the most widely attempted quick-aging method since Pasteur implicated oxidation as the main reaction of aging. Few investigators claim to have achieved a similarly high quality if rapid oxidation is used rather than slow diffusion as in traditional aging. The implication is that slow admssion of oxygen attacks only the most readily oxidized substances whereas rapid oxidation attacks more different compounds. Controlling the rate of oxygen admission and using low temperatures might enable a net faster oxidation of the more 
readily oxidized substances than in traditional aging, but still limit attack of other components. This would appear to warrant investigation. Further data upon the solubility of oxygen in various wines at various temperatures, pressures, etc., also are needed as well as temperature coefficients of the various important reactions.

\section{Irradiation Treatments}

Infrared radiation may be absorbed by molecules and as a result the molecule doing the absorbing is stretched, bent, rotated, or otherwise agitated. This is essentially the same effect, adding energy of motion, as is accomplished by less elaborate means of heating and this is what is accompaniedheating. It has already been stated that at least part of the effect of sunlight used to age wine is to heat it. Apparently this is still being used-aging of wine by placing it in the sun-in some parts of the world, but seems to be something of an anachronism (Georgeakopoulos, 1960; Gerasimov and Ochremenko, 1929) and not well suited to modern commercial needs. Little (1939) patented a process for aging liquors such as whiskey by subjecting the outside of the charred oak barrel containing it to infrared radiation for $48-170 \mathrm{hrs}\left(45^{\circ}-65^{\circ} \mathrm{C}\right)$. Castaing (1951) includes infrared irradiation as part of his several-stage treatment. At one time aging of sherry in oak butts exposed to the sun was practiced and it may still survive in some localities. If so, the effect produced by the sun must be primarily heating because very little light either visible, ultraviolet, or infrared penetrates more than 0.1 inch into wood (Browne and Simonson, 1957). The sunlight does cause reactions in the wood with formation of water-soluble brown material, but at least in weathering this material does not penetrate more than about 0.1 inch into the wood from the outside.

Theoretically it might be possible to limit the wavelength of the infrared radiation used so that it would tend to activate a particular molecular species or bond-type, but various practical difficulties make this possibility seem very remote indeed. No future for infrared radiation as a rapid aging treatment can be visualized except as it might serve as a convenient form of heat in some special situation.

Ultraviolet and visible light have similar chemical effects and can be considered together. If such radiation is to have an effect upon molecules it must interact with them and contribute energy to them. Materials completely transparent to a given wavelength of radiation are not changed by the pasage of this radiation any more than is the radiation itself diminished. Conversely, however, if radiation of a given wavelength is absorbed during passage through a material, the energy of the absorbed radiation has been consumed in producing some effect within the material. The absorption of radiant energy provides energy of motion to the absorbing molecules. This motion could take the form of rotation of the whole molecule, vibration of the atoms within the molecule, or motion of the electrons, but in the ultraviolet and visible regions of the electromagnetic spectrum the primary absorption act is limited to adding energy to the electrons (Rosenberg, 1955).

As a result of the absorption of the radiant energy the molecule is excited or activated. The excited state is unstable, of course, and the molecule must 
lose energy via one of three pathways: (1) re-emission of light-fluorescence or phosphorescence, (2) thermal energy, or (3) chemical energy-production of reactions that directly or indirectly result in new molecules (Masson et al., 1956). During fluorescence the quantum yield is often less than one and also the emitted light is ordinarily appreciably less energetic, quantum for quantum, than the exciting radiation. The difference in energy appears as heat. Thus, the net effect of the absorption of ultraviolet or visible radiation should be to promote chemical reaction either by the addition of more or less heat or by molecular excitation. It is not surprising, therefore, that such treatments have been reported to have effects on the flavor of spiritous products and have been tried as quick aging treatments.

As we have said, the light must be absorbed to produce a chemical effect. The specific electronic configurations capable of intense absorption in either the visible or ultraviolet region are the well-known "chromophoric" groups which result in the characteristic absorption spectra so useful in identification of compounds and analysis. At least within the range of wavelengths usual for spectrophotometry of solutions of organic compounds (200 $\mathrm{m} \mu$ to $700 \mathrm{~m} \mu$ approximately), these chromophores are mostly some type of unsaturated or multiple electron-pair bonds. A single such chromophoric group absorbs maximally at some specific wavelength which may or may not distinguish it from other types of absorbing structures. As more substituent groups and other chromophoric groups are added to a molecule the absorption may be affected. For example, an isolated carbon to carbon double bond absorbs maximally at a wavelength of about $190 \mathrm{~m} \mu$, two such bonds in conjugation at about $220 \mathrm{~m} \mu$, three at about $260 \mathrm{~m} \mu$, four at about $290 \mathrm{~m} \mu$, etc. (Scott, 1955; Braude, 1945). One might presume that all one need do would be to determine the absorption spectrum of the beverage to be treated and then treat with radiation of the wavelength most readily absorbed in order to determine the effectiveness of photochemistry as a quick-aging procedure. This might, in fact, be a step in the right direction and one unfortunately not always considered in treating products with light, but several complications are also important.

Because of several factors, the radiation absorbed by complex organic molecules in solution is not restricted to discrete narrow bands as would be expected from quantum theory. Rather, the absorption covers a more or less wide range of wavelengths and in complex solutions like wines, beer, aged distilled beverages, etc. with many absorbing species present there is appreciable absorption through most of the ultraviolet and into the visible if they are colored. Thus, light of many wavelengths can be absorbed and may produce chemical changes.

The molecular species which absorbs the radiation may not be that which participates in the reaction of interest. For example, a mixture of mercury vapor, ethylene, and hydrogen irradiated at $253.7 \mathrm{~m} \mu$ results in rapid hydrogenation of the ethylene. The mercury atoms are the only constituent capable of absorbing this radiation. They are activated with sufficient excess energy that upon collision they can dissociate hydrogen molecules to hydrogen atoms. As they collide with the hydrogen molecules the excited mercury atoms return to the ground state. The hydrogen atoms (free radicals) pro- 
duced readily combine with the ethylene. The mercury absorbs the radiant energy, transfers it, and is itself chemically unchanged. In this type of reaction the absorbing, but not reacting compound is called a sensitizer (Masson et al., 1956; Heidt et al., 1957).

Light does intereact with matter in "chunks" or quanta and the wavelength governs the energy content of a quantum which in turn governs whether or not it can be absorbed by a given molecule. The energy content of a single quantum times Avogadro's number equals an einstein, and in kilocalories per mole this equals $2.859 \times 10^{5}$ divided by the wavelength in angstroms (Rosenberg, 1955). An einstein of red light (6,000 A) equals $47.4 \mathrm{Kcal} / \mathrm{mole}$, and of short UV (2,000 A) $142 \mathrm{Kcal} / \mathrm{mole}$. Since the bond dissociation energies are about 70-80 Kcal for carbon to carbon bonds and about 90-100 Kcal for $\mathrm{C}-\mathrm{H}$ bonds, it follows that wavelengths shorter than about 3,800 and $3,000 \mathrm{~A}$, respectively, will be required to supply sufficient energy to enable such a bond rupture to occur (Masson et al., 1956). As a sidelight it can be noted that, although carbon to carbon double bonds and carbonyl groups are important in the absorbing of light energy, these bonds are so strong that except in the very short ultraviolet near the limit of quartz transmission the light can not contribute directly enough energy to break these bonds. This helps to point out that the absorbed energy is not localized but is distributed throughout the molecule in such a manner that the bond ultimately ruptured by the reaction of the activated molecule may be remote from the group conferring the ability to absorb radiation.

As has been discussed briefly in connection with heating, a molecular species capable thermodynamically of undergoing a reaction must acquire a certain activation energy to initiate the reaction. If this molecular type absorbs light energy and if the amount absorbed is equal to or in excess of the activation energy for the chemical reaction, such irradiation will enable the reaction to proceed. If, however, the energy absorbed is less than the activation energy, it contributes to initiating the reaction only to the extent that it decreases the increment of thermal energy necessary to produce an appreciable reaction rate. From these facts one could surmise that radiant energy would, as a rule, promote the same reactions that one would expect from ordinary chemistry. This is usually true, but in some cases special effects are noted such as decrease or increase in side reactions or even different reaction products (Masson et al., 1956; Calvert, 1959).

A great many specific photochemical reactions of pure compounds or simple mixtures have been studied and yet for complex molecules predictions of reactivity and products cannot be made with any degree of conviction (Masson et al., 1956). The effect of light on complex mixtures like spiritous beverages is much less well understood. Photochemical reactions can be very complex and produce many products. For example, irradiation of acetone may give appreciable quantities of methane, ethane, biacetyl, ketene, ethylene, methyl ethyl ketone, carbon monoxide, and other products depending upon conditions used (Masson et al., 1956; Noyes et al., 1956).

These photochemical reactions involve breaking of a bond to produce two free radicals. Free radicals are molecular fragments or atomic species with neutral electrical charge but unpaired electrons and are not only very reac- 
tive but unless two free radicals combine with each other the products of a free radical reaction often include another free radical (Ingram, 1958). This, of course, gives rise to chain reactions and a high yield of products in proportion to the triggering light energy. Photochemical reactions can produce more complicated molecules as well as degrade them. Ultraviolet radiation of carbon dioxide and water can give aldehydes and oxygen, and of methane, ammonia, and water can give amino acids (Heidt et al., 1957). There is even a report claiming that tartaric acid plus formaldehyde or ethanol in aqueous solution irradiated in tropical sunlight produced sugar (Gore, 1933).

Only a few chemical reactions produced by irradiation which seem particularly interesting from a spiritous product viewpoint can be mentioned and no attempt is made to cover the subject intensively, much less extensively. Those interested in more details must refer to appropriate reference works several of which have been cited in this section. Loiseleur (1954) has classed ultraviolet light as a peroxidizing agent (along with X-rays and ultrasound) on the basis of production of typical dye reactions in aqueous solution in the presence of oxygen and there is much evidence in favor of such a description. Ultraviolet radiation of methyl through amyl alcohols in the presence of oxygen gave the corresponding aldehyde and acid (Cantieni, 1936). Markham et al. (1958) irradiated dilute aqueous solutions of alcohols with $366 \mathrm{~m} \mu \mathrm{UV}$ in the presence of zinc oxide. Hydrogen peroxide or other peroxides, and aldehydes or ketones of the alcohol or phenol were produced. Bolland and Cooper $(1953,1954)$ studied photooxidation of alcohols in aqueous solution using $365 \mathrm{~m} \mu \mathrm{UV}$ and an anthraquinone sensitizer in the presence of oxygen. A nonchain mechanism involving acceptance of a hydrogen atom from the alcohol by the quinone was described. The resultant semiquinone reacts with oxygen regenerating the quinone. The products of the reaction with ethanol were hydrogen peroxide, acetaldehyde, and acetic acid. The acetic acid arose directly from the ethanol not via secondary oxidation of acetaldehyde. The rate was independent of $\mathrm{pH}$ below $\mathrm{pH} 7$, suggesting a free radical rather than ionic mechanism. The ability of alcohols to donate hydrogen to quinones during photooxidation increased as the carbon chain length increased and with increased alkyl substitution, but decreased with multiple $\mathrm{OH}$ groups (Wells, 1956).

Le Clerc et al. (1959) presented evidence for the occurrence of the semiquinone free radical in ultraviolet irradiated cold solutions of pyrocatechol in 96 per cent ethanol. The amount of hydrogen peroxide produced in calamine liniment by ultraviolet light varied by the kind of phenolic compounds present, their concentration, and the age of the product (Young and Guth, 1956). Pigments can act as sensitizers of photooxidation by light of visible wavelengths. Methylene blue can produce a stable semiquinone upon visible light irradiation of aqueous solutions containing a little ethanol to act as an $\mathrm{OH}$ radical scavenger (Koizumi and Obata, 1958). Riboflavin serves as a photosensitizer for the oxidation of tyrosine, $p$-cresol, ascorbic acid, dihydroxyfumaric acid, and phloroglucinol by light with the formation of $\mathrm{H}_{2} \mathrm{O}_{2}$ (Kolesnikov, 1958).

Irradiation of ascorbic acid solutions with $253.7 \mathrm{~m} \mu$ ultraviolet produces 
an intense oxidation of the ascorbic acid. When the irradiation is stopped the oxidation decreases in rate but continues for some time. This continuation is believed the result of the presence of the $\mathrm{HO}_{2}$ free radical (Douzou, 1958). Irradiation could be replaced by ferric or cupric ions. The photooxidation was more rapid in the presence of air $\left(\mathrm{O}_{2}\right)$, but did occur in the absence of air at $\mathrm{pH}$ greater than 2.5. Irradiation of water with short ultraviolet gives several products including $\mathrm{H}, \mathrm{OH}$, and $\mathrm{HO}_{2}$ radicals and $\mathrm{H}_{2} \mathrm{O}_{2}$. Irradiation of oxygen can give ozone (Smith, 1958; Burton et al., 1960; Ingram, 1958).

The molecular fragments produced by irradiation are both oxidative and reductive and the secondary reactions and ultimate classification as a net oxidative or reductive reaction depend upon the system. In the presence of oxygen or in systems with more readily oxidizable than reducible constituents the net effect expected would be oxidation. The photooxidation of aldehydes is potently inhibited by the presence of alcohol and the oxidation rate of one aldehyde is decreased in the presence of another (Bogert and Davidson, 1930). Irradiation of esters in vapor and in solution can give alkanes, alkenes, acids, carbon monoxide, hydrogen, carbon dioxide, etc., but variations in solvent, temperature, etc., varied the amount and nature of the products (Ausloos, 1958a, $b$ ). Pure ethanol irradiated with a mercury arc lamp for $50 \mathrm{hrs}$ at temperatures well below its boiling point gave hydrogen and 11 per cent 2,3-butylene glycol (Leuschner and Pfordte, 1958). Yamada and coworkers $(1952,1957)$ studied the effect of sunlight on distilled spirit containing biacetyl. The biacetyl was converted into acetic acid and acetoin by sunlight.

As can be seen, the picture is by no means clear and simple regarding the chemical effects of light, but neither does it appear that the application of irradiation to wine and spirit aging need be purely empirical. This discussion may seem unduly detailed to the uninitiated or superficial to the expert, but it is felt that it is important to consider the fundamentals as they help us in evaluating practical, empirical trials, particularly when such considerations were unknown at the time of some investigators of spirit aging and were not considered by others.

For application to practical situations such as wine aging, several other factors involved in photochemistry need to be considered. The nature of the radiation reaching the test solution is conditioned by the light source and by the transmission of the fluid and container. Sunlight is mainly useful in the range 350 to $600 \mathrm{~m} \mu$, although bright summer sunlight contains some ultraviolet of low intensity down to about $290 \mathrm{~m} \mu$. Mercury arcs, hydrogen lamps, Mazda lamps, and various other types of ultraviolet and visible radiation sources can be used. The spectrum and intensity of the emission of these sources vary and although important experimentally can not be considered here (see Masson et al., 1956). If more nearly monochromatic light is desired, portions of the spectrum can be selected by interposing suitable filters and absorbers in the beam. The container may serve as a filter. Quartz transmits useful amounts of light down to about $185 \mathrm{~m} \mu$, but colorless Pyrex and Lucite are opaque below about $320 \mathrm{~m} \mu$ and optical glass and most other soft glass types below about $350 \mathrm{~m} \mu$ (Masson et al., 1956). Colored glass, of course, ab- 
sorbs some further portion of the spectrum. Oxygen of the air absorbs low wavelength ultraviolet and few materials transmit enough ultraviolet below about $200 \mathrm{~m} \mu$ to allow us much interest in this region of the spectrum (until one reaches sufficiently short wavelengths for $\mathrm{X}$-rays and these will be considered in the next section). Water and dilute aqueous solutions of salts, especially $0.2 \mathrm{M}, \mathrm{CuCl}_{2}$, can be used to filter the wavelengths beyond about $600 \mathrm{~m} \mu$ from sunlight and other sources and thus minimize heating by the infrared end of the spectrum (Bowen, 1946).

The effect of light on alcoholic beverages that has been most studied is the effect of ambient light, especially sunlight, on the bottled product. Since such an effect occurs after the product is prepared for merchandising and usually either in the retailer or consumer's hands, it is invariably considered deleterious if the change is readily noted. This may be because the flavor or color is changed in a manner which is really objectionable to consumers. It might be that it is considered bad because it is uncontrolled and affects clarity or uniformity so as to create consumer complaints, but if it was a controlled process before final bottling for sale, could contribute favorably to quality. In general, the conclusion of the producer is reflected in the color of the bottle. If light does not seem to affect the product, it may be sold in clear bottles to exhibit its appearance. If light has much effect the product is usually sold in a dark colored bottle. Many food products are sensitive to light and the development of glass containers capable of protecting foods, beer, and wines from light has given us some insight into the type of light most damaging and the type of chemical effect we may get from light treatment.

Glass of various colors has been studied regarding the protective effect versus light, i.e. sunlight, for various products. Of course, from a purely protective view a soft-glass bottle colored black would be opaque and give complete protection from light, as would metal cans, etc. Colored glass has advantages such as eye-appeal and in fact, the less colored types seem desirable from a sales viewpoint. Therefore considerable experience has developed regarding glass color versus quality-change effects that will aid us in understanding light as an agent for producing age-like changes in spiritous products.

In general the blue end of the spectrum is more damaging to these products than is the red and this is to be expected from an energy viewpoint as we have already discussed (Gray et al., 1941). This is in line with the numerous reports (and standard practice) that a reddish brown bottle (i.e. transmits some red but absorbs most of the shorter wavelengths) is best for beer (Brand, 1908). Szilvinyi (1948 finds that light 420 to $520 \mathrm{~m} \mu$ is active in causing sunstruck flavor of beer. Jacobsson and Högberg (1947) based their estimation of the protective effect of various glasses upon the prevention of oxidation-reduction potential drop in excess of $15 \mathrm{mv}$ after $3 \mathrm{hrs}$ of sunlight. On this basis, 700-760 $\mathrm{m} \mu$ light had no effect, $600 \mathrm{~m} \mu$ slight effect, but $500 \mathrm{~m} \mu$ considerable and $450 \mathrm{~m} \mu$ more. Yamanishi and Obata (1950) with filtered sunlight and model systems concluded that light in the 406$453 \mathrm{~m} \mu$ range was active and longer than $453 \mathrm{~m} \mu$ was not, in sunstruck flavor production in beer. It has been noted that amber glass may transmit 
some light in the lower wavelengths and therefore not afford complete protection and in fact the changes appear to proceed slowly in the dark (Gray et al., 1941). Uihlein and Lawrie (1948) claimed on the basis of experiments reported, but not described in their patent, that containers transmitting light in the approximate range of 560 to $700 \mathrm{~m} \mu$ gave improved quality retention of beer particularly with respect to protein stabilization as compared even to completely opaque containers.

The chemical nature of the sunstruck flavor of beer has been the subject of several studies. Brand (1908) noted that sunlight had no effect upon the flavor of wort and concluded that the constituents influenced by light were formed during fermentation. Komatsu et al. (1938) noted that autolysed yeast without enzymic activity contributed. Gray et al. (1941) reviewed and did further work on the problem showing that the primary maladorous constituents were sulfhydryl in nature. These are derived from non-odorous sulfur containing compounds ; yeast proteins, cystine, and related compounds being implicated (Jacobsson and Högberg, 1947 ; Szilvinyi, 1948). Total sulfhydryl content of beer increases when it is exposed to light (Brenner et al., 1958). The reaction is not simple, however, and hydrogen sulfide, methyl mercaptan, ethyl thioglycolate, and 3-methyl-2-butene-1-thiol have been reported to be important in the very volatile sunstruck malodor (Obata and Yamanishi, 1947 ; Gray et al., 1941; Obata and Horitsu, 1958a, b; Jacobsson and Högberg, 1947 ; Kuroiwa and Hashimoto, 1961 ; Kuroiwa et al., 1960 ; Yamanishi and Obata, 1950).

Beer components other than those containing sulfur also appear to be involved. Hop constituents such as lupulone and humulone evidently play a role (Obata and Horitsu, 1958a, b, 1959 ; Obata and Koshika, 1960). Flavins, respiratory enzymes, and uronides have been claimed to be involved also (Obata and Yamanishi, 1949; Komatsu et al., 1938). Such compounds may he acting as sensitizers. Jacobsson and Högberg (1947) note that methylene blue added to beer enlarges the spectrum within which beer is sensitive to light. They think melanoidins probably act the same way. This type of photosensitization probably helps explain the autocatalytic effect of light on browning; as the solution browns the action spectrum widens and therefore the rate of further reaction increases.

There is ample evidence that the reaction is reductive in nature in beer. The oxidation-reduction potential drops after beer is bottled unless air is entrapped in the bottle and this drop is much faster if light acts on the beer. It may reach its limiting potential in about $1 / 2$ hour in sunlight and this rapid drop is associated with the development of sunstruck flavor (Pozen, 1935; de Clerck, 1934; Mendlik, 1938). The development of the typical off-flavor is inhibited by oxygen and other oxidants (Mendlik, 1938; de Clerck, 1934), but once developed is not readily removed by oxidation (de Clerck, 1934; Pozen, 1935; Gray et al., 1941). Carbon monoxide is found in beer and other products such as soft drinks which have been affected by light, but this does not correlate with the sunstruck flavor and is apparently promoted by previous oxygen contact (Mendlik, 1938; Szilvinyi, 1948 ; Gray et al., 1941 ; Jacobsson, and Högberg, 1947). Sunlight does produce flavor change in beer in the presence of oxygen, but it is of a different 
type or if sunstruck flavor does develop it is slower in appearing (Mendlik, 1938; Kuroiwa et al., 1960).

Considering the universal agreement upon the undesirable nature of the sunstruck flavor of beer when it is caused by inadequate protection of bottled beer on its way to the consumer, one might wonder at our treating of the subject in a report aimed at desirable results simulating aging. It is felt that the situation is a bit like the botanist's definition of a weed as a plant out of place. Several beers with considerable sales volume and presumably satisfied customers have "skunky" notes in their flavor suggesting mercaptans or similar compounds. The work by Uihlein and Lawrie (1948) has already been cited in which they noted favorable effects of longer wavelength radiation. Webber (1960) has patented a procedure for artificially ripening beer by treatment with $\mathrm{CO}_{2}$ followed by 350-450 $\mathrm{m} \mu$ light treatment. Thus, there appears to be justification for the belief that treatment with light or any treatment which has flavor or other quality effect may be undesirable under some circumstances and desirable under others. Even universally undesirable changes if understood will contribute knowledge fundamental to the eventual complete control of changes of quality both good and bad by aging or simulated aging.

Other alcoholic products have not been studied in as much detail as beer regarding the effect of light on the bottled product. Sake has been reported to give a garlic-like odor and spoiled flavor on exposure to ultraviolet radiation for $10 \mathrm{~min}$ (Suzuki and Towatari, 1956). Deleterious effects of light on sake were also noted by Kazama (1954) and Nishiwaki (1958) compared the fading of sake, caramel, and melanine solutions in ultraviolet and sunlight. Carpenter (1933) reported that the red end of the visible spectrum affected apple juice flavor favorably. This was accompanied by considerable darkening. Kraut juice similarly treated developed a decaying cabbage odor. Strausz $(1947 a, b)$ considers both ultraviolet and sunlight harmful to perfumes. Few reports on alteration of distilled spirits by light during bottle storage were found and perhaps the fact that many are sold in colorless bottles is an indication the problem is not considered serious with them. This does not mean there are no changes, however. Austin and Boruff (1960) published gas chromatographic traces of a commercial grain neutral spirit one sample of which had been kept in the dark and the other in normal laboratory light for two years. The traces differed considerably particularly with regard to increased content of acetaldehyde and hydrocarbons in the irradiated sample. Mathieu $(1904,1913)$ has reported an increased rate of oxidation of brandy ethanol to acetaldehyde under the influence of light which was inhibited by green versus colorless glass bottles. Novak and Adams (1943) have reported that thiamin or nicotinic acid added to whiskey in clear or amber bottles exposed to daylight were stable for six months, but riboflavin was not. The latter was 90 per cent destroyed in three weeks in clear bottles and even in amber or wrapped bottles 50 per cent was lost in two months. Levine (1942) reviewed the factors affecting flavor of beverages in storage and production and noted that oxidative off-flavors were promoted by sunlight and additions of $B$ vitamins.

Cornelius (1951) considers that brown bottles are much better than green 
bottles for wine storage. Dark brown bottles gave better color retention, more rapid lowering, and longer retention of a low oxidation-reduction potential than light brown, green, or colorless bottles filled with port wine (Anon., 1959). In the tests of Pederson et al. (1941), eastern United States commercial wines labeled tokay, sauterne, port, and burgundy were stored in colorless bottles in full sunlight. If the bottles were full, the wines withstood two months exposure without visible change, but if the time was more prolonged or if the headspace was such that considerable air was admitted, sunlight promoted tannin precipitation, browning, red pigment loss, and inerease in aldehyde and volatile acid content. Storage at $85^{\circ} \mathrm{F}$ gave similar, but less drastic changes than full sunlight. In connection with a study of haze formation by copper in wine, Kean and Marsh (1956 $a, b)$ noted that sunlight promoted precipitation of copper proteinate. From a comparison of the effect of different bottles in this respect and the absorption spectrum of the glass, they conclude that light of wavelength $350-500 \mathrm{~m} \mu$ is active in causing copper clouds in wine and therefore brown or red-brown bottles are preferable to green or colorless. Uematsu and Kagami (1957) reported little effect of the light incident to 140 days of bottle storage on the absorption spectrum of a table wine. Hanak (1930) attributed the darkening of the color of wine exposed to ultraviolet light to the alternate reduction and oxidation of the iron present in the wine. Kielhöfer and Würdig (1958) noted that tartaric acid was oxidized in the presence of iron in water solution and in model solutions resembling wine in daylight, but not in the dark. In the presence of added ascorbic acid the reaction did not require light.

Schanderl (1950-51) has studied the effect of direct sunlight on the oxidation-reduction potential of a white table wine in colorless, green, and brown bottles. The bottled wine was allowed to stand in the dark for 24 hours after filling and then treated with light while in a $21^{\circ} \mathrm{C}$ waterbath. The starting potential was $140 \mathrm{mv}$. After $10 \mathrm{~min}$ the potentials were about 158 for the colorless bottle, 150 for green, and 138 for the brown. At the end of $90 \mathrm{~min}$ they were about 102, 148, and 131 respectively. Deibner (1957b) has reviewed the few data on the effects of sunlight on wine potential. It appears that light accelerates the increase in potential resulting from contact with and consumption of oxygen by wine, but as the oxygen is consumed or if it is not present a drop in potential is accelerated by light. This appears to be in line with the results observed and expected with other systems.

Ultraviolet light can be used as a sterilizing agent both from its own action and from its secondary effects such as ozone production (Proctor and Goldblith, 1951). The high absorption and therefore poor penetration of ultraviolet radiation into wine would limit the practicality of any such application. Mack et al. (1955) preserved apple juice by ultraviolet treatment. Although the flavor was altered it was still palatable. Similar effects of visible light on apple juice have already been mentioned (Carpenter, 1933). The work of Sastry and Tischer (1952) indicated that tannins had a protective effect upon the destruction of anthocyanins of Concord grapes by ultraviolet light. Michael (1931) has reported interesting and charac- 
teristic odor changes produced by the ultraviolet irradiation of aromatic organic substances.

Let us turn now to light treatments more specifically intended as aging treatments. Discussion of this subject has been included in reviews by Perin (1952), Jacobs (1947a), and others. The exposure of wine containers to the sun has been practiced since Roman times and it is not surprising that Pasteur (1873) tried the effect of sunlight on wine in glass ampoules in his early experiments. Pasteur concluded that sunlight had little effect if the container was full and no oxygen reached the wine. Malvezin (1903) reviews experiments by himself, by Boireau, Berthelot, and others with similar conclusions. They did find, however, that in the presence of air oxidation was accelerated by light. Their descriptions of the visual, flavor, and analytical changes are in line with those effects of sunlight we have been discussing and if the objective was a maderized or rancio flavor with the accompanying browning and (for red wines) pigment-tannin precipitation, aging was certainly accelerated. Therefore, they were able to consider their results as favorable for fortified sweet wines and sherry types. Malvezin (1903) describes an apparatus invented by Anibaro in Spain called the "Enophote." It consisted of a large glass covered tray with appropriate connections, valves, thermometer, etc. so that wine could be exposed in it to the sun and circulated or returned to the barrels after the desired treatment. Although it was described as capable of being used with or without the wine being in contact with the air, the primary use described included air and sherry was probably the wine intended to be treated. Malvezin notes that at least one Spanish wine company tried a large installation of this type, but later abandoned it and no further interest was being displayed. More recent experiments have been reported by González Toriño and Tuneu Sala (1939) and Tuneu Sala (1941). Sunlight effect on wines in barrels, demijohns, and bottles was studied. The wines should be of high alcohol (18 per cent), high acidity, and with enough tannin $(2 \mathrm{~g} / \mathrm{l})$ so that its decrease during the treatment will not spoil the flavor. Small volume, colorless glass containers were preferred and exposure to the sun should not exceed five months. With the exception of an increase in volatile acidity, the changes in analytical values suggest some evaporation. Timova (1959) used exposure to the sun for ten days as one treatment for quick-aging of dessert wines, but found it less satisfactory than heat treatments. Brief mention has been made of commercial trial in California of "solarized" wine processing. Special glass filters were used and claimed to eliminate the harmful rays from sunlight and transmit those which clarify, purify, and improve flavor (Anon., 1937). Philipsky (1930) has patented the aging of spirits by subjecting them to the action of yellow-orange light from a neon lamp in the presence of oxygen. In an addition to this patent (1933) similar treatment of mead is accomplished, but only upon the bouquet-producing extract. The originals of this work are unavailable to the author, but based upon the experiments and theoretical considerations already discussed, one would expect orange light to be capable of minimal photochemical effect.

More photochemically energetic ultraviolet irradiation has been reported as a spirit aging technique. An apparatus (Henri, 1910 ; Henri et al., 1915) 
which exposed a thin layer of wine in air near to and directly irradiated by an ultraviolet lamp was said to age a Banyuls wine equivalent to several years of natural age. An apparatus the main point of which appears to be to conduct the ultraviolet radiation into a remote, closed container via quartz rods so that temperature rise is prevented was patented by Mancini and Archangel (1936). Aging of whiskey equivalent to seven years in a charred barrel was claimed in eight hours. The color darkened, the aroma improved, and fusel oils and other obnoxious matter disappeared, evidently in a truly miraculous manner. Since no wood was mentioned, it isn't clear how the extractives equivalent to seven years in a charred barrel arose.

In a patent by Ryan (1953) ultraviolet radiation, electrical discharge, and a halogen containing catalyst are used to convert oxygen to ozone. The treated "halogen-activated polymeric oxygen gas" is used to treat various potable alcoholic products. A freshly barreled bourbon whiskey was said to acquire the smooth taste and good bouquet of a two-year-old product after a one-hour treatment with $11 / 2 \mathrm{l} / \mathrm{min}$ of gas. Fusel oil analyses purport to show a ten-fold increase in fusel oil after $5 \mathrm{~min}$ followed by a drop to slightly less than the original in 25 min of treatment. Lord Investment Corp. (1936-7) patented a process for aging wines, etc. involving ultraviolet irradiations with periods of natural aging between exposures. Reinisch $(1928,1929 a, b)$ has patented procedures for aging alcoholic beverages, perfumes, etc. by ultraviolet irradiation of them or the water used in their preparation, especially in the presence of air or oxidizing agents.

An "actinator" capable of applying infrared, visible, and/or ultraviolet light to wine, beer, milk, etc. for pasteurization, stabilization, and aging has recently been announced (Anon., 1960). The irradiation of alcoholic distillates in the vapor phase has been patented (Stein, 1936). A similar idea has been briefly described by Meroy (1936). The vapors are stated to lose the usual "spirity" character when treated by ultraviolet light within the still itself. Shmakova (1947) reported accelerated wine aging by treatment with ozone and ultraviolet light. Excellent port and Madeira-type wine were said to result. Muraki et al. (1957) improved the flavor of pomace brandy with additions of 0.01 to $0.1 \mathrm{~g}$ of the sodium salt of copper chlorophyllin per liter. It was necessary to determine the correct deodorizing dose with each brandy to be treated, but the effectiveness of small doses was increased by ultraviolet irradiation. The process appeared to lower the absorption of the spirit at 240 to $250 \mathrm{~m} \mu$. Janicki et al. (1958) improved apple and rhubarb wines with aeration and ultraviolet irradiation. The density, ester, aldehyde, and volatile acid content increased, but total acidity and higher alcohols decreased. No effect was observed from treatment of colored (presumably wood-aged) brandy.

The status of spirit aging via ultraviolet or visible irradiation as indicated by these reports can only be described as indefinite. The theoretical considerations and the results of photochemical experiments in relatively simple systems suggest useful possibilities, but the largely unsubstantiated claims of effectiveness in spirit aging leave one wishing for more fundamental, controlled studies. Irradiation with ultraviolet or possibly visible light appears to have possibilities as a relatively rapid yet easily controlled method 
of accelerating oxidation by air. If air and other oxidants are excluded it appears possible that reductive and carbon-chain-length modifications may be produced. That these reactions alone would simulate traditional aging appears doubtful, but useful flavor manipulation appears quite likely.

Ionizing radiation. It is probably evident to the reader from our previous examples that shortly after a potential treatment becomes available it can be expected to be tried and probably claimed effective in the aging of spiritous products. Nuclear radiation and X-rays are no exception. Much of what has been said about the effects of short wave ultraviolet applies, only more so, to ionizing radiation-X-rays, gamma rays, beta particles or energetic free electrons, alpha particles or helium ions, and other such radiation and atomic fragments. In fact, $X$ and gamma rays are a continuation of the electromagnetic spectrum at wavelengths shorter than the ultraviolet. As we noted before, the energy per quantum rises with shorter wavelengths. Since even $200 \mathrm{~m} \mu \mathrm{UV}$ has sufficient energy to disrupt many chemical bonds, it follows that $\mathrm{X}$ and gamma radiation have energy in excess of this level. Particulate bombardment (alpha or beta) also has very high energy content and therefore is capable of causing extensive molecular disruption. The following approximations are informative to chemists not accustomed to thinking in electron volts-the usual energy content expression for ionizing radiation. Desrosier and Rosenstock (1960) in their recent book have summarized much of the information upon the nature of ionizing radiation and its capabilities in food treatment. They report the following energy approximations: kinetic energy of molecules at room temperature 0.02 electron volts; chemical bond strength 1 to 12 ; activation energy of chemical reactions 0 to 4 ; binding energies of outer electrons 5 to 20 ; binding energy of inner electrons 15 to 150,000 ; gamma-ray photon 500,000 to $5,000,000$; and alpha particle 4,000,000 to $9,000,000 \mathrm{ev}$ (electron volts). It can be seen from an energy viewpoint these "projectiles" of ionizing radiation have more than sufficient energy to strip electrons from internal as well as external orbits and to disrupt not only one but many chemical bonds. The molecular fragments produced by ionizing radiation, the "ion-pair" of a given "collision," receive in addition to the energy for the break, excess energy in the form of motion which causes them to move apart with considerable speed (Ingram, 1958). The fragments themselves, particularly ejected electrons (secondary beta particles), may cause further ion-pair production and reaction in the medium. The radiation loses something of the order of $35 \mathrm{ev}$ per ion-pair produced (in air) (Friedlander and Kennedy, 1955) and thus the single energetic particle or photon will cause many ion-pairs before exhausting its tremendous energy. The "ion-pair" produced in a given collision or activating event might be a usual cation (with momentum) and an electron (beta particle), it might be a pair of free radicals (with momentum), or it might be a pair of fragments unusual from a chemical viewpoint.

The specific nature of the radiation involved and the nature of the medium will affect the distance between ion-pairs and the distance of penetration of the radiation. In general, alpha particles produce dense but very short and non-penetrating paths of ion production. X-rays and gamma rays can pene- 
trate considerable thicknesses of "solid" matter, but proportionately few ionization events are produced. Beta particle streams are generally intermediate in both respects but can cover a wide energy range. The energy of ionizing radiation being such that it is capable of disrupting not only any usual bonding electrons, but also electrons in internal orbits and the possibilities of secondary reactions of the pair of reactive fragments being so great, the products of irradiation of simple substances may be very complex. With an initially complex mixture such as a spiritous beverage the molecular hash which could be produced can scarcely be imagined much less predicted.

A few notes on the radiation chemistry of water, ethanol and a few other constituents may help estimate the effect of treatment with ionizing radiation on wines and other alcoholic solutions. Irradiation of water usually results ultimately in the formation of $\mathrm{H}_{2}, \mathrm{O}_{2}$ and $\mathrm{H}_{2} \mathrm{O}_{2}$ (Burton, 1952). Initial products appear to be $\mathrm{H}$ and $\mathrm{OH}$ radicals. These can combine with each other to give $\mathrm{H}_{2}$ and $\mathrm{H}_{2} \mathrm{O}_{2}$, the latter apparently in an activated form (Alexander and Rosen, 1960). The oxidative effect in irradiated water solutions is generally considerably greater if the water solution contains oxygen than if oxygen is excluded (Barron, 1954; Vermeil, 1958; Hart et al., 1955). The $H$ radical doesn't appear to be important, in biological systems at least, possibly because it readily combines with another $\mathrm{H}$ to give $\mathrm{H}_{2}$ and with $\mathrm{O}_{2}$ to give the $\mathrm{HO}_{2}$ radical. Ghormley and Hochanadel (1954) have shown that there is considerable recombining of $\mathrm{H}$ and $\mathrm{OH}$ radicals back to water. Even so the initial yield of $\mathrm{H}_{2} \mathrm{O}_{2}$ in oxygen-saturated water in closed vessels was 1.31 molecules per $100 \mathrm{ev}$ absorbed (the $\mathrm{G}$ value) in their tests with gamma rays from radioactive cobalt. In pure aerated water Mayneord et al. (1955) report $\mathrm{G}\left(\mathrm{H}_{2} \mathrm{O}_{2}\right)=1.83$ with their test system and X-rays. This initial yield was linear with dose rate over a considerable range $(0-1250 \mathrm{r})$. Depending upon pressure build-up in closed systems (Dolin, 1955) and other environmental and irradiation factors, aqueous systems may reach a steady state condition during continued irradiation. Henderson et al. (1959) report a steady-state potential of $-850 \mathrm{mv}$ for several such systems. Much study has been devoted to the radiochemistry of water (Harwood, 1958; Friedlander and Kennedy, 1955 ; Burton et al., 1960 ; Mahlman and Boyle, 1958 ; Desrosier and Rosenstock, 1960 ; and many others) and the mechanisms and yields for given conditions with simple water-air systems are rather well known.

The situation pertaining when other materials are present is much less clear. Suspended matter, in particular certain semiconductor-oxides, may sensitize the reactions (Shub et al., 1957) in a manner similar to photosensitization which has already been discussed. Aqueous $\mathrm{CO}_{2}$ can be reduced to other compounds, especially formic acid, by irradiation (Garrison and Rollefson, 1952). Malic acid X-irradiated in oxygenated aqueous solution gave $\mathrm{G}=2.6$ (molecules per $100 \mathrm{ev}$ absorbed) of oxalacetate and 1.7 of $\alpha$-hydroxy- $\beta$-ketosuccinate as the primary products. If oxygen was excluded, the latter compound was not produced and the $\mathrm{G}$ (oxalacetate) was 2.2 (Putney and Pratt, 1956). Fatty acid esters under oxidative conditions gave odorous products including carbonyl compounds (Chipault et al., 1957). Irradiation of polymeric materials such as proteins is likely to cause 
cross-linking reactions, etc. which lead to decreased solubility, gel-forming ability, etc. Amino acid solutions give hydroperoxides, ammonia, chain fragmentation, and with aromatic rings both hydroxylation and ring break-down are noted (Khenokh and Lapinskaya, 1957; Okada, 1958). It should be noted that resonance-stabilized aromatic ring systems are relatively resistant to disruption by irradiation (Friedlander and Kennedy, 1955). Sugars irradiated in aqueous solution have been reported to produce gaseous products other than $\mathrm{CO}_{2}$, reductone-like compounds, and peroxyacids (Streuli, $1957 a, b$; Binder and Vincze, 1957).

Ethanol irradiated in the absence of oxygen gave acetaldehyde, water, hydrogen, methane, and carbon monoxide with a total molecular yield of $9 / 100 \mathrm{ev}$. In the presence of oxygen the yield of these products was 150 per cent or more of these yields and peroxy and acidic products totaling 25 molecules/100 ev were produced (Bakh and Sorokin, 1955). McDonell (1951) and McDonell and Newton (1954) studied the radiation chemistry of alcohols including ethanol. Products of radiolysis of ethanol included the products mentioned above as well as 2,3-butylene glycol and hydrocarbons including unsaturated compounds particularly ethylene. These products can be considered the results of oxidation in some cases and reduction in others. Day and Stein (1957) note that in the absence of $\mathrm{O}_{2}$ the alkyl radicals produced by irradiation of aqueous ethanol serve as efficient reducing agents.

The effects of ionizing radiation on complex molecules and complex products such as foods have been and are being studied in many laboratories and with many objectives (Collinson and Swallow, 1955 ; Desrosier and Rosenstock, 1960 ; Mark, 1957 ; Kraybill, 1959 ; Kraybill and Brunton, 1960 ; Morgan, 1959; Kuprianoff, 1956; Proctor and Goldblith, 1951; Dainton et al., 1952 ; Restaino, 1960 ; Urbain, 1960 ; Read, 1960 ; and many more). The nutritional and toxicological effects of irradiation on foods were discussed in an extensive symposium (Friedemann et al., 1956). At least at the sterilization level of irradiation, no injurious effects were noted even after long periods of exclusive consumption of treated foods by experimental animals. Palatability problems do arise, however. Day et al. (1957) related the principal off-flavor in irradiated milk to potent and disagreeable sulfur compounds such as methyl mercaptan. They found acetaldehyde was related to a malty flavor in irradiated milk. Lactose solutions became slightly acidic, but not objectionable. Meat has been noted for off-flavor development on irradiation which has been described with terms such as "wet-dog." Sulfur compounds appear to be involved here too. Drake et al. (1960) have discussed some of these effects of radiation and conclude that although flavor differences are produced by irradiation they are not necessarily objectionable. Laug (1957) notes that flavor change in beer exposed to radiation from atomic bomb detonation could be detected only by experts.

Of some interest to us are reports by Sharkov et al. (1958), 'Freidin et al. (1959) and Mark (1957) on the effects of irradiation on wood and wood constituents. The water-extractable constituents could be increased considerably by irradiation of wood. Among the degradation products of cellulose were mono-, di-, and oligosaccharides. Hemicelluloses decreased, pentoses increased, lignin degradation products included vanillin, and at strong dosages some carbonization was produced. 
Browning of crystalline sugar and 50 per cent sucrose solutions occurs during radiation. Reducing substances (but not hexoses) increase and the absorption spectra suggest enols or endiols are produced in crystalline sucrose along with hydrogen, methanol, formaldehyde, and $\mathrm{CO}_{2}$ (Liggett et al., 1959). The reactions in solution appear more similar to the browning caused by heat.

The study of radioactivity and ionizing radiation in connection with wine and other spiritous products has been rather limited. Of course, wine and all foods containing potassium have a small amount of radioactivity from the naturally occurring $\mathrm{K}^{40}$ which is a long lived ( $\mathrm{T} 1 / 2$ about $10^{\circ}$ years) isotope present to about 0.012 per cent in natural potassium and decays with the emission of beta particles of about $1.35 \times 10^{8} \mathrm{ev}$ (Kamen, 1948). According to early reports (Nodon and Cuvier, 1928; Cuvier and Nodon, 1930) the radioactivity of wine was rather high and a relationship with quality was suggested. Canals and Médaille (1932), however, reported that the previous values were too high. They noted that old wines were less radioactive than new. Kaufman and Libby (1954) found that the tritium content reflected the age of old wines $\left(\mathrm{H}^{3}\right.$ has a half-life of about 12 years). With the advent of nuclear explosions, the tritium content of water and natural systems containing water has increased. Pro and Etienne (1959) have developed a technique to check the validity of age claims especially for distilled spirits, based upon tritium content. The natural radioactivity or the tritium level is no higher than in other parts of the environment and is so low that it is no doubt not a significant factor in either nutrition or product aging.

Application of ionizing radiation during fermentation has been claimed (Société Ind. Brasseries, 1960) to produce a more rapid beer fermentation and improved stability in the finished beer. Teramoto et al. $(1958,1959)$ irradiated fresh and aged sake. Color was darkened and an unpleasant odor was produced under conditions which did not sterilize the sake. Acetoin was formed in the irradiated sake and a possible origin was the acetaldehyde produced from acids and amino acids by the irradiation. Anthocyanins in a cherry drink were unstable to irradiation (Salunkhe et al., 1959) and oxygen uptake was directly proportional to the irradiation dose.

Aging and quality modifications of alcoholic products via ionizing radiation have been reported mostly from the Soviet Union. Brasch (1950) does hold a patent in the United States for rapid aging of various spiritous products such as beer, wine, etc. by bombardment with accelerated electrons. No data or examples are presented, but tests are reported as being very favorable with some products. Some side-reactions with some products are reported as detrimental and exclusion of oxygen is considered desirable. Kipiani and Nutsubidze (1956) found that gamma irradiation maderized wines and accelerated the production of Madeira and port type wines. The content of acetaldehyde and acetals increased; alcohol, total tannins, and phloroglucinol content of the tannins decreased as shown in table 3 . The organoleptic scores were higher for the irradiated than the control wine. In the two cases where the same wine was treated by the usual 20 day baking procedure (temperature not given), the compositional changes 


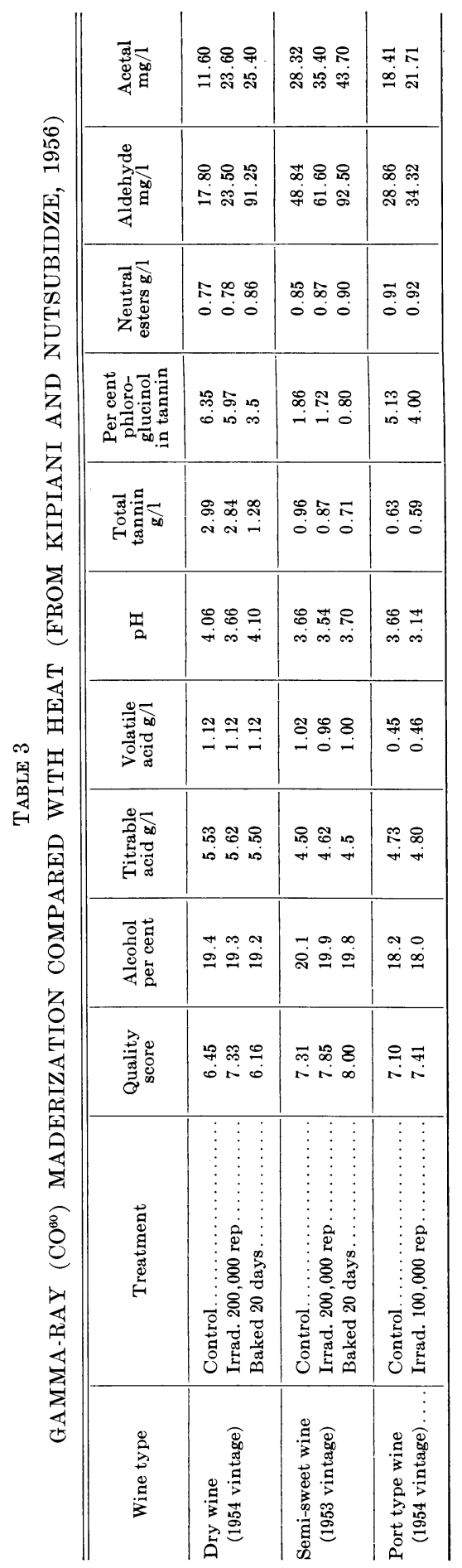


were in the same direction but considerably larger. The baked sample scored above the irradiated in one case and below in the other. Tsetskhladze and coworkers $(1956 a, b, 1957)$ report similar work. Irradiation with $\mathrm{Co}^{60} \gamma$-rays gave temporary precipitates in wines and increased acidity and esters at dosages of 100,000 roentgen equivalent, physical (rep). Color change was small unless dosage was large in which case color was lightened. Cognacs were improved in taste; wines usually did so too but well-aged wines were damaged.

A series of studies have been reported by Beridze and coworkers (1956, 1957, 1958). A European table wine, two Kakhetinic table wines, a port, and two Madeira-type dessert wines were treated with 12,000 and 50,000 rep of $\mathrm{Co}^{60}$ gamma radiation. The analytical changes were small except for a small increase in aldehydes and a decrease in acetals (see table 4 ). The table wines developed a taste described as "blunt" plus hydrogen sulfide and sediment. The dessert wines became mousey. Quality scores were slightly lower for the treated wines. Storage for two to three months restored the characteristic properties. Dosage less than 12,000 rep had little effect, but at or above this level the amount of amino acids decreased in irradiated wines and new types of amino acids were formed. Defective wines (mousey, acetic, etc.) were treated with 100,000 and 1,000,000 rep. The treated wines differed from the original in that the contaminating organisms were killed and color, aroma, composition, and physical properties were changed. Rather small but consistant decreases in alcohol, total acid, volatile acid, and tannin were produced by the irradiation. The mousey and acetic flavors decreased or disappeared.

Rapid aging by means of ionizing radiation appears to be a possibility, but more work is needed. As has been said in connection with several other treatments the irradiated product may resemble the traditionally aged product, but can hardly be expected to exactly imitate it. Much of the effort to adapt radioactivity to sterilization and food processing has been aimed at overcoming the bad features of heating. For example, fresh fruit turn to mush if heated and it was hoped that ionizing radiation might be used to extend storage life without such ill effects. In such a situation color or flavor change appears to be detrimental and would seem to require considerable re-education of the consumers to convince them otherwise. As mentioned in the introduction, the situation is different with spiritous products and a degree of variation and distinctiveness even within a single type of product is appreciated by the more sophiscated consumer. Under these conditions a distinctive flavor produced by irradiation if generally considered not unpleasant would seem to be interesting. Therefore, it is felt that further study of treatment of alcoholic beverages with ionizing radiation is justified, but at this stage a simple cure-all application as a quick-aging procedure seems unlikely. Like ultraviolet light and ultrasound, ionizing irradiation of spirits (aqueous solutions) especially in the presence of the oxygen of the air appears to act primarily as a "peroxidizing" agent. Therefore its use with maderization as an objective (sherrys, perhaps other dessert wines) would appear to be worthy of more study. 


\begin{tabular}{|c|c|c|c|c|c|c|c|}
\hline & 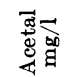 & 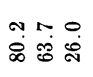 & 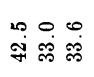 & $\overrightarrow{8} \ddot{8}$ & 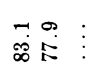 & 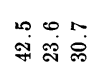 & 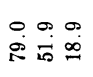 \\
\hline & 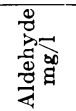 & 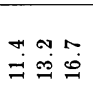 & 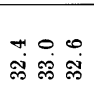 & $\begin{array}{l:c}\infty & 0 \\
\approx & \vdots\end{array}$ & $\begin{array}{l}\vec{b} \\
\vec{\infty} \\
\dot{\infty}\end{array}$ & 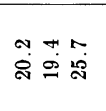 & $\begin{array}{l}+ \\
= \\
=\end{array}$ \\
\hline & 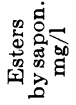 & 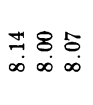 & 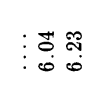 & $\begin{array}{l}0.8 \\
\infty \\
\infty \\
\infty\end{array}$ & 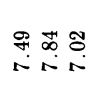 & 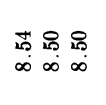 & $\begin{array}{lll}8 & 0 \\
0 & 0 \\
0 & 0 & 0\end{array}$ \\
\hline & 告 & 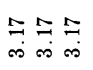 & 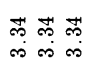 & 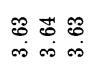 & $\begin{array}{l}=\vec{c} \\
\infty \\
\infty\end{array}$ & 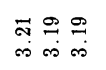 & 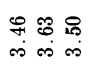 \\
\hline 崖 & क्वृ & 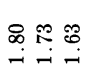 & 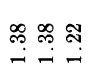 & הi & 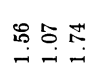 & 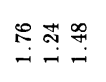 & $\stackrel{\infty}{\stackrel{\infty}{-}}$ \\
\hline 幽 & 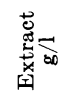 & 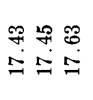 & 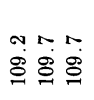 & 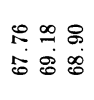 & 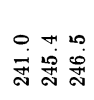 & 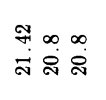 & 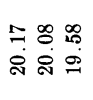 \\
\hline 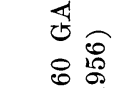 & 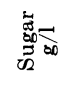 & 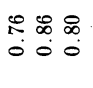 & 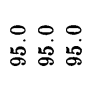 & $\begin{array}{ll}\infty & 0 \\
\exists & 0 \\
F & \end{array}$ & 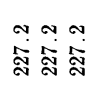 & 兽 8.8 & $\begin{array}{ll}\mathscr{H} & \vec{\infty} \\
0 & 0 \\
0 & -0 \\
0\end{array}$ \\
\hline 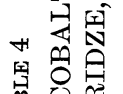 & 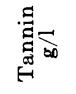 & 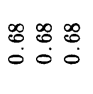 & \begin{tabular}{ll}
$\vec{m}$ \\
\hdashline \\
0
\end{tabular} & 牙 & 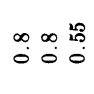 & 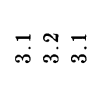 & $\vec{i} \vec{i} \vec{i}$ \\
\hline 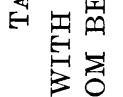 & 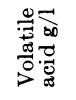 & 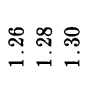 & مُ & 政 & $\hat{0} \ddot{0}$ & 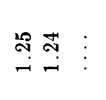 & $\begin{array}{ll}1 & 0 \\
0 & \infty \\
0 & 0 \\
0 & 0\end{array}$ \\
\hline 量荭 & 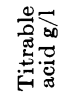 & $\begin{array}{lll}0 & 0 & 0 \\
\text { is } & \text { is is }\end{array}$ & $\begin{array}{l}\vec{\infty} \dot{\infty} \\
\dot{\infty} \dot{\infty}\end{array}$ & 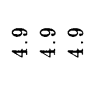 & $\begin{array}{l}0 \\
\dot{\sigma} \\
\dot{H}\end{array}$ & 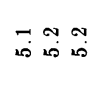 & 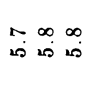 \\
\hline $\begin{array}{l}\text { ry } \\
0 \\
\text { E-1 }\end{array}$ & 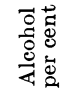 & $\stackrel{\infty}{=} \stackrel{\sim}{\exists} \stackrel{\sim}{\Xi}$ & $\begin{array}{l}\stackrel{\infty}{\infty} \stackrel{+}{=} \\
\stackrel{\infty}{=}\end{array}$ & 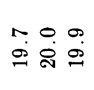 & 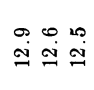 & $\stackrel{\infty}{=} \stackrel{\infty}{=} \stackrel{\infty}{=}$ & 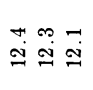 \\
\hline 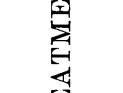 & 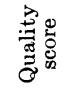 & $\begin{array}{lll} & \infty & 0 \\
0 & \infty & \infty \\
\infty & \infty\end{array}$ & مִ & $\underset{\infty}{+}: \underset{\infty}{\infty}$ & $\begin{array}{lll}1 & 0 & 0 \\
\infty & \infty & \infty \\
\infty & \infty\end{array}$ & 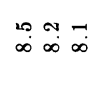 & $\begin{array}{lll}0 & 0 & \infty \\
\infty & \infty & \infty \\
\infty & \infty\end{array}$ \\
\hline Feg & 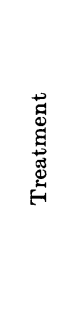 & 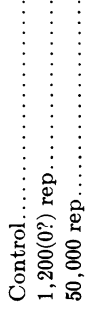 & 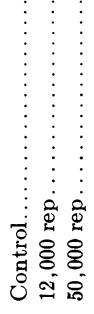 & 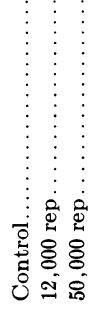 & 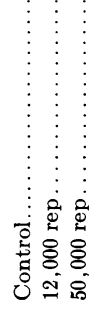 & 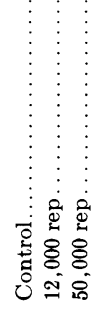 & 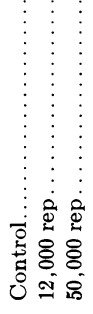 \\
\hline & 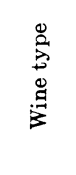 & 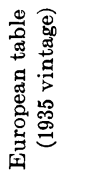 & 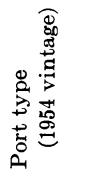 & 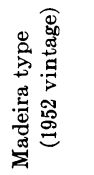 & 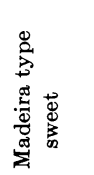 & 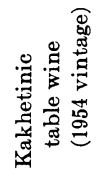 & 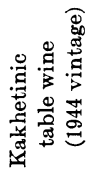 \\
\hline
\end{tabular}




\section{Electrical Treatments}

Pertinent to this topic are treatments with direct electrical action upon the spiritous product. Of course, many of the pieces of apparatus necessary for other treatments such as ultraviolet lamps, heaters, particle accelerators, etc. are or may be electrically operated, but they are not of interest just because of their electrical feature.

Electric current may have several actions upon solutions. A conducting solution will be heated in proportion to the electrical power and its own resistance. Direct electrical current produces in solutions ion migration, electrolysis, cathodic reduction, anodic oxidation, etc. The nature of the electrodes, the current, the solution, and other environmental factors influence the result. Since electrochemistry is rather well and generally understood its discussion can be limited here. For further theory, equipment and technique, possible organic reactions, and oxidation-reduction characteristics of organic compounds one may consult excellent monographs (e.g., Glasstone, 1946; Clark, 1960; Swann, 1956; and Allen, 1958).

Electric current and heating. The grouping of aging treatments for wines and spirits under this topic is arbitrary and perhaps not always justified, but those treatments in which the effect may be primarily heating or in which insufficient details of the treatment prevent assigning the importance of other effects are grouped here. The chemical effects of alternating current are at least partly nullified by the rapid reversal of polarity and considerable heat generally results if a.c. is passed through a solution. Although it cannot be said that alternating current passing through complex alcoholic solutions produces only heat, neither is it easy to estimate or control other effects. Therefore such treatments are placed under this heading.

The effects of heat have already been discussed. Except for convenience, economy, control, and perhaps avoidance of local overheating, electrical inductive heating or heating by making use of the resistance of the solution should not differ in effect from other heating. Shijo et al. (1960) report that heating of fortified grape juice by means of alternating current between carbon electrodes gave a product not distinguishable from that produced by heating with hot water. Bloom (1915) in his 23 page patent describes a technique for wine and grape juice treatment and his theories to explain its operation. Inductive heating to the preferred temperature of $130^{\circ} \mathrm{F}$ is a main effect although electrostatic precipitation of colloids upon packing materials in the wine pipeline is considered important. Electrolysis is specifically avoided and pasteurization and stable clarity are the primary objects rather than aging. Meygret $(1912 a, b)$ has patented a procedure and apparatus for electrically aging and clarifying wines and must. Lachmans (1916) describes a system for aging wine with provision for both a heating coil (water, steam, etc.) and "high tension alternating current." Pressure of $5-25 \mathrm{psi}, 140^{\circ} \mathrm{F}$ for variable time, and recirculation conditions are claimed to give the aging effect of many months in 24 hours.

Spellmeyer (1936) aged 100 proof distillate by adding an acidic "catalyst" (electrolyte?) such as acetic, tartaric, or tannic acid (25-50 mg/100cc) and treating with less than $1 \mathrm{amp}$ a.c. in a charred barrel for two days to three 
weeks. Sandor and Fuhrer (1941) aged alcoholic liquors with 120-190 v (a.c.), air, and stirring. Aldehyde rapidly decreased and ester content increased. An acceleration of the formation of ethyl acetate from ethanol and acetic acid under the influence (heat?) of an alternating current and the attributing of the catalytic effect on wine aging to this cause has been reported (de Pereira Forjaz, 1934). The apparatus of Seitz (1908a, b, 1909) aged liquors in barrels with air and electricity. The electricity was discharged at short intervals through the liquid or over a fine wire of high resistance in the liquid. Heating occurred.

Noguchi $(1949,1951)$ has described the application of both low and high frequency alternating current to various organic materials. Aging of synthetic sake, vinegar, perfumes, synthetic whiskey, etc. was claimed. Heating was apparently involved. Formation of ethyl succinate, decreased dielectric constant, and decreased viscosity were mentioned as effects of the treatment on sake. The aging of sake was performed with 60 cycle superimposed upon 30 megacycle current. Akahoshi (1951) has patented a somewhat similar process. Lebbe (1911) has reported both the control of fermentation and aging by the use of electric current passed through the liquid.

Maltseva et al. (1953) report an interesting test for the suitability of a lot of wine for bottling. It depends upon testing the wine by heating with an electrical apparatus. If no coagulum or turbidity is produced by heating the sample with the electrodes to $60^{\circ}-65^{\circ} \mathrm{C}$, the wine is considered mature for bottling. Presumably, similar results would be obtained by other hot-stability tests.

Electric current and ozone production. A series of somewhat similar treatments involving electricity has been used in attempts to age wines and similar products which depend or may depend upon ozone production. The effects of ozone are not a part of our consideration of physical treatments, but since the generation of ozone in air or oxygen occurs from electric sparks and high voltage silent discharge (and ultraviolet light) a brief discussion of such treatments belongs here. Jacobs (1947b) has reviewed oxidative-electrolytic treatments for whiskey aging. Plotti (1907) attributes most of the effect of aging of wines to oxidative reactions and believed that conversion of dissolved $\mathrm{O}_{2}$ to $\mathrm{O}_{3}$ by electrical discharge within the liquid was the reason for favorable effect and rapid aging produced by electrical treatment. Similar conclusions were drawn by Fenie (1928), but he notes that the yield of ozone is difficult to control, some of the generating equipment is unreliable, and overtreatment is very easy. Delyannis (1938) reports favorable results such as intensification of aroma and slight decrease in acid.

There can be little doubt that both oxygen and ozone are playing a role in the treatments that are performed on the gases which are used to treat wines and spirits. Such treatments were made by Marsais (1930) on six types of wine. Flavor was made flat by the treatment but soon recovered. Partial sterilization was produced. Sulfur dioxide was oxidized and other changes similar to simple air oxidation were produced. Walter (1927) removed a mousey taste from wines with ozonization, but was troubled with pigment destruction. Ozone generated electrically was reported to have desirable results in aging wine and cognac (Hirschmann, 1907) and alcoholic beverages 
in general (Tensora, 1960). Becker (1929) reports liquor was made more bland and both aldehydes and esters increased by such treatment.

Air treated under ozonizing conditions contains oxides of nitrogen and these were suggested as important factors in the Brabender Company's patent for improving whiskey, cognac, etc. (1928). Scheibler (1949) treated vapors such as distilling brandy with nitrogen ionized in a high voltage electrical field (12,000 v, 50 cycle a.c.). The brandy produced was claimed to taste like that aged several years.

Darrah (1938) patented a process for aging distilled alcoholic beverages, whitening clothing during laundering, purification of milk, and treatment of sewage sludge. A high voltage, silent electrical discharge is made through the liquid and the oxygen flowing over it. Ozone is involved. A drastic drop in alcohol content was sustained in the two examples given (61 to 49 per cent, and 70 to 58 per cent). Acids increased (in parts per 100,000, respectively, for grain and potato whiskey distillate) 6 to 25 and 8 to 28 , as did esters 31 to 42 and 33 to 37 , higher alcohols 56 to 64 and 141 to 182, and aldehydes 6 to 11 and 13 to 67 . These compositional changes suggest strong evaporation and this could not be tolerated unless some provision was made to recover the vapor.

Maximov (1955) also treated alcoholic beverages with high frequency current and ozone. Increase in quality was observed for rum and whiskey especially, cognac and port wine improved but less so. Beer flavor and quality was claimed to be improved and fermentation controlled by means of pulses from a high voltage induction coil (Allen, 1909). An oxygen and electrode apparatus (Handels, 1907) for insertion into cask bungs was patented for improving alcoholic beverages.

The available data suggest that for processes depending upon ozone more attention should be paid to the determination of the effect of specific doses of ozone using more carefully controlled and more thoroughly evaluated experiments.

Electrolysis and oxidation-reduction. A d.c. potential placed across electrodes in a conducting solution gives rise to a completed circuit and current flows. Ions migrate to the poles. At the cathode a reduction occurs and at the anode an oxidation. The specific reaction which occurs depends upon the nature of the solution, the electrical current, the electrodes, etc. The oxidation and the reduction may produce simple electrolysis of water with hydrogen and oxygen evolution or if metals are present they may be converted to different ions, plated out, etc. If organic compounds are present they may be oxidized or reduced and they may react with other electrode products.

A considerable amount of research has gone into the analytical application of these facts to wine and spirits, but relatively little into the application to spirit aging and processing. The most complete report is that by Joslyn (1938). Although alternating current was used and the wines heated to similar temperatures as other baking procedures, electrolytic oxidation produced a more rapid increase than the normal sherry baking procedure in acetaldehyde content. Electrolytic treatment at $137^{\circ} \mathrm{F}$ gave $115 \mathrm{mg}$ aldehyde/l, but baking at $130^{\circ} \mathrm{F}$ for 90 days only produced $55 \mathrm{mg} / \mathrm{l}$. The flavor 
produced by electrolytic treatment was more similar to Spanish sherry than if acetaldehyde was merely added, but the aldehyde-forming reaction proceeded too fast compared to the caramelization reactions. The best flavor appeared to require both a short or weak electrolysis and more prolonged heating. A small drop in total acidity appeared in several cases with the electrolytic heating, but not with the usual baking.

Electrolytic oxidation of ethanol in acidic aqueous solution produces both acetaldehyde and acetic acid (Zeller Herrera, 1947 ; Shul'man, 1958; Bogdanovskil, and Shlygin, 1957). The proportions vary with the ethanol concentration. At high ethanol concentrations acetaldehyde was produced alone on platinized electrodes at $0.65 \mathrm{v}$, at potentials above $1.9 \mathrm{v}$ acetic acid was exclusively produced, and between these potentials both were formed. In dilute solution the total rate was less and the proportion of acetaldehyde increased.

Jarraud $(1920,1924)$ reported favorable effects from electrolysis of spirits in barrels or those containing oak extractives. Selection of electrodes so that hydrogen is not produced and a potential such that ethanol is not decomposed produced oxidation and artificial aging similar to but not identical with natural aging. Brandies and fortified sweet wines were improved, but table wines were not.

Contrary results were reported by Murdfield (1914) who passed oxygen through a Bordeaux wine and electrolysed it at the same time. Samples treated for 10 to 35 min were examined immediately, after 19 days in wood, and after 14 months in bottles. Although the treatment was said to produce rapid aging, the bouquet was of inferior quality and did not reproduce the natural process. Progressive increase in acetic acid content was found for the length of the treatment. Ester content of the treated samples was higher than the untreated when the wine was bottled, but increased for the untreated and decreased for the treated until the reverse situation pertained at the end of the 14 months.

Lherme and Débordes (1950) electrolysed wines between aluminum electrodes at 4.2-4.4 v, 0.8-1 amp. Hydrogen and oxygen were evolved and both electrodes contributed aluminum to the solution. Nottelle (1931) patented an electrolytic aging procedure for alcoholic beverages in which hydrogen and oxygen were produced. Štefanić (1954) used electroreduction on grape juice and noted a slight decrease in total acidity but a considerable increase (3.36 to 3.71 ) in $\mathrm{pH}$. The concentrated treated juice retained a fresh, aromatic taste and light color; the untreated did not. Electrical decomposition of amino acids in alcoholic solution has been reported to produce an odor and taste in the product so that it is useful in preparing synthetic sake (Katsumé and Fujita, 1928). Henry (1912, 1914) has patented an aging procedure for beer, wine, spirits, perfumes, etc. in which high voltage, low amperage currents are used and heating is avoided. It is not clear whether ozone production is involved.

Electrodialysis. Jarraud's patent (1920) already mentioned, includes a statement that the electric current can be applied between the cathode in the bung and anodes connected by means of moist pads to the outside of the cask. This was said to facilitate and speed the extraction of materials from the 
cask. Paronetto (1941) applied membrane electrodialysis to reduce the acidity of wines and Fukuoka et al. (1949) increased the yield of extractives, especially the volatile materials, from oak wood by an electrical treatment, but aging relationships were not discussed.

\section{Miscellaneous and Complex Treatments}

Rapid aging has been attempted by several complex treatments. Most of these have already been mentioned in connection with specific parts of the treatment. Some of these seem well designed and each partial treatment has a logical basis. In other cases it appears the experimenter was only making sure no bets were left uncovered. Malvezin's (1903) combination of refrigeration, oxygenation, and pasteurization and the similar processes such as that of Monti (1914) have not been discussed in detail since they depend heavily on the nonphysical reaction of oxidation for their effect. It is the author's opinion, however, that such combination treatments do have the most future in accelerated aging. The treatment of Castaing (1951) makes use of infrared, cooling, electrolysis, cooling, clarification, and filtration and that of Stein (1936) electrical current, ultraviolet, and infrared radiation.

A few reports have suggested that treatment with long wavelength waves of the radio frequencies, Hertzian waves, were a means of accelerating aging of spiritous products (Jarraud, 1910a, b; Gayraud et al., 1949). It is presumed that the effect of such treatment depends upon heating (Proctor and Goldblith, 1951).

Concentration of wine by preferential evaporation of water from it by enclosing it in a container such that the vapor can contact a drying agent, calcium chloride, etc., has been used to improve it (Prandi, 1924). Similar procedures by $\mathrm{F}$. Ivison, using caustic soda, or by Baudoin and Scribeaux and by Garrigou with distillation apparatus, have been described by Malvezin (1903). Simulation of aging is claimed, but improvement is more proper terminology and practical, economical treatment under modern Californian conditions seems doubtful.

A few other physical treatments have been discussed. Whether they were sheer quackery or not is difficult to ascertain, but one has one's suspicions. In any case too little evidence for their effectiveness exists for any great interest. A Washington, D.C. newspaper item of some years ago mentioned a process in which bottles were clamped to a radio-like box for the treatment. In a blind-tasting, five of six experts were wrong as to which was the treated bottle. Nothing further has been heard of the treatment. The San Francisco Daily Examiner during August of 1899 carried several items on the 7 th annual viticultural convention. A series of lively debates, including one involving the professor for whom this journal is named, were gleefully reported. This discussion centered around a quick-aging process invented by a Dr. Fraser. This process involved passing an electric current around but not through the wine and was based upon the "well known fact" that wines have been materially improved by a flash of lightning. 


\section{CONCLUDING REMARKS}

Human ingenuity has extended itself in the field of physical treatments for wine and spirit aging. In spite of many such claims no "black box" has been produced which will accept harsh, raw, young products at one end and pass out premium quality, aged products at the other. The problem or rather the group of problems is too complex for that.

On the other hand, considerable data of promise have been obtained and in individual cases improvement of single lots or single types of spiritous products has been claimed, with the evidence supporting the claim. The gamut of Edisonian trials appears to have been rather thoroughly covered. The need is for more fundamental, controlled, and evaluated scientific testing to exploit the leads that have appeared.

It has been the fashion to say that after all is said and done no quick aging process has ever approached the quality of the traditionally aged product (Singleton, 1959 ; Ramond, 1957 ; Bellstedt, 1961 ; Brown, 1937 ; and others). As a matter of fact, many individually small and gradual changes have taken place in the production methods which sum up to the final products. To put one's finger on a generally useful quick-aging process is not yet possible, but many of the problems of clarity, stability, keeping quality, defect correction, etc. which were once solved by aging are now pretty well solved by other means, more surely and in less time.

The problem remaining seems to be one of taking the sanitary, fault-free, stable product of today and enhancing the character, strength, complexity, and quality of its flavor. As we have gone along we have attempted to point out ways that appear likely to achieve this end. We have tried to summarize as completely as possible the knowledge of the physical treatments tested on spiritous products. We have tried to supplement this summary with discussions of fundamental knowledge of the results one has a right to expect from the various treatments. In nearly every case the data taken together seem to the reviewer to present a much clearer and more hopeful picture than is apparent from the limited view available without such summarizing.

Higher quality products produced by quick-aging appear to this reviewer as eminently possible. The successful treatment, at least for wines, would appear to require a full-flavored nondefective starting material, a carefully controlled and limited oxidative or peroxidative treatment, a controlled heat treatment, the addition of flavors of external origin, and appropriate final processing to retain and make stable the quality built in by these treatments. Before a specific series of procedures can be suggested in more detail, more experimental study in needed. If these experiments build on the information available and are planned to include a proper number of tests over the range of typical products and are carefully evaluated, quick-aging processes appear quite possible. 


\section{ACKNOWLEDGMENT}

Aid from funds supplied by the Wine Advisory Board of California, which has partially supported this study, is gratefully acknowledged. Professors H. W. Berg, J. F. Guymon, and J. L. Ingraham are thanked for their constructive criticism of the manuscript.

\section{LITERATURE CITED*}

AKahoshi, R.

1951. Short-time aging of alcoholic beverage. Japanese Patent 4,098, July 27; C. A. $47: 2428$ d.

Alexander, P., and D. Rosen

1960. Formation of activated hydrogen peroxide by irradiation of water with a-rays. Nature 188:574-75.

Allen, G. W. J.

1909. Beer. British Patent 11,277, May 12; C. A. 4:1345.

Allen, M. J.

1958. Organic Electrode Processes. Chapman Hall Ltd., London, 174 p.

A merine, M. A.

1938. Aging of California wines. Wine Review 6 (5):10-12.

1948. Hydroxymethylfurfural in California wines. Food Research 13:264-69.

1950. The response of wine to aging. Wines \& Vines $31(3): 19-22 ;(4): 71-74 ;(5)$ : $28-31$.

Amerine, M. A., and W. V. Cruess

1960. The technology of wine making. Avi Publishing Co., Westport, Conn. 709 p.

AMERINe, M. A., and M. A. Jostyn

1951. Table wines. The technology of their production in California. University of California Press, Berkeley and Los Angeles. $397 \mathrm{p}$.

Amerine, M. A., and C. S. Ough

1957. Controlled fermentations. III. Am. J. Enol. 8:18-30.

ANONYMous

1937. Solarized wine gains. Wine Review $5(9): 26$.

1956. Supersonic vibrations used to clear wine. Wines \& Vines $37(4): 20$.

1959. Ensaios sobre a influência da cor do vidro das garrafas no envelhecimento do vinho do Porto. Cadernos Mens. estatist. infor. inst. vinho Porto 233:244-47.

1960. De Stoutz actinator-Société Actini-France. Inds. aliment. agr. (Paris) 77:211.

ANQUEZ, M.

1950. L'Emploi du froíd en vinification. Bull. Off. Internatl. Vin 23 (231) :43-55.

ARroyo, $R$.

1939. Natural rum aroma. Univ. Puerto Rico Agr. Exp. Sta., Ann. Rept. 1938-9:42-4; C. A. 35:1177.

1940. The problem of the ripening of crude rum. Rev. agr., ind. y com. Puerto Rico 32: 588-91; C. A. $35: 1578$.

Aso, K., T. Nakayama, and A. Sato

1956. Utilization of grape. V. The color change of Coneord grape juice by various treatments and pasteurization. J. Fermentation Technol. (Japan) 34:37-41.

Astruc, $\mathrm{H}$. VI. Color change of Concord grape juice during storage. Ibid. 127-33.

1910. Les applications du froid artificiel en viticulture et oenologie. Progrès Agricole et Viticole 54:221-34.

Atlas-Werke AKt.-Ges.

1952. Beschallung von Flüssigkeiten, besonders zur Alterung alkoholischer Getränke. German Patent 830,039, Jan. 31; Chem. Zentr. 1952:5500.

* Following the citation of the original source, secondary sources esp. Chemical Abstracts (C. A.) are listed where it was not possible to consult the original. 
Ausloos, $\mathbf{P}$.

1958 $a$. The effect of solvents on the liquid phase photolysis of alkyl esters. J. Am. Chem. Soc. 80:1310-13.

1958b. The photolysis of alkyl esters. Can. J. Chem. 36:383-92.

Austin, F. L., and C. S. BorufF

1960. Concentration of congeners of grain spirits and their analysis by gas chromatog. raphy. J. Assoc. Offic. Agr. Chemists 43:675-79.

Bachmann, J. A., and R. Wilkins

1937. Accelerating the artificial aging of raw fermented and distilled alcoholic bever. ages. U. S. Patent 2,086, 891, July 13.

BAKH, N. A., and Yu. I. Sorokin

1955. Oxidation of organic compounds by molecular oxygen under the action of ionizing radiations. III. Oxidative radiolysis of ethyl alcohol. Sbornik Rabot Radiatsionnoi Khim., Akad. Nauk S.S.S.R. 163-74; C. A. 50:4649c.

BARRoN, E. S. G.

1954. The role of free radicals and oxygen in reactions produced by ionizing radiations. Radiation Research 1:109-24.

BECKER, J.

1929. Einige neuere elektrochemische Verfahren. Chem. Fabrik, 49-51.

Bedoukian, P. Z.

1952. Aspects of aging in perfumes. Am. Perfumer Essent. Oil Rev. 60:263-66.

Bellstedt, F. H.

1961. Production and maturation of hrandy. Wine, Spirit \& Malt 30(1):16-18.

BERG, H. W.

$1953 a$. Varietal susceptibility of white wines to browning.

I. Ultraviolet absorption of wines. Food Research 18:399-406.

$1953 b$. II. Accelerated storage tests. Ibid. 407-10.

Berg, H. W., and G. L. MARSH

1956. Effects of heat-treatment of musts on the color characterisites of red wine. Food Technol. 10:4-9.

BERgMANN, L.

1954. Der Ultraschall. 6th Ed. 1114 p. S. Hirzel Verlag, Stuttgart.

BERIDZE, G. I.

1956. Novyi sposob prigotovleniya belogo kakhetinskogo vina. Vinodelie i Vinogradarstvo S.S.S.R. 16(1):11-16.

Beridze, G. I., and M. V. KURDGELASHVILI

1956. Vliyanie ionizirovannykh gamma-luceĭ na kachestvo vina. Vinodelie i Vinogradarstvo S.S.S.R. 16(7) : 8-13.

1957. Ispravlenie bol'nykh vin radioktivnym kobal'tom. Vinodelie i Vinogradarstvo S.S.S.R. $17(5): 4-7$.

Beridze, G. I., M. V. Kurdgelashvili, and M. G. Sirbiladze

1958. Change in the amino acid composition of grape wines in the presence of cobalt-60. Novye Fiz. Metody Obrabotki Pishchev. Produktov, Sbornik 2:68-70; C. A. $55: 5860 \mathrm{~d}$.

Berti, L. A.

1936. Rapid ageing of sweet wine. Wine Review 4(2):10-12, 24.

Binder, G., and A. Vincze

1957. Radioöxidation of irradiated sugars in dilute air-saturated water solutions. Magyar Tudományos Akad. Központi Fis. Kutató Intézetének Közleményei 5: 364-78; C. A. $53: 21036 i$.

BLÁHA, J.

1955. Umělé stárnutí vín revových. Kvasný Průmysl 1:31-34.

BLOом, J. E.

1915. Process and apparatus for preparing beverages, and products produced thereby.

U. S. Patent 1,162, 212, Nov. 30 .

Bogdanovskil, G. A., and A. I. Shlygin

1957. The mechanism of the electrolytic oxidation of alcohols and aldehydes on platinum. The mechanism of the electrolytic ethanol oxidation. Zhur. Fiz. Khim. 31:2428-34; C. A. 52:8794e. 
Bogert, M. T., and D. Davinson

1930. Researches on aldehydes. Am. Perfumer 24:587-88; II. Comparison of rates of oxidation of several aldehydes. Ibid. 667-68; C. A. 24:1932.

Bokuchava, M. A., and N. I. Skobeleva

1957. The role and significance of aldehydes in the transformation of tannin substances at high temperatures. Biokhimiya 22:1004-07; Biochemistry (USSR) 22:952.

Bokuchava, M. A., G. A. Soboleva, and A. M. Knyazeva

1958. Transformation of tea-leaf catechins at high temperatures. Biokhimiya 23:2668; Biochemistry (USSR) $23: 249-51$.

Bolland, J. L., and H. R. CoOPER

1953. Photosensitized oxidation of alcohols. Nature 172:413-14.

1954. The photosensitized oxidation of ethanol. Proc. Roy. Soc. (London) A225:405-26.

BonIs, A., and MOROY

1948. Le vieillissement artificiel des eaux de vie. Ann. fals. fraud. 41:380-83.

Bowen, E. J.

1946. The chemical aspects of light. 2 d Ed., University Press, Oxford. 300 p.

Brabender Elektromaschinen G.M.B.H.

1928. Verfahren zur künstlichen Alterung und Geschmacksverbesserung von Spirituosen und anderen alkoholhaltigen Getränken. German Patent 500,708 Feb. 21; C. A. 24:4894.

BRAND, J.

1908. Zur Prüfung des Bierflaschenglases auf seine Schutzwirkung gegenüber dem Einflusse des Lichtes. Z. ges. Brauw. 31:333-35.

BRASCH, A.

1950. Electronic aging of alcoholic beverages. U. S. Patent 2,498,735, Feb. 28.

Braude, E. A.

1945. Ultra-violet light absorption and the structure of organic compounds. Ann. Repts. Progress Chem. (Chem. Soc. London) 42:105-30.

Brenner, M. W., G. J. Schapiro, and J. L. OWAdes

1958. Total sulfhydryl content of beer. II. Changes during brewing. Proc. Am. Soc. Brewing Chemists 104-11; J. Inst. Brewing 65:70 (1959).

Brown, E. M.

1937. Brandy improvement after distillation. Wine Review 5(6):15-16.

Brown, E. M., and V. DE F. Henriques

1935. Vinification in California wineries. Ind. Eng. Chem. 27:1235-40.

Browne, F. L., and H. C. Simonson

1957. The penetration of light into wood. Forest Products J. 7:308-14; C. A. 52:2399f.

BRUSILOVSKIǏ, S. A.

1959a. Usovershenstvovaie metoda nepreryvnǒ shampanizatsii. Vinodelie i Vinogradarstvo S.S.S.R. $19(3): 12-26$.

1959b. Avtomatizatsiya kontrolya i regulirovaniya protsessov nepreryvnǒ shampanizatsii vina. Vinodelie i Vinogradarstvo S.S.S.R. 19(5):1-6.

Bugard, P.

1948. Vieillissement du vin et eau-de-vie. French Patent 964,295.

BURMEISTER, $\mathrm{H}$.

1952. Der Einfluss von Ultraschall auf die Reifung von Spirituosen. Aether. Ole., Reichstoffe, Parf. $2(3): 60-61$.

Burton, M.

1952. Elementary chemical processes in radiobiological reactions. Symposium on Radiobiol., Oberlin Coll. 1950:117-38; C. A. 47:2785g.

BUrton, M., J. S. Kirby-Smith, and J. L. MAGEE

1960. Comparative effects of radiation. John Wiley and Sons, New York, $426 \mathrm{p}$.

Calvert, J. G.

1959. Problems in the determination of rate constants from photochemical experiments. Chem. Revs. 59:569-81.

Canals, E., and A. Médaille

1932. Radio-activité des mouts et des vins. J. pharm. chim. 16:62-67. 
CANTIENi, R.

1936. Photochemische Peroxyd-Bildung. I. Oxydation des Methylalkohols mittels molekularen Sauerstoffs durch ultraviolettes Licht. Ber. 69B:1101-06; II. Oxydation von Äthyl-, Propl-, and Amylalkohol mittels molekularen Sauerstoffs durch ultraviolettes Licht. Photochemisches Bildung von Peralkoholen. Ibid. 1386-94.

Carles, J., and M. Lamazou-Betbeder

1959. Le problème du-vieillissement des vins. Bull. soc. hist. nat. Toulouse 94:452-61. Carles, $\mathrm{P}$.

1913. The degreening of wines by cold. Ann. chim. anal. 17:447-50; C. A. $7: 1576$.

CARPenter, D. C.

1933. Effect of light on bottled juices. Apple and kraut juices. Ind. Eng. Chem. 25: 932-4.

Carrell, W. A.

1936. Accelerated aging of distilled liquors. U. S. Patent 2,044,898 June 23.

Castaing, M.

1951. Beverage treatment. French Patent 985,408 July 18; C. A. $49: 11238$ a.

Ceresa, G.

1960. Value of the test for $\omega$-hydroxymethylfurfural for the identification of concentrated musts in fortified wines. Ann. Sper. Agrar. (Rome) 14(Suppl. 1) : 121-24; C. A. 54:15825d.

Chambers, L. A.

1938. Sound waves a new tool for food manufacturers. Food Industries 10:133-35.

Chambers, L. A., and E. W. Smith

1937. Aging alcoholic liquors. U. S. Patent 2,088,585, Aug. 3.

1940. Aging alcoholic liquors. U. S. Patent 2,196,193, Apr. 9.

Chatelanat, E.

1948. Preparation and rapid aging of alcoholic liquids, such as liquors and perfumes. Italian Patent 441,520 Nov. 5; C. A. 44:5064a.

Chipault, J. R., O. S. Privett, G. R. Mizuno, E. C. Nickell, and W. O. Lundberg

1957. Effect of ionizing radiations on fatty-acid esters. Ind. Eng. Chem. 49:1713-20.

Clark, W. M.

1960. Oxidation-reduction potentials of organic systems. Williams \& Wilkins Co., Baltimore, $584 \mathrm{p}$.

DE CleRcK, J.

1934. $\mathrm{rH}$ and its application in brewing. J. Inst. Brewing 40:407-19.

Collinson, E., and A. J. Swallow

1955. The radiation chemistry of organic substances. Chem. Rev. 56:471-68.

CONRAD, $\mathrm{H}$.

1950. Künstliche Alterung des Branntweins. Die Alkohol-Industrie 63(5):85-87.

Cornelius, C.

1951. Brown or green bottles of wine? Sprechsaal 84:132; C. A. 45:5359h.

Cousseilhat, M.

1867. Procédé de Cousseilhat, servant à vieillir les liquides alcoholiques. French Patent 76,321, May 21.

Crampton, C. A., and L. M. Tolman

1908. A study of the changes taking place in whiskey stored in wood. J. Am. Chem. Soc. $30: 98-136$.

CrefF, R.

1957. Oxidations et réductions en ciderie. Ann. inst. natl. recherche agron. Sér. E. 6: $461-500$.

Curtel, G.

1903. La vigne et le vin chez les romains. C, Naud, ed., Bibliothèque générale des Sciences, Paris, $182 \mathrm{p}$.

Curtze, A., and H. Burmeister

1950. Schnellreifung von Spirituosen durch Ultraschall. Die Alkohol-Industrie 63(4): 1267-127; quoted by Bergmann, 1954.

Cuvier, G., and A. M. Nodon

1930. Microradioactivity of wine. Detection and determination. Interest in nutrition and therapeutics. Chimie \& industrie 23:1511; C. A. 24:4580. 
DAINTON, F. S.

1952. Radiation chemistry. Discussions Faraday Soc. 12:9-318.

DARRAH, W. A.

1938. Process of oxidation. U. S. Patent 2,108,030, Feb. 8.

Dascalov, L. I.

1957. Prouchvane v'rkhu povishenie tsveta na chervenite vina. Nauch. Trudove, Nauch. Issledovatel. Teknol. Inst. Vin i Pivov. Prom. 1:161-208.

DAy, E. A., D. A. Forss, and S. PatTon

1957. Flavor and odor defects of gamma-irradiated skimmilk. I. Preliminary observations and role of volatile carbonyl compounds. J. Dairy Sci. 40:922-31.

DAY, M. J., and G. STEIN

1957. The action of ionizing radiations on aqueous solutions of methylene blue. Radiation Research 6:666-79.

DEIBNER, L.

1956. Potentiel d'oxydo-réduction et ses relations avec les proprietés organoleptiques des vins doux naturels. Ann. inst. natl. recherche agron. Sér. E 5:399-415.

1957a. Factors regulating the maturation and aging of alcoholic beverages. Am. J. Enol. 8:94-104.

1957b. Effet de différents traitements sur le potentiel oxydoréducteur des vins au cours de leur conservation. Ann. inst. natl. recherche agron., Sér. E, 6:363-73.

DEIBNER, L., and P. BÉnARD

1956a. Recherches sur la maturation des vins doux naturels. I. Influence du traitement thermique prolongé a l'abri de l'air. Ann. natl. inst. recherche agron. Sér. E, 5: $357-76$.

1956b. II. Essai de catalyseurs métalliques. Ibid. 377-97.

Dekov, L., and D. Tsakov

1957. Termicheskaya obrabotka kon'yachnogo spirta. Sadovodstvo, Vinogradarstvo i Vinodelie Moldavii 12(1):45-47.

Del Duca, M., E. Yeager, M. O. Davies, and F. Hovorka

1958. Isotopic techniques in the study of the sonochemical formation of hydrogen peroxide. J. Acoust. Soc. Am. 30:301-07.

Deleuze, J.

1931. Les applications du froid en oenologie. Rev. vit. 74:277-81.

Delyannis, A. A.

1938. Vieillissement artificiel des spiritueux. Chim. Chronica (Greece) : 319-20; Chimie $\&$ industrie 43:605. 1940.

Desrosier, N. W., and H. M. Rosenstock

1960. Radiation technology in food, agriculture and biology. Avi Publishing Co., Westport, Conn., 401 p.

Dolin, P. I.

1955. Influence of dissolved oxygen on the radiolysis of water by the action of X-rays. Sbornik Rabot Radiatsionnoĭ Khim., Akad. Nauk S.S.S.R., 7-23; C. A. 50:9160d.

Douzou, $\mathrm{P}$.

1958. Activation of oxygen and oxidizing power of ascorbic acid. Actions chim. et biol. radiations $4: 86-95$; C. A. $53: 5883 \mathrm{~h}$.

Drake, M. P., B. J. Kroll, and F. J. Pilgrim

1960. Radiation flavor-fact or fancy. Science 132:1394-95.

DREW, L. L.

1935. Apparatus for aging alcoholic spirits. U. S. Patent 2,017,235, Oct. 15.

DubaquiÉ, J.

1929. Le chauffage de la vendange. Ann. fals. fraud. 22:211-13.

EGGER, W.

1955. Ultrasonic treatment of albumin-containing liquids in beer manufacture. Swiss Patent 305,101, Apr. 16; C. A. 51:2230i.

EISENEGGER, F.

1951. Veredeln von alkoholischen Flüssigkeiten. Swiss Patent 276,400, July 15; C. A. 47:820a.

1954. Apparatus for ultrasonic purification of alcohol-containing liquids. Swiss Patent 298,027, June 16 ; C. A. 51:4069h. 
EsCRITT, L. B.

1960. Wine and the thermometer. Wine Magazine (12):2-4.

Espinosa, N. A.

1959. Mesures et méthodes pour empêcher la fabrication de "vins" de sucre ou l'addition de telles hoissons aux vins naturels. Bull. Off. Internatl. Vin $32(344): 50-65$.

FAIx, J. M., and F. J). SNELL.

1934. Artificial aging of spirits. Ind. Eng. Chem., News Ed. 12:120-21.

Fakbeindesthie, I. (

1925. Maturing aleoholie beverages and perfumes. British Patent 259,598, Oct. 12.

FExIE, P.

1928. L'ozone en oenologie. Prog. agr. vit. 90:19-22.

Flanzy, M., A. Ot'kine, and Ch. Polx

1953. Recherches sur la coneentration des vins par le froill. Inds. agr. aliment. (Paris) $70: 759-61$.

ForkR, A. G.

1933. Apparatus for agring alcoholic liquors. Russian Patent 32,468, Oct. 31; C. A. 28:3521.

FreỸD, A. S., YU. M. MALINSKII, and V. L. KakPOY

1959. The effect of radiation on ehemical stability of wood. Gidroliz. i Lesokhim. Prom. $12(4): 4-7 ;$ C. A. $53: 2: 2927 \mathrm{f}$.

Friedeman, T. F., et al.

1956. Symposium on nutritional and toxicological stulles on irradiated foods. Federation Proc. 15:90:3-37.

Friedianider, (x., and J. W. Keximfily

1955. Nuclear and radiochemistry. John Wiley and Sons, Ine., New York, $468 \mathrm{p}$.

F'KU⿴Ka, J., T. KitSUTAKA, and K. Higashi

1949. Dielectric extraction method. Jipan. J. Platm. \& (hom. $21: 224-7$; ( A A. 45: $2724 \mathrm{i}$.

GARRISON, W. MI., and G. K. Rol.t.EF'son

1952. Radiation chemistry of aqueous solutions containing both ferrous ion and carbon dioxide. Discussions Faraday Soc. 12:15:5-.61.

(iAY, I.

1951. The treatment of wines, fruit juices, and aleohols hy refrigeration. Rev. gén. froid $31: 1263-80$; C. A. $52: 8449 \mathrm{~g}$.

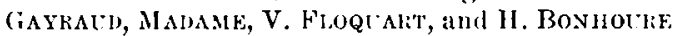

1949. Artifieial maturing of alcohol. French Patent 94(6,300, Nay 30; C. A. 45:35i54e.

GEORGEAKOPOTILOS

1960. Stabilisation des vins doux par tous procédés physiques, chimiques et hiologiques. Rapports nationaux, (irèce. Bull. Off. internatl. vin $33(35 i):(65-74$.

Gerasimov, גi. A.

1955. Rezhimy teplovoi obrahotki vin. Vinodelie i Vinogradarstvo S.S.S.R. 15(2):8-10.

1958. La stabilisation des vins ( rapport russe). Bull. Off. internatl. vin $31(328): 41-52$.

(AERAsimov, M. A., and N. OCHRFMEN ko

1929. Waterialy po ryderzhke vin pod vliyaniem solneehnyk lucher. Zap. Gos. Nikitskogo hotan. sada 12(1); Deibner \& Bénarl 1956.

Gerasimor, M. A., and T. K. Politora Sorzenko

1946. Fffect of wine components on its freezing point. Vinodelie i Vinogradarstro S.S.S.R. $6(9): 6-10 ;($ ' A. $41: 4272$ ff.

1950. Termicheskaya obrahotka krepkikh desertnyk vin. Biochim. Vinordeliya, Akad. Nauk S.S.S.R. Shornik 3:14i-70.

GHORMIEY, J. A., and C. J. HoChaNaDei,

1954. 'The yields of hydrogen and hydrogen peroxide in the irradiation of oxygen satu. rated water with eobalt gamma-rays. J. Am. Chem. Soc. 76:3351-52.

GI.ASSTUNE, S.

1946. Texthook of physical 'hemistry. 2d Ed., 1). Van Nostrand Co., New York, 1320 p.

GoNzál,zz Toriño, H., and R. TUNet Sata

1939. Envejecimiento de vinos bajo la influeneia de la aecion solar. Rer. facultad agron., Cuiv. rep. (Monterideo) 18:89-114. 
GoRE, V.

1933. Formation of sugars in mixtures of tartaric acid and aldehydes in tropical sunlight. J. Phys. Chem. 37:745-49.

Gray, P. P., I. Stone, and H. Rothchild

1941. The action of sunlight on beer. Wallerstein Labs. Commun. 4:29-40.

GuENTHER, E.

1957. Recent progress in the perfume industry. Inds. parfum. et cosmét. 12:317-20; C. A. 54:15846f.

GuYmon, J. F.

1955. Effect of brandy upon the quality and changes in composition of California-type sherry during baking. Am. J. Enol.6:36-41.

HANAK, A.

1930. Zur Kenntnis der Rolle des Eisens in Wein und anderen Obsterzeugnissen. Z. Untersuch. Lebensm. 60:291-97.

HANDELS- UND INDUSTRIE-GESELLSCHAFT M.B.H.

1907. Vorrichtung zum Veredeln von Flüssigkeiten, insbesondere alkoholischen Getränken, mittels Elektrizität und Sauerstoffs. German Patent 203,281, Sept. 1; C. A. $3: 686$.

Hart, E. J., S. GoRdon, and D. A. Hutchison

1955. Formation d'eau oxygenée par action des rayons gamma sur des solutions aqueuses $\mathrm{O}^{16}, \mathrm{O}^{18}-\mathrm{H}_{2} \mathrm{O}^{16}$. J. chim. phys. $52: 570-77$.

Harwood, J. J., H. H. Hausner, J. G. Morse, and W. G. Rauch

1958. Effects of radiation of materials. Reinhold, New York, 355p.

HEGE, R.

1954. Weinklärung und -alterung durch Kälte. Kälte (Hamburg) 2:314-7.

Heidt, L. J., R. S. Livingston, E. Rabinowitch, and F. Daniels

1957. Photochemistry in the liquid and solid states. John Wiley and sons, New York. $174 \mathrm{p}$.

Heitz, J. E., E. B. Roessler, M. A. Amerine, and G. A. Baker

1951. A study of certain factors influencing the composition of California-type sherry during baking. Food Research 16:192-200.

Henderson, I. H. S., E. G. Lovering, R. L. Haines, and E. J. Casey

1959. On the equivalent redox potential of aqueous solutions under ionizing radiation. Can. J. Chem. 37:164-72.

Hennig, K.

1951. Die Ultraschallbehandlung der Traubenweine. Deut. Wein-Ztg. 87:99-101.

HENRI, V.

1910. Artificial aging or maturing wines. British Patent 13,129, May 30 ; C. A. 5:3120.

Henri, V., A. Helbronner, and M. von Recklinghausen

1915. Process for artificially maturing or aging wines, spirits, or other potable liquor. U. S. Patent 1,130,400, Mar. 2.

Henry, C.

1912. Aging wines, etc., electrically. French Patent 459,141, Aug. 27 ; C. A. 8:3344.

1914. Treating beverages, etc., electrically. British Patent 17,400, May 7; C. A. 11:15.

HENRY, G. E.

1954. Ultrasonies. Sei. American 190:55-63.

Herstein, K. M., and M. B. Jacobs

1948. Chemistry and technology of wines and liquors. 2d Ed., D. Van Nostrand Co., New York, 436 p.

HirschmanN, W. A.

1907. Verfahren zum Altern alkoholischer Flüssigkeiten mittels hochgespannter Induktionsströme. German Patent 199,26̣5, Mar. 8; Chem. Zentr. 1908II:113.

Hurono, K., E. Katsumé, and E. Fujita

1928. Synthetic saké. Bull. Research Inst. Fermentation (Japan) 102:1-48; C. A. 24: 1180.

INGRAM, D. J. E.

1958. Free radicals as studied by electron spin resonance. Butterworth's Scientific Publications, London, $274 \mathrm{p}$. 
JACOBS, M. B.

1947a. Rapid aging of whisky. Am. Perfumer 49:157-58.

$1947 b$. Oxidative aging of whisky. Am. Perfumer $49: 263-5$.

1951. Chemistry and technology of food products. 3, 2d Ed., Interscience Publishers, N. Y., p. 2382-2470.

JACOBSSON, B., and B. HögBERG

1947. The sensitivity of beer to light. Protection afforded by glass bottles. Wallerstein Labs. Commun. 10:5-16.

Janicki, J., E. Sobkowska, J. Antrowiak, J. Pawlowski, and G. Mazur

1958. Accelerated aging of alcoholic beverages. Przemysl Spożywczy 12:184-8; C. A. $53: 14410 \mathrm{c}$.

JARRAUD, A.

1910a. Aging and improving wines, spirits, and liquors. German Patent 239,300, Aug. 13; C.A. $6: 2134$.

1910b. (Found as Garraud, A. but believed in error) Improving or artificially aging wines, spirits, and liquors. British Patent 19,024, Aug. 12; C. A. 5:2523.

1920. Ageing and maturing beverages. British Patent 141,687, Mar. 31; C. A. 14:2677.

1924. Vieilliesement des vins. Electrolyse appliquée aux vins et aux eaux-de-vie. Chimie \& industrie Special No., 613-5. May.

Jaulmes, P., and G. HAMELLE

1954. Composition et emploi des vins concentrés par le froid à fort degré alcoolique. Ann. inst. natl. recherche agron., Sér. E, 3:241-58.

JEAN, F. P. L., and D. M. F. LiZÉE

1935. Aging alcoholic beverages. French Patent 779,311, Apr. 2; British Patent 448,881, June 17, 1936; C. A. $29: 5594$.

JENARD, H.

1960. Volatile constituents of beer. Brewers Dig. 35(4):58-60; C. A. 55:897a.

Joslyn, M. A.

1934. The possibilities and limitations of the artificial aging of wine. Fruit Products J. $13(7): 208-10 ;(8): 241-44$.

1935. Preliminary observations on the mellowing and stabilization of wine. Fruit Products J. 15:10-12, 24.

1936. The process of aging or maturing wines. Food Ind. 8, 444-45, 449.

1938. Electrolytic production of rancio flavor in sherries. Ind. Eng. Chem. 30:568-77.

Joslyn, M. A., and M. A. A MERINe

1941a. Commercial production of dessert wines. Bull. 651. University of California, College of Agriculture, Berkeley. $186 \mathrm{p}$.

1941b. Commercial production of brandies. Bull. 652. University of California, College of Agriculture, Berkeley. $80 \mathrm{p}$.

Joslyn, M. A., and G. L. Marsh

1935. Effect of cold and freezing storage on wine composition. Ind. Eng. Chem. 27: $33-35$.

KAMEN, M. D.

1948. Radioactive tracers in biology. Academic Press Inc., New York, 281 p.

KAUFMAN, S., and W. F. LiBBY

1954. The natural distribution of tritium. Phys. Rev. 93:1337-44.

KAWASAKI, S., et al.

1954. Ripening of alcoholic beverages. Japanese Patent 6197, Sept. 27 ; C. A. 50:2118e.

KAZAMA, Y.

1954. Studies on the storage of saké. On the change of some components by light and the remaining enzymes. J. Soc. Brewing Japan 49:69-72.

Kazumov, N. B., M. B. Alaverdyan, and R. N. Akhnazaryan

1956. Heat-treatment of wine stocks of various composition. Izvest. Akad. Nauk Armyan S.S.R., Biol. i Sel'skokhoz. Nauki 9(9):103-07; C. A. $51: 10834$ f.

KeAN, C. E., and G. L. Marsh

1956a. Investigation of copper complexes causing cloudiness in wines. I. Chemical composition. Food Research 21:441-47.

1956b. II. Bentonite treatment of wines. Food Technol. 10:355-59. 
KenOKH, M. A., and E. M. Lapinskaya

1958. Action of cobalt-60 gamma-radiation upon albumins and amino acids. Trudy Pervogo Vsesoyuz. Soveshchaniya po Radiatsion. Khim., Akad. Nauk S.S.S.R., Otdel. Khim. Nauk, Moscow: 1957, 182-7; C. A. 53:12020c.

KIELHÖFER, E.

1956. Reifung kohlensäurereicher Weine. German Patent 940,523, Mar. 22.

KIELHÖFER, E., and G. WÜRDIG

1958. Die Bindung des Sauerstoffs durch schweflige Säure und durch Ascorbinsäure. Weinberg u. Keller 5:644-56.

KiESSKALT, S.

1951. Aging or Maturing of Spirits. German Patent 824,936, Dec. 13; C. A. $49: 1278$ e. KILP, W.

1951. Utraschall-Behandlung von Korndestillaten. Die Alkohol-Ind. 64:383-84.

Kipiani, R. YA., and N. N. Nutsubidze

1956. Gamma-luchevaya maderizatsiya vin. Vinodelie i Vinogradarstvo S.S.S.R.16(6): $16-17$.

Косн, J.

1950. Investigations with ultrasonic waves on unfermented grape juice and berry wines. I. Ind. Obst- u. Gemüseverwert. 35:3-7.

1951. II. Ind. Obst- u. Gemüseverwert. 36:402-06; C. A. 48:2283i.

1955. Probleme der modernen Kellertechnik in der Weingrosskellerei. Weinberg $u$. Keller 2:393-406.

1956. Kellertechuische Erfahrungen mit der neuzeitlichen Most- und Weinbehandlung. Weinberg u. Keller 3:49-59.

1957. Die Eiweissstoffe des Weines und ihre veränderungen bei verschiedenen kellertechnischen Behandlungsmethoden. Weinberg u. Keller 4:521-26.

Koch, J., and G. BRETthaUeR

1950-51. Der Einfluss von Ultraschallwellen auf das Aroma verschiedener Weine. Wein u. Rebe, Jahrbuch der Weinbauwissenschaft und önologie. Deutsche Wein-Zeitung, Kirchleim and Co., Mainz, p. 85-98.

1957a. Zur Kenntnis der Eiweissstoffe des Weines. I. Chemische Zusammensetzung des Wärmetrubes kurzzeiterhitzter Weissweine und seine Beziehung zur Eiweisstrübung und zum Weineiweiss. Z. Lebensm.- Untersuch. u. -Forsch. 106:272-80.

1957b. II. Einfluss der Mosterhitzung auf die Eiweissstabilität der Weissweine. Z. Lebensm.- Untersuch. u. -Forsch. 106:361-67.

KoCH, J., and E. GEISs

1954. Der Einfluss verschiedener kellertechnischer Massnahmen auf den Ausbau der Weissweine. I. Die Unterkühlung der Weine. Z. Lebensm.- Untersuch. u. -Forsch. $99: 188-96$.

1955. Der Einfluss verschiedener kellertechnischer Massnahmen auf den Ausbau der Weissweine. II. Die Kurzzeiterhitzung der Weine. Z. Lebensm.- Untersuch. u. -Forsch. 100:15-24.

KoIzumi, M., and H. ОватA

1958. The formation of stable semiquinone of methylene blue by the irradiation of visible light and $\gamma$-rays. Bull. Chem. Soc. Japan 31:823-27.

Kolesnikov, P. A.

1958. Riboflavin-sensitized photo-oxidation of phenols. Biokhimiya 23:434-39; Biochemistry (trans) 23:404-09.

Komatsu, S., S. Otsuka, S. Tanaka, and T. Suzuki

1938. Biochemical studies on beer. J. Soc. Chem. Ind., Japan 41: Suppl. binding 82-3; C. A. $32: 5576$.

KONLECHER, H., and H. HAUs HOFER

1958. Versuche zur Herstellung von Rotwein mittels Heissfermentierung der Maische. Mitt. Klosterneuberg, Ser. A, Rebe u. Wein 8:169-74.

Kraft, C. W.

1950. Treatment of alcoholic liquor. U. S. Patent 2,500,951, Mar. 21.

KRAYBILL, H. F.

1959. Nutritional and biochemical aspects of foods preserved by ionizing radiation. J. Home Econ. 51:695-700. 
Kraybill, H. F., and D. C. Brunton

1960. Commercialization technology and economics in radiation processing. J. Agr. Food Chem. 8:349-56.

KuPRIANOFF, J.

1956. Les radiations ionisantes et leurs application à la conservation des aliments. Inds. aliment. et agr. (Paris) 73:645-55.

Kuroiwa, Y., and N. Hashimoto

1961. Composition of sunstruck flavor-substance of beer. Agr. Biol. Chem. (Tokyo) 25:257-58.

Kuroiwa, Y., H. Hashimoto, and K. Nakagawa

1960. Quantitative evaluation of sunstruck flavor of beer. Rept. Research Labs. Kirin Brewery 3:17-23.

Kushida, T.

1960. Effect of thermal treatment of musts on the quality of wines. I. Experimental fermentation of the must treated with high temperature. Yamanashi Daigaku Hakkô Kenkyûsho Kenkyû Hôkoku 7:27-31.

Kushida, T., and C. Maruyama

1960a. Effect of thermal treatment of musts on the quality of wines. II. Production of white wines from musts baked at various temperatures. Yamanashi Daigaku Hakkô Kenkyûsho Kenkyû Hôkoku 7:33-36.

$1960 b$. Experimental production of a sweet table wine of the Sauterne type. Yamanashi Daigaku Hakkô Kenkyûsho Kenkyû Hôkuku 7:47-51.

KuTtelvašer, Z.

1955. Použití tepla ve vinařské technologii. Kvasný Průmysl 1:201-02.

LACHMAN, A.

1916. Process for aging wine. U. S. Patent 1,204,669, Nov. 14.

LA Grassa, F.

1926. La refrigerazione del vino Marsala. Notiz. chim.-ind. 1:315-16.

1927. Sull' invecchiamento artificiale del Marsala a mezzo del freddo. Notiz. chim.-ind. $2: 131-32$.

LAMORT, C.

1958. Chromatographie, spectra d'adsorption et dégradation d'anthocyanines de fruits. Rev. fermentations et inds. aliment. 13:153-57.

LAPINskaya, E. M., and M. A. KhenoKH

1953. Oxidation of alcohols under the influence of ultrasonic vibrations. Zhur. Obshchei Khim. $23: 1464-68$; C. A. $48: 1815$ g.

LAUG, E. P.

1957. Exposure of foods and foodstuffs to nuclear explosions. J. Assoc. Offic. Agr. Chemists $40: 544-61$.

LEBBE, A.

1911. Fermentation of liquids and aging fermented liquids. British Patent 12,723, May 26 ; C. A. 6:3507.

Le Clerc, A. M., J. Mondy, P. Douzou, and S. Lissitzky

1959. Mise en evidence par oxydation photochemique ou enzymatique du radical libre du catechol. Biochim. et Biophys. Acta 32:499-504.

Le Corvaisier, $\mathrm{H}$.

1959. Composition of the nonbiological precipitates in beer. Brasserie 148:10-12; C. A. 53:10658i.

Leuschner, G., and K. PFordte

1958. Intermolekulare Dehydrierungen durch UV-Licht. Photoreaktionen der Alkohole. Ann. 619:1-9.

Levine, M.

1942. Factors affecting taste and flavor of beverages. Can. Beverage Rev. 13(5):9; C. A. 38:5321.

LHERME, G., and G. DÉBordes

1950. Quelques résultats sur l'electrolyse des vins. Bull. soc. chim. France, 1061-62.

Lichev, V.

1956. Accelerated maturation of brandy by ultrasonics. Nauch. Trudove Vissh. Inst. Khranitelna i Vkusova Prom., Plovidiv 3:237-73; C. A. 54:25555c. 
1958. Aldehyde composition of Bulgarian plum brandy. Lozarstvo i Vinarstvo (Sofia) $7(5): 42-46$; C. A. $55: 16904 \mathrm{~g}$.

1959. N'rkhu aldekhidniya s'stav na b'lgarskata slivova rakiya. Nauch. Trudove, Nauch. Issledovatel. Tekhnol. Inst. Vin. i Pivov. Prom. 3:141-53.

Lichev, V., K. Petrova, and E. Georgieva

1958. V'rku termichnata obrabotka na konyachniya spirt. Nauch. Trudove, Nauch. Issledovatel. Tekhnol. Inst. Vin. i Pivov. Prom. 2:173-82.

Liggett, R. W., C. E. Feazel, and J. Y. Ellenberg

1959. Browning reaction initiated by gamma radiation. J. Agr. Food Chem. 7:277-80.

LiNDSTROM, O.

1955. Physico-chemical aspects of chemically active ultrasonic cavitation in aqueous solutions. J. Acoust. Soc. Am. 27:654-71.

LIPIS, B. V.

1957. The temperature of the wine and the velocity of the oxidation-reduction reaction. Sadovodstvo, Vinogradarstvo i Vinodelie Moldavii 12(6):40-41; C. A. 52:7614a.

Lipis, B. V., V. N. Nykandrova, and L. A. Kalguskina

1959. Thermal treatment of ordinary fortified wines. Sadovodstvo, Vinogradarstvo i Vinodelie Moldavii 14(4):48-50; C. A. 54:7059c.

LitTLE, L. F.

1939. Process for the artificial aging of alcoholic liquors. U. S. Patent 2,180,685, Nov. 21.

LOISELEUR, J.

1954. Les synthèses chimiques réalisées par les rayons $\mathrm{X}$ et par d'autres agents physiques peroxydants (rayons ultra-violets et ultra-sons). Ann. inst. Pasteur 86: $262-75$.

LORD INVESTMENT CORP., LTD.

1936-7. Aging wines, spirits, etc. German Patent 638,936, Nov. 25, 1936; German Patent 652,858, Nov. 10, 1937; German Patent 807,371, Jan. 11, 1937; British Patent 468,990, July 16, 1937.

Mack, S. D., J. J. Albrecht, J. H. Litchfield, and M. E. Parker

1959. Studies in the cold sterilization of liquid foods using mercury resonance radiation. II. Apple juice. Food Research 24:383-91.

Mahlman, H. A., and J. W. Boyle

1958. Primary cobalt-60 radiolysis yields in heavy water. J. Am. Chem. Soc. 80:773-74.

Maksimov, G. A.

1955. Artificial aging of alcoholic beverages by ozone and high-frequency current. Trudy Nauch. Sessii, Posvyashchennoř Dostizheniyam i Zadacham Sovet. Biofiziki v Sel'sk. Khoz. Sbornik, 210-12; C. A. 52:19009a.

MaL'tseva, M. A., A. E. Kravets, and I. M. RozhdestvenskiI

1953. Ustanovlenie rozlivozrelosti vina. Vinodelie i Vinogradarstvo S.S.S.R. 13(5): $10-11$.

MALVEZIN, F.

1903. Viellissement des vins et spiritueux. Nouveau traitement des vins ou Pasteuroxyfrigorie. Bernard Tignol, Paris; Feret \& Fils, Bordeaux, 152 p.

Malvezin, P.

1909. Maderization des vins blanes. Bull. assoc. chim. sucr. dist. 27:569-76.

Mancini, J., and N. Di ArChangel

1936. Apparatus for aging whisky or other alcoholic beverages. U. S. Patent 2,040,264, May 12.

MAŇKová, D.

1957. Výskum praktického spracovania hybridov na dezertné vína. Kvasný Průmysl $3: 90$.

MARK, $\mathrm{H}$.

1957. Radiation chemistry and wood. Composite Wood (India) 4:1-8; C. A. 52:720b.

Markham, M. C., M. C. Hannan, R. M. Paternostro, and C. B. Rose

1958. Oxidation of alcohols catalyzed by zinc oxide and light. J. Am. Chem. Soc. 80: 5394-97.

Marsais, P.

1930. Traitement des vins par l'air ozoné. Rev. vit. 73:311-14. 
MARSH, G. L., and J. F. GUYMON

1959. Air conditioning-Refrigerating Data Book. 1(1):10-01 to 10-06, American Society of Refrigerating Engineers, New York.

Masson, C. R., V. Boekelheide, and W. A. Noyes, JR.

1956. Photochemical reactions. Technique of organic chemistry Vol. 2, 2d Ed., Interscience Publishers Inc., N. Y., p. 257-384.

Mathieu, L.

1904. Sur l'oxydation spontanée de l'alcool êthylique. Bull. assoc. chim. sucr. dist. 22: 1283-93.

1913. Variation de la composition des eaux-de-vie suivant le mode de conservation. Bull. assoc. chim. sucr. dist. $29: 772-77$.

MatTiat, O.

1954. The processing possibilities of ultrasonics. J. Acoust. Soc. Am. 26:241-3.

MATTICK, L. R., and W. B. RoBINSON

1960. Changes in the volatile acids during the baking of sherry wine by the Tressler baking process. Am. J. Enol. Viticult. 11:113-16.

Maverhoff, A.

1949. Enologia 335, 406 ; Deibner and Bénard (1956).

MAYER-OBERPLAN, M.

1953. Erfahrungen und Probleme der Wärme- und Kältebehandlung und das Pasteurisieren von Most und Wein. Deut. Wein-Ztg. $89: 432$, 434, 436, 438, 440, 442.

Mayneord, W. V., W. Anderson, H. D. Evans, and D. Rosen

1955. Hydrogen peroxide yields in X-irradiated aqueous solutions. A sensitive method based on hydrazide chemiluminescence. Radiation Research 3:379-92.

MCDONELL, W. R.

1951. Chemical products of the irradiation of aliphatic alcohols with high-energy nuclear particles. U. S. Atomic Energy Comm., Tech. Inform. Service, Oak Ridge, Tenn., UCRL-1378, 125 p.; C. A. 46:831a.

MCDonelL, W. R., and A. S. NewToN

1954. Radiation chemistry of the aliphatic alcohols. J. Am. Chem. Soc. 76:4651-8.

Mechanical Spirit Maturing Syndicate, Ltd.

1890. Système de vieillissement des eaux-de-vie et autres liqueurs. French Patent 207,506, Aug. 8.

Mehlitz, A., and H. Drews

1959. Concentration, occurrence, and origin of hydroxymethylfurfural in grape and MeNDLIK, F. apple juices. Ind. Obst.- u. Gemüseverwert. 44(7):141-45; C. A. 53:19211c.

1938. Einiges über die Einwirkung des Lichtes auf Bier. Wochschr. Brau. 55:393-95.

MEROY, J.

1936. A new method for rapid aging. Wine Review 4(12):16-17.

Merritt, R. W., and A. A. White

1943. Partial pyrolysis of wood. Ind. Eng. Chem. 35:297-301.

Mestre Artigas, C.

1942. Le froid industriel appliqué aux vins. Bull. Off. internat. vin 15(150):53-59.

Meygret, C. A.

1912a. Clarifying and aging wine and must. French Patent 456,495, June 19; C. A. 8: 2216.

1921b. Electric apparatus for aging wines, etc. French Patent Addition 17,467 to 456,495 , Sept. 17 ; C. A. $8: 2595$.

Michael, $\mathrm{S}$.

1931. Über die Einwirkung von ultraviolettem Licht auf einige organische Geruchstoffe. Biochem. Z. 233:470-77.

MIRoIR, V.

1931. La pasteurisation des vins et leur traitement par le froid artificiel. Chimie \& industrie, Special No., 805-08.

Miyagawa, I.

1949. Application of supersonic waves to organic chemical syntheses. J. Soc. Org. Synthetic Chem. (Japan) 7:167-72; C. A. 47:4831e. 
MonTi, E.

1905. Verfahren zur Konzentration von Lösungen, insbesondere von Bier und Wein, durch Gefrierlassen. German Patent 163,101: Cl 6 d, 19 Sept. 1905; addition 164,499: 21 Oct., 1905; Chèm. Zentr. 1905II:1057, 1472.

1906. Process of clarifying, aging, maderizing wines and liquors in a short time. French Patent 358,278 , Oct. 5; C. A. 1:1081.

1914. Process of clarifying, aging, and refining wines, liqueurs, and other vegetable extracts. U. S. Patent 1,108,777, Aug. 25.

Morgan, B. H.

1959. Radiation chemistry of foods-1958. Proc. U. N. Intern. Conf. Peaceful Uses At. Energy, 2d, Geneva, 1958, 27:423-9.

MURDFIELD, R.

1914. Über ein Verfahren zur künstlichen Alterung von Wein. Z. Nahr-Genussm. 27: $236-43$.

Muraki, H., N. ShiJo, K. Otsuka, and R. Mochizuki

1957a. Thermal treatment in the production of a tawny port-type sweet wine. Yamanashi Daigaku Hakkô Kenkyûsho Kenkyû Hôkoku. 4:41-8.

MUraKi, H., N. ShiJo, and S. TADA

$1957 b$. Improvement of the flavor of pomace brandy. Yamanashi Daigaku Hakkô Kenkyûsho Kenkyû Hôkoku 4: 59-67; C. A. 53:9563h.

1960a. Thermal treatment of alcoholic beverages. I. Certain factors influencing the effect of thermal treatment. Yamanashi Daigaku Hakkô Kenkyûsho Kenkyû Hôkoku $7: 53-60$.

Muraki, H., N. ShiJo, M. Wada, and H. Watanabe

$1960 \mathrm{~b}$. IV. Production of a sweet wine by heating fruit juices with the addition of alcohol. Yamanashi Daigaku Hakkô Kenkyûsho Kenkyû Hôkoku 7: 69-72.

Muraki, H., N. Shijo, H. Watanabe, and M. WAdA

1960c. III. Effect of the thermal treatment on various alcoholic beverages. Yamanashi Daigaku Hakkô Kenkyûsho Kenkyû Hôkoku 7: 65-68.

NANitASHVILI, S. T.

1957. Termincheskaya obrabotka Kakhetinskogo vina. Vinodelie i Vinogradarstvo S.S.S.R. 17(1) : 5-7.

NAYLOR, J. R.

1929. Spirits-aging apparatus. U. S. Patent $1,741,727$, Dec. 31 .

NEDELCHEV, $\mathrm{N}$. I.

1959. Porouchvane v'rkhu p'rvichnata tekhnologiya desertnite vina ot sorta "shiroka melnishka loza". Nauch. Trudove, Nauch. Issledovatel. Tekhnol. Inst. Vin. i Pivov. Prom. 3:5-37.

Negui, A., P. COLOMBIER, and I. BONNEL

1934. Vins. French Patent 760,190, Feb. 17; C. A. $28: 3522$.

NikandRova, V. N.

1957. Diffusion of tannin and coloring substances during processing of grapes. Sadovodstvo, Vinogradarstvo i Vinodelie Moldavii 12(2):47-49; C. A. 51:18461e.

Nikolaev, L. A., and A. A. AskadskiI

1958. Effect of ultrasonic waves on catalytic processes. Khim. Nauka. i Prom. 3:131-2; C. A. 52:11543b.

NishiwaKI, $\mathrm{Y}$.

1958. Coloring matter for synthetic sake. I. The color tone and fading of artificial coloring matter. Hakkô Kyôkaishi 16:391; C. A. 53:9563f.

NoDon, A., and G. Cuvier

1928. Recherches sur la radioactivité des vins. Compt. rend. 187:725-27.

NoGUCHI, $\mathrm{K}$.

1949. Ripening effect of high-frequency electricity upon organic mixed materials. I.

et seq. Research Rept. Nagoya Ind. Sci. Research Inst. 1: 19-20; 2:32-3 (1950); 3:39-40 (1951) ; 4:49-50 (1951); 5:26-8 (1952); 6:20-2 (1953); C. A. 48:10951i.

NoGUCHI, T., et al.

1951. Electric aging of synthetic saké, vinegar, crude perfumes, etc. Japanese Patent 5895, Sept. 29 ; C. A. $47: 3518$ d. 
NotTelle, L. E.

1931. Alcoholic beverages. French Patent 711,300, Feb. 14; C. A. 26:1706.

Novak, A. F., and S. L. AdAMs

1943. Determination of the stability of thiamine, nicotinic acid and riboflavin in whisky over a 6-month period. Quart. J. Studies Alc. 3:541-45.

Noyes, W. A., Jr., G. B. Porter, J. E. Jolly

1956. The primary photochemical process in simple ketones. Chem. Revs. 56:49-94.

OBATA, Y., and H. HoRITsu

1958a. Studies on the sunlight flavor of beer. IV. Distribution of sulfur compounds and determination of volatile sulfur compounds. Nippon Nôgei-kagaku Kaishi 32: 615-17.

1958b. Studies on the sunlight flavor of beer. V. The genetical conditions of occurrence of sunlight flavor of beer. Bull. Agr. Chem. Soc. Japan 22:153-56.

1959. Studies on the sunlight flavor of beer. VI. Correlation of the occurrence of the sunlight flavor of beer to humulone, lupulone, and related compounds. Bull. Agr. Chem. Soc. Japan 23:186-94.

OвAтA, Y., and M. KoshikA

1960. Studies on the sunlight flavor of beer. VII. Correlation of the occurrence of the sunlight flavor of beer to humulone, lupulone, and related compounds (2). Bull. Agr. Chem. Soc. Japan 24:644-46.

OBATA, Y., and T. Yamanishi

1947. Studies on the sunlight flavor of beer I. Nôgaku Shuko (Sci. of Agr.) 1:537-40; C. A. 46:10529f.

1949. The sunflavor of beer. II. Essential substance of sunflavor. Bull. Chem. Soc. Japan 22:247-50.

OKADA, S.

1958. Formation of hydroperoxides from certain amino acids and peptides in aqueous solutions by irradiation in presence of oxygen. Actions chim. et biol. radiations 4: $46-49$; C. A. $53: 881 \mathrm{~g}$.

Okolelov, I. N., and M. R. Kothyarenko

1951. Ispol'eovaie kholoda v vinodelii. Vinodelie i Vinogradarstvo S.S.S.R. 11(12):5-8.

OTs, I.

1954. Quels résultats peut-on attendre des ultrasons dans les industries alimentaires et plus particulièrement en brasserie. Rev. fermentations et inds. aliment. 9:78-85.

Ough, C. S., and M. A. Amerine

1961. Studies on controlled fermentation. V. Effects on color, composition, and quality of red wines. Am. J. Enol. Viticult. 12:9-19.

Ough, C. S., and E. B. Roessler, and M. A. A merine

1960. Effects of sulfur dioxide, temperature, time, and closures on the quality of bottled dry white table wines. Food Technol. 14:352-56.

Parke, A. V. M., and D. TAylor

1956. The chemical action of ultrasonic waves. J. Chem. Soc. 4442-50.

Paronetto, L.

1941. Applicazione dell' elettrodialisi in enologia. Annuar. staz. sper. viticolt. enol. Conegliano $10: 123-49$

Pasteur, L.

1873. Études sur le vin., 2nd Ed., F. Savy, Paris, 344 p.

Pederson, C. S., H. E. Goresline, A. L. Curl, and E. A. Beavens

1941. Keeping quality of bottled wines. Ind. Eng. Chem. 33:304-07.

de Pereira Forjaz, A.

1934. Oscillatory chemical mechanics. Chimie \& industrie, Special No. 203 Apr.; C. A. $28: 5742$.

PERIN, J.

1952. Artificial aging of wines with ultraviolet, infrared, ultrasound, electrophoresis, and magnetic field treatment. Le Moniteur Vinicole, Dec. 3 issue.

Philipsky, A. J. H.

1930. Verfahren zum Altern von Spirituosen. German Patent 557,806, July 15.

1933. Verfahren zur Alterung von Met. German Patent 572,539, Mar. 18. 
Plotтi, A.

1907. Le vieillisement artificiel des vins et des spiritueux par l'ozone. Prog. agr. vit. 48:674-80.

Plume, B. A.

1937. Apparatus for aging and purifying liquors. U. S. Patent 2,088,337, July 27.

Politova-Sovzenko, T. K.

1954. Vliyanie teploı̆ obrabotki na sostav vina. Vinodelie i Vinogradarstvo S.S.S.R. $14(7): 8-12$.

Pozen, M. A.

1935. Oxidation-reduction potentials in brewing. Brewery Age 3(7):41-3; (8):45-7; (9) :53-5; C. A. $29: 8224$.

Pozzi-Escot, E.

1905. Le vieillissement artificiel des vins et des spiritueux. Bull. assoc. chim. sucr. dist. $23: 114-30$.

Prandi, O.

1924. Wine in dry and moist surroundings. Staz. sper. agrar. ital. 57:204-12; C. A. 19:1175.

Pro, M. J., and A. D. Etienne

1959. Dating distilled spirits. J. Assoc. Offic. Agr. Chemists 42:386-92.

Proctor, B. E., and S. A. Goldblith

1951. Electromagnetic radiation fundamentals and their applications in food technology, Advances in Food Research 3:120-96.

Prostoserdov, N. N., and R. D. Taranova

1949. Oksimetilfurfurol $\mathrm{v}$ vinogradnykh vinakh. Vinodelie i Vinogradarstvo S.S.S.R. $9(11): 43-44$.

Protopopov, B. A.

1938. Ultrasonics in aging wines and liquors. Russian Patent 59,911; Bergmann, 1954.

Purtschert, F., and F. Caratsch

1955. Extraction of hop bitter resins by ultrasonic treatment. Brasserie 10(108): 178-84; C. A. $51: 14198 \mathrm{~h}$

Putney, F. K., and A. W. Pratt

1956. X-irradiation of L-malic acid in aqueous solutions. Radiation Research 5:134-45.

QUERBERITZ, F.

1951. Tiefkühlversuche an Moselweinen. Deut. Wein-Ztg. 87:182-86.

1953. Tiefkühlung von Weimen. Deut. Wein-Ztg. $89: 308,310,312$.

1961. Betrachtung über Vorkommen und Beurteilung von Hydroxymethylfurfurol und Reversionsprodukten in Weinen und Mosten. Deut. Wein-Ztg. 97:426, 428, 430, $452,454$.

Rakcsányi, L., and G. Peszeszér

1958. Borélelés Ultrahang-Besugárzással. Szolészeti Kutakó Intézet Evkönyve (Budapest) 11(2):47-59 (1952-7) (Published 1958).

RAMOND, C.

1957. Le vin de Porto-la vinification dans le haut Douro-le vieillissement. L'Agria (Ecole nat. agr., Algiers) 26:4-12.

RavinetTi, C.

1955. Apparatus for the stabilization and saturation of wine and beverages. Italian Patent 532,221 Aug. 18; C. A. 52:15826g.

READ, M. S.

1960. Current aspects of the wholesomeness of irradiated food. J. Agr. Food Chem. 8:342-49.

REIMAN, C. K.

1938. Aging distilled alcoholic spirits. U. S. Patent 2,132,435, Oct. 11.

REINISCH, E.

1928. Treatment of alcoholic liquids. Austrian Patent 112,976, Dec. 15; C. A. 23:3771.

1929a. Aging alcoholic liquids. Austrian Patent 115,902, Apr. 15; C. A. 24:2234.

1929b. Beverages. Austrian Patent 116,502, Sept. 15; C. A. 24:2812.

RENAUd, P.

1960. Les effets chimiques de la cavitation ultra-sonore. Parf. Cosm. Savon. 3(10): $398-400$. 
RENTSCHLER, H.

1956. Die Beeinflussung von Traubenmosten und Weinen durch Kälte. Schweiz. Z. Obst- u. Weinbau 65:281-84.

RENTSChLER, H., and R. SCHAEPPI

1957. Die Beeinflussung von Rotweinen durch Kälte. Schweiz. Z. Obst- u. Weinbau $66: 437-39$.

Restaino, A. J.

1960. Radiation technology for nonbiological materials. Ind. Eng. Chem. 52:683-87.

Reuss, B. L. L.

1961. A question of age. Wine Magazine (14):26-28.

REYNET, J.

1960. Procédés physiques de stabilisation des vins. Revue Vinicole, Nov/Dec.

RibÉREAU-Gayon, J.

1948-9. Interpretation scientifique de la practique oenologique du vieillissement. Ann. Accad. Agr. Torino 91(2):1-28.

RichaRDSON, E. G.

1957. Technical aspects of sound. Elsevier Publishing Co., New York, Vol. 2, 412 p.

Rodopulo, A. K., and V. V. AgApov

1957. Biokhimicheskie izmeneniya shampanskikh vino materialov pri termicheskoì obrabotke. Vinodelie i Vinogradarstvo S.S.S.R. 17(4):4-12.

ROSENBerg, J. L.

1955. Photochemistry and luminescence. Physical techniques in biological research, G. Oster and A. W. Pollister eds., Acad. Press Inc., N. Y., 1:1-49.

Rosenstiehl, A.

1908. Influence de la tempèrature de stèrilisation du moût et de cells de la fermentation sur la bouquet des vins. Compt. rend. 146:1417-20.

RöTTGEN, T.

1926. Von der Entsäuerung der Traubenweine durch warme Lagerung derselben. Pharm. Zentralhalle 67:743-45; Süddtsch. Apoth.-Ztg. 66:462-63; C. A. 21:474.

RUGGLI, P.

1912. Über einen Ring mit dreifacher Bindung. Ann. 392:92-100.

RYAN, E. J.

1953. Alcoholic beverages and method. U. S. Patent 2,637,652 May 5.

SALAČ, V.

1955. O možnostech použití ultrazvuku pivovarském a sladařském průmyslu. Kvasný Průmysl 1:221-23.

SALLER, W.

1955. Qualitätsverbesserung der Weine und Süssmoste durch Kälte. Verlag Zigurd Horn, Frankfort am Main, Germany.

Salunkhe, D. K., R. K. Gerber, and L. H. Pollard

1959. Physiological and chemical effects of gamma radiation on certain fruits, vegetables, and their products. Proc. Am. Soc. Hort. Sci. 74:423-29.

SÁNDOR, Z., and I. FUHRER

1941. Method and apparatus for the aging of alcoholic liquors. Hungarian Patent 127,624, Aug. 1; C. A. 36:2680.

SARishvili, N. G., and P. Ya. Pazyrev

1959. Vnedrenie v proizvodstvo novoĭ tekhnologicheskor skhemy prigotovleniya Sovetskogo shampanskogo. Vinodelie i Vinogradarstvo S.S.S.R. 19(1):25-9.

SASTRY, L. V. L., and R. G. TISCHER

1952. Stability of the anthocyanin pigments in Concord grape juice. Food Technol. $6: 264-8$.

SCAzzola, E.

1959. Clarification et stabilisation des vins. Application practique dans le cadre d'une entreprise commerciale. Inds. aliment. et agr. (Paris) 76(1):27-30.

SChAFFer, F., and E. Philippe

1912. The content of nitrogen compounds in wine. Mitt. Lebensm. Hyg. 3:1-11. 
SCHANDERL, H.

1950-1. Über den Einfluss des Entsäurens verschiedener Schönungen und des Lichtes auf das $\mathrm{rH}$ und $\mathrm{pH}$ der Weine. Wein $\mathrm{u}$. Rebe, Jahrbuch der Weinbauwissenschaft und önologie. Deut. Wein-Zeitung, Kirchleim and Co. Mainz, p. 118-28.

SCHEIBLER, E., JR.

1949. Treatment of organic compounds by means of a gaseous medium activated by electric energy. Hungarian Patent 139,858, Aug. 16; C. A. 44:6168b.

SCHILD, E., and W. WEYH

1960. Ultrasonic experiments with the hop double-extraction process. Brauwissenschaft

SCHMIDT, H. $13: 206-11$; C. A. $54: 23176$ c.

1951. Kölnisch-wasser, Parfüm oder Kosmeticum. Fette u. Seifen 53:89-91.

Sсотт, J. F.

1955. Ultraviolet absorption spectrophotometry. Physical techniques in biological research. G. Oster and A. W. Pollister, Eds. ; Academic Press Inc., N.Y., 1:131-203.

SEITZ, J.

1908a. Apparatus for treating liquors in barrels. U. S. Patent 961,167 June 14.

1908b. Apparatus for aging liquors by compressed air and electric treatment. U. S. Patent 967,574. Aug. 16.

1909. Apparatus for aging liquors. U. S. Patent 967,575 .

SHARKov, V. I., I. I. KoRoL'Kov, and A. V. KRUPNOVA

1958. Conversion of cellulose and lignin into readily hydrolysable compounds under the influence of $\gamma$-rays. Gidroliz. i Lesokhim. Prom. 11(8):3-4; C. A. 53:7583c.

SHIJo, N., M. WADA, and H. MURAKI

1960. Report on the thermal treatment of alcoholic beverages. V. Heating by alternating current with carbon electrodes. Yamanashi Daigaku Hakkô Kenkyûsho Kenkyû Hôkoku 7:73-6.

Shmakova, N. P.

1947. Acceleration of aging of wine by treatment with ozone and ultraviolet light. Biokhim. Vinodeliya, Akad. Nauk S.S.S.R., Sbornik 1:47-59; C. A. 48:7844c.

Shub, D. M., G. S. TruRikov, and V. I. VeselovskiI

1958. Formation and decomposition of hydrogen peroxide in water solution under the action of $\gamma$-radiation, induced by the radiation-sensitized oxides of semiconductors. Trudy Pervogo. Vsesoyuz. Soveskchaniya po Radiatsion. Khim., Akad. Nauk S.S.S.R., Otdel. Khim. Nauk, Moscow 1957:160-66; C. A. 53:12020e.

Shul'MAN, M. S.

1958. Electrochemical oxidation of ethyl alcohol. Byull. Nauch.-Tekh. Inform., Vsesoyuz. Nauch.-Issledovatel. Inst. Spirt. i Likero-Vodoch. Prom. 5:100; C. A. $54: 18867 \mathrm{~h}$.

SiCHEL, O. E.

1946. Bottle aging of table wine. Am. Wine Merchant 5(3):17, 33-35.

Sieben, C. M., and C. I. ElliotT

1959. Air Conditioning-Refrigerating Data Book. 1(1):9-01 to 9-09, American Society of Refrigerating Engineers, New York.

Siemens-SCHUCKERTWERKE AKT.-GeS.

1952. Altern von Weinen, Spirituosen und dergleichen. German Patent 826,744, Jan. 3 ; Chem. Zentr. 1952:5499.

SingLeTon, V. L.

1959. Some possibilities of rapid aging. Wines \& Vines $40(7): 26$.

Slave, T.

1960. Modern methods for the production, conditioning, stabilization, and storage of wines. Ind. aliment. Produse vegetale 11:266-70; C. A. 55:11755b.

Smirnova, A. P., and O. T. Babkina

1960. Izmenie dubil'nykh veshehestv pri termicheskoŕ obrabotke vina. Vinodelie i Vinogradarstvo S.S.S.R. $20(5): 8-11$.

Sмiтh, P.

1958. Mechanism of the decomposition of hydrogen peroxide in aqueous solution initiated by ultraviolet light. J. Phys. Chem. 62:120-2. 
SoCIÉTÉ INDUSTRIELLE DE BRASSERIES

1960. Fermentation by using brewer's yeast exposed to short-wave radiations. French

SPECHT, W. Patent 1,213,464 Apr. 1; C. A. 55:16908i.

1950a. Ultraschallreaktionen in Spirituosen (Versuche in technischem Masstab). Angewandte Chemie 62:465-6.

1950b. Ultraschallreaktionen in Spirituosen (Versuche in technischem Masstab). Il Nuovo Cimento 7[9]: supplement 2:435-45; N. Zanichelli, Pub., Bologna, 1951.

1950c. Alterung und Veredelung von Spirituosen durch Ultraschall. Die Alkohol. Industrie 63(4):87-9.

1950d. Ultraschallreaktionen in Spirituosen. Mitteilungsblatt der G. D. Ch.-Fachgruppe SPEIGHT, J. Lebensmittelchemie, 56-61.

1958. Brewing beer. British Patent 803,073, Oct. 15; C. A. 53:11756d.

SPELlmeYer, E. F.

1936. Aging alcoholic beverages. U. S. Patent 2,031,232, Feb. 18.

Srivastava, S. C.

1958. Chemical reactions initiated by ultrasonic waves. Nature 182:47.

ŠTEFANIĆ, I.

1954. The application of electroreduction in the production of pasteurized and concentrated grape juice. Kem. u. ind. (Zagreb) 3:219-20; C. A. 49:1236d.

STEIGER, F. H.

1958. The Arrhenius equation in accelerated aging studies. Am. Dyestuff Reptr. 47: 287-90.

STEIN, J-G.

1936. Liqueurs. German Patent 635,964, Oct. 5 ; C. A. 31:805.

Strausz, H. J.

1947a. Chemical aspects of aging of essential oils, especially citrus oils, and maturing of perfume mixtures. Perfumery Essent. Oil Record 38:260-63, 280.

$1947 b$. The aging of perfume mixtures. Ibid. 302-05.

STREULI, $\mathrm{H}$.

1957a. Chemische Veränderungen von Zuckern durch Kathodenstrahlen IV. Mitt. Gebiete Lebensm. u. Hyg. 48:224-34.

$1957 b$. V. Zersetzung bestrahlter Zucker durch Wasser unter Gasbildung. Mitt. Gebiete Lebensm. u. Hyg. 48:234-37.

Surkov, V., S. BARKAN, and E. GARLinskaya

1960. Cavitation and structural changes in milk produced by its exposure to ultrasonic waves. Molochnaya Prom. 21 (4):24-6; C. A. 54:15743c.

Suzuki, M., and G. Towatari

1956. Influence of ultra-violet ray irradiation on "sake." J. Soc. Brewing, Japan 51: 538-39.

SWANN, S., JR.

1956. Electrolytic reactions. Technique of organic chemistry. Interscience Publishers, New York, 2(2nd Ed.) :385-523.

SzILVINYI, A.

1948. The influence of light on the taste of beer. Mitt. Versuchsanstalt Gärungsgewerbe u. Insts. angew. Mikrobiol. Hochschule Bodenkult. 2(9-10):4-9; C. A. 47:6600c.

Takahashi, T.

1907. Studies on the quick aging of sake. J. Soc. Brewing (Japan) 2(5):399-401.

TAKI, S., and M. KunITOMI

1951. Effect of ultrasonic waves on alcohols. I. Oxidation of ethyl alcohol by ultrasonic waves. J. Chem. Soc. Japan. (Pure Chem. Section) 72:820-3 ; C. A. 46:5942f.

Tensora, G. m. b. H. für technische und industrielle Erzeugnisse

1960. Verfahren und Vorrichtung zur künstlichen Alterung Alkoholischer Getränke. German Patent 1,078,974, July 4; Weinberg u. Keller 7:383-4 (1960).

Teramoto, S., H. Taguchi, W. Hashida, R. Ueda, A. Misaki, and S. Yoshi

1958. The effect of gamma-radiation on the micro-organisms concerned with Japanese foods and its application to sterilization. I. J. Fermentation Technol. (Japan) $36: 169-72$. 
Teramoto, S., H. Taguchi, W. Hashida, R. Ueda, K. Yoshikawa, and S. Yoshi

1959. III. The mechanism of the formation of mercaptan and acetoin in gamma-ray irradiated saké. J. Fermentation Technol. (Japan) 37:231-33.

Ter-Karapetyan, M. A., and A. M. Ogandzhanyan

1953. Directed formation of acetals in wine by means of thermal treatment. Zhur. Priklad. Khim. 26:233-35; C. A. 47:11651f.

Thompson, D., F. C. Vilbrandt, and W. C. Gray

1953. The effect of insonation on the specific reaction rate constant in the acid hydrolysis of ethyl acetate. J. Acoust. Soc. Am. 25:485-90.

Timby, M.

1892. Procédé et appareil pour vieillir les vins, spiritueux et autres liqueurs et leur donner de la maturité. French Patent 225,497, Nov. 8.

Timova, L.

1959. Opiti s termichna obrabotka na nashi trapezni vina. Nauch. Trudove, Nauch. Issledovatel. Tekhnol. Inst. Vin. i Pivov. Prom. 3:63-86.

TRESSLER, D. K.

1939a. Wine Process. U. S. Patent 2,181,838, Nov. 28.

1939b. Wine Process. U. S. Patent 2,181,839, Nov. 28.

TSETSKhladze, T. V., and R. Ya. KiPIANi

1956a. Accelerating the aging of alcoholic beverages. Russian Patent 103,296, July 25; C. A. 50:17314e.

1956b. Action of $\gamma$-radiation on grape wines and cognaes. Soobshcheniya Akad. Nauk Gruzin S.S.R. 17:303-8; C. A. 51:2230d.

Tsetskhladze, T. V., R. Ya. Kipiani, and A. D. Lashkhi

1957. Organoleptic and biochemical changes in wines irradiated with $\gamma$-rays. Soobshcheniya Akad. Nauk Gruzin S.S.R. 18(2):183-8; C. A. 52:4099h.

Tuneu Sala, R.

1941. Envejecimiento de vinos bajo la influencia de la accion solar. Rev. facultad agron., Univ. rep. (Montevideo) 24:49-65.

Uematsu, T., and M. Kagami

1957. Spectrophotometric measurement of color change of table wine during bottle storage. Yamanashi Daigaku Hakkô Kenkyûsho Kenkyû Kôkoku 4:49-57 ; C. A. 53:9565e.

UiHLein, E. C., and J. W. LAwRIE

1948. Method of stabilizing beer against radiation deterioration. U. S. Patent 2,452,968, Nov. 2.

Ultra-Technik, G. m. b. H.

1957. Herstellung von Bier. German Patent 967,433, Nov. 14; Chem. Zentr. 1957:9537; (Oest. Pat. 189,147, Feb. 25, 1957).

Unguryan, P. N., and B. V. LiPIS

1957. Processing ordinary table wines. Sadovodstvo, Vinogradarstvo i Vinodelie Moldavii 12:43-46; C. A. 51:18460i.

Urbain, W. M.

1960. Progress and problems in radiation processing of food. J. Agr. Food Chem. 8: $340-42$.

URION, E.

1957. Fermentation rapide. Brasserie 12:254-8; also Petit J. Brasseur 66:34-43 (1958).

Valaer, P., and W. H. Frazier

1936. Changes in whiskey stored for four years. Ind. Eng. Chem. 28:92-105.

VALVASSORI, S.

1957. Contributo allo studio della lamporizzazione dei vermut. Riv. viticolt. e enol. (Conegliano) 10:49-62.

Van HaArlem, J. R., R. F. Crowther, and J. H. L. TruscotT

1956. Variety tests of grapes for wine. Rept. Hort. Prod. Lab., Vineland, Ontario, Canada, 1953-4:130-52; C. A. $53: 12580 \mathrm{~h}$.

DE VERgnetTe-Lamotte, A.

1868. Le Vin. 2nd Ed., Librairie Agricole de la Maison Rustique, Paris, 402 p. 
VERMEIL, C.

1958. Chain reactions in the aqueous phase and the oxygen effect. Actions chim. et biol. radiations $4: 124-30$; C. A. 53:1930b.

VIANNA, J. DA V.

1913. Aging and maturing beverages. British Patent 23,548, Oct. 17.

WALDSCHMIDT-LeITZ, E., and G. KLOOS

1959. Über die spezifische Zusammensetzung der Kältetrübungen aus Bier. Z. physiol. Chem. 316:88-96.

WALTER, E.

1927. Die Behandlung mäuselnder Weine mit dem Siemensschen Ozonisator. Abt. Trinkbranntwein-Likörfabrikat. 17:20-1; Chem. Zentr. 1927 II, 1211.

WEBBER, G. R.

1960. Artificial ripening of beer. British Patent 850,635, Oct. 5 ; C. A. 55:10798d.

WEGNER, N.

1955. Kellerklima und Temperaturschwankungen. Deut. Weinbau 10:181-84.

WEISSLER, A.

1953. Sonochemistry: the production of chemical changes with sound waves. J. Acoust. Soc. Am. 25:651-57.

WELLS, C. F.

1956. Transfer of hydrogen from alcohols to quinones. Nature 177:483-4.

WILKEN, C. J.

1952. Method of treating potable distilled spirits. U. S. Patent 2,586,133, Feb. 19.

YAMADA, M., and H. FuKumitsu

1952. Studies on diacetyl. VI. The formation of acetoin from diacetyl. J. Soc. Brewing (Japan) 47:373-75.

Yamada, M., S. Masai, K. Yoshizawa, S. Sazaki, and S. HanaI

1957. Biacetyl. VIII. Formation of acetoin from biacetyl. J. Soc. Brewing (Japan) 52:59-60.

YAMANishi, T., and Y. OBATA

1950. Sunflavor of beer. III. Mechanism of sunflavor development. Bull. Chem. Soc. Japan 23:125-27.

Young, J. C., and E. P. GUTH

1956. The effect of selected phenols on the formation of hydrogen peroxide by calamine liniment N. F. IX. J. Am. Pharm. Assoc. 45:724-7.

ZECHMEISTER, L., and E. F. MAGOON

1957. Experiments with ultrasonic waves. Festschr. Arthur Stoll, 1957, 59-63.

ZELLER HeRrera, J.

1947. Electrolytic oxidation of ethyl alcohol to acetic acid. Química ind. (Uruguay) $1: 103-24$; C. A. $44: 2868 f$. 
The journal Hilgardia is published at irregular intervals, in volumes of about 600 pages. The number of issues per volume varies. Subscriptions are not sold. The periodical is sent as published only to libraries, or to institutions in foreign countries having publications to offer in exchange.

You may obtain a single copy of any issue free, as long as the supply lasts; please request by volume and issue number from:

$$
\begin{aligned}
& \text { Agricultural Publications } \\
& 207 \text { University Hall } \\
& \text { University of California } \\
& \text { Berkeley 4, California }
\end{aligned}
$$

The limit to nonresidents of California is 10 separate issues on a single order. A list of the issues still available will be sent on request. 